Portland State University

PDXScholar

1998

\title{
Intuition in the Undergraduate Nursing Curriculum: Faculty Attitudes, Practices and Preparation
}

Beverly Jean Epeneter

Portland State University

Follow this and additional works at: https://pdxscholar.library.pdx.edu/open_access_etds

Part of the Curriculum and Instruction Commons, Educational Leadership Commons, and the Educational Methods Commons

Let us know how access to this document benefits you.

\section{Recommended Citation}

Epeneter, Beverly Jean, "Intuition in the Undergraduate Nursing Curriculum: Faculty Attitudes, Practices and Preparation" (1998). Dissertations and Theses. Paper 3398.

https://doi.org/10.15760/etd.5282

This Dissertation is brought to you for free and open access. It has been accepted for inclusion in Dissertations and Theses by an authorized administrator of PDXScholar. Please contact us if we can make this document more accessible: pdxscholar@pdx.edu. 
INTUITION IN THE UNDERGRADUATE NURSING CURRICULUM:

FACULTY ATTITUDES, PRACTICES AND PREPARATION

\author{
by \\ BEVERLY JEAN EPENETER
}

A dissertation submitted in partial fulfillment of the requirements for the degree of

\author{
DOCTOR OF EDUCATION \\ in \\ EDUCATIONAL LEADERSHIP : \\ POSTSECONDARY EDUCATION
}

Portland State University

${ }^{0} 1998$ 


\section{DISSERTATION APPROVAL}

The abstract and dissertation of Beverly Jean Epeneter for the Doctor of Education in Educational Leadership: Postsecondary Education were presented May 4, 1998, and accepted by the dissertation committee and the doctoral program.

COMMITTEE APPROVALS:
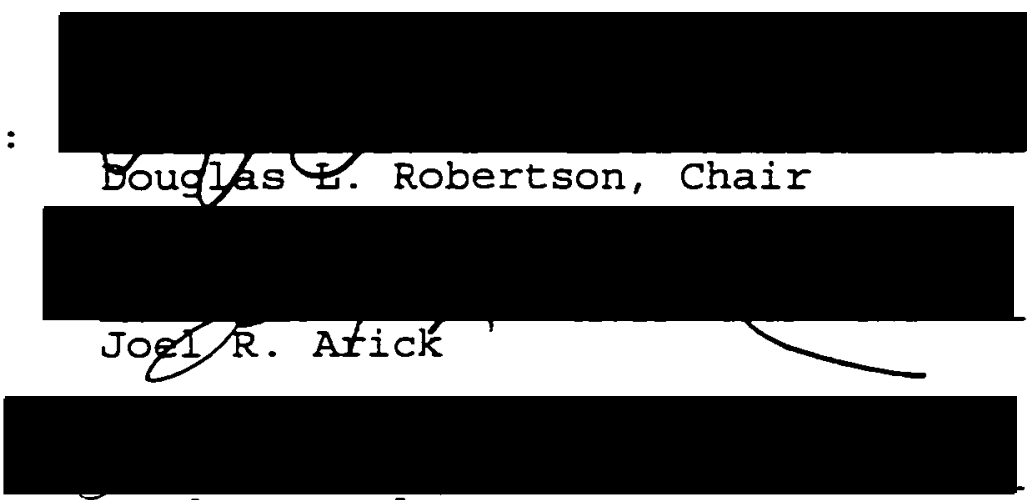

Loyde $\mathbf{W}$. Hales

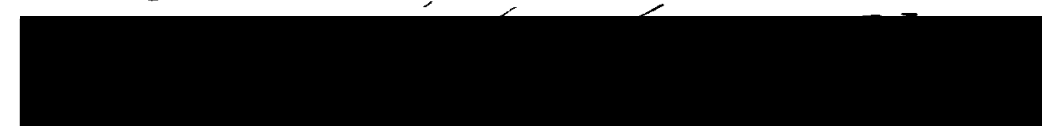

Máry K. Kinnick

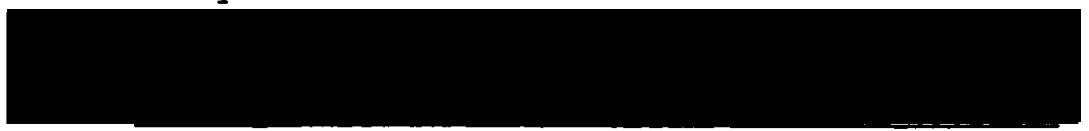

Leslie G. McBride

Representative of the office of Graduate Studies

DOCTORAL PROGRAM APPROVAL :

Robert B. Everhart, Dean

School of Education 


\begin{abstract}
An abstract of the dissertation of Beverly Jean Epeneter for the Doctor of Education in Educational Leadership: Postsecondary Education presented May 4, 1998.
\end{abstract}

Title: Intuition in the Undergraduate Nursing Curriculum: Faculty Attitudes, Practices and Preparation

The primary goal of undergraduate nursing programs is to prepare students for nursing practice. Achievement of this goal may be hindered by reliance on the scientific method in nursing education. Nursing practice often requires the ability to make judgments in situations of ambiguity without the benefit of objective data. The ability to rapidly "read" a situation and respond appropriately is critical to safe nursing care. This requires education in the intuitive way of knowing. Intuitive development may be impeded when students are taught to rely on the rational, scientific way of knowing. The end result may be that students are unprepared to meet the demands of nursing practice. 
Research on intuition in nursing has focused on nursing practice. To date, no study has explored intuition in nursing education.

This study provides data on intuition in undergraduate nursing curricula. A descriptive research study was done on faculty members of the National League for Nursing (NLN). An intuition survey was developed and pilot tested on 10 undergraduate nursing faculty. The survey was sent to a random sample of 676 NLN faculty members nationally. A $51 \%(\underline{\underline{N}}=330)$ response rate was achieved. The survey included: (a) intuition attitudes, (b) attitudes toward including intuition in the undergraduate nursing curriculum, (c) intuition in the current curricula, (d) practices related to development and teaching of intuition, and (e) preparation for teaching about intuition.

The major findings are:

1. Faculty expressed attitudes of value for intuition.

2. Faculty expressed attitudes that support the importance and appropriateness of including intuition but had concerns about including intuition.

3. Intuition is currently included in the undergraduate nursing curriculum on a limited bases. 
4. Faculty use many strategies to develop their own intuition and to help students develop intuition. The majority of faculty rate the strategies as effective.

5. A Iimited number of respondents had preparation to teach about intuition and the majority expressed interest in learning more about intuition.

6. Program type, years in nursing education, and highest degree in nursing made a difference on intuition attitudes. 


\section{ACKNOWLEDGEMENTS}

I wish to express my thanks to Dr. Douglas Robertson and acknowledge his support, encouragement, and expert guidance through my years in the doctoral program but especially in the dissertation process. He saw me through the delays resulting from "real life events" and the challenges of this work. I also wish to thank Dr. Joel Arick for his constructive suggestions, Dr. Loyde Hales for his assistance with the statistics, Dr. Mary Kinnick for serving on my committee while on sabbatical, and Dr. Leslie McBride for her time and interest in my topic.

I am grateful to Linfield college for granting me a sabbatical for doctoral study as well as for providing financial support. I also appreciate the support of my colleagues at Linfield.

To my husband, Jan, and to my children, Jean, Kevin, and James, thank-you for your love and support and for giving me space to write my dissertation.

Finally, I am grateful to Dr. Pamela A. Daniels who believed from the start that I could successfully complete this work. 
TABLE OF CONTENTS

PAGE

ACKNOWLEDGMENTS . . . . . . . . . . . . . . . . .

LIST OF TABLES. . . . . . . . . . . . . . . . . . . vii v vi

CHAPTER

I INTRODUCTION. . . . . . . . . . . . . . 1

Introduction . . . . . . . . . 1

Purpose Statement. . . . . . . . 6

Research Questions . . . . . . . 7

Significance of the Study. . . . . . 9

Assumptions. . . . . . . . . . . 10

Limitations. . . . . . . . . . 10

Definition of Terms. . . . . . . . 11

II LITERATURE REVIEW . . . . . . . . . . . 12

Introduction . . . . . . . . . . . . 12

Definitions of Intuition . . . . . . 13

Intuition as Perception

Intuition as Cognitive

Inference

Intuition as a Way of

knowing

Levels of Irtuitive Awareness. . . . 29

Imagery and Intuitive Modalities . . 31 
Types of Intuition . . . . . . . . 31

Intuition and the Creative

Process. . . . . . . . . . 37

Intuition and Experience . . . . . 40

A Taxonomy for the Intuitive Domain . . . . . . . . . . . 44

Concept Analysis of Intuition . . . 46

Ways of knowing. . . . . . . . . . 47

Nursing Research on Intuition. . . 49

Difficulties of Measurement. . . . . 54

Cultural Value of Scientific Method in Nursing... . . . . . . . . 56

Teaching Intuition in Nursing. . . . 61

Conclusion . . . . . . . . . . 63

III METHODOLOGY . . . . . . . . . . . . 65

Introduction... . . . . . . . 65

Population and Sampling. . . . . . 65

Instrumentation. . . . . . . . 67

Data Collection. . . . . . . . 68

Data Analysis. . . . . . . . . 70

IV RESULTS . . . . . . . . . . . . . . 74

Introduction . . . . . . . . . . . . 74

General Characteristics of
Respondents. . . . . . . . . . 75

Response Rates

Respondent Characteristics

Respondents' Institution

Characteristics 
Intuition Attitudes. . . . . . . . 79

Attitudes About Including Intuition. . . . . . . . . . . . 85

Intuition in Current Curricula . . . 94

Narrative Responses

Teaching Methods

Time Spent Teaching Intuition

Faculty Development of Intuition. . 106

Development of Student Intuition . . 111

Faculty Preparation to Teach

Intuition. . . . . . . . . . . . 121

Faculty Responses by Program

Type . . . . . . . . . . . 126

Intuition Attitudes and Program Type

Intuition in current Curricula by Program Type

Faculty Use and Effectiveness of Strategies for Self by Program Type

Faculty Use and Effectiveness of Strategies with Students by Program Type

Professional Preparation

Intuition Attitudes and

Demographic Variables. . . . . . 148

Professional Preparation

Years in Nursing Education

Highest Academic Degree

in Nursing

other Variables

Summary

Narrative Responses. . . . . . . . 159

Intuition Attitudes and

Narratives

other Variables 
V DISCUSSION AND RECOMMENDATIONS. . . . . 162

Introduction . . . . . . . . . . . 162

Main Themes. . . . . . . . . . . 162

Value of Intuition

Concerns

Ways of Knowing in Nursing

Including Intuition

Professional Development Strategies

Recommendations. . . . . . . . 167

Future Research. . . . . . . . . 169

Conclusion . . . . . . . . . . . 170

REFERENCES. . . . . . . . . . . . . . . . . . 172

APPENDICES

A INTUITION SURVEY. . . . . . . . . . . . . . 180

B CHARTS. . . . . . . . . . . . . . . . . 188 
LIST OF TABLES

1. Definitions and Processing of

Intuition............... . . 25

2. Outcomes of Intuition . . . . . . . . 26

3. Types of Intuition. . . . . . . . . . 32

4. Intuition and Experience. . . . . . . . 41

5. Relationships Among Research Questions

Survey Questions and Analytic

Procedures. . . . . . . . . . . 69

6. Characteristics of Respondents. . . . . 77

7. Respondents' Institution

Characteristics. . . . . . . . . 78

8. Respondents' Attitudes Toward Using

Intuition in Percentage... . . . . 80

9. Respondents' Attitudes Toward Using

Intuition . . . . . . . . . . . . 82

10. Respondents' Attitudes Toward Including

Intlition in Percentage... . . . . . 86

11. Respondents' Attitudes Toward Including

Intuition in the Curriculum... . . . 88

12. Percent of Faculty Including Intuition

in an Undergraduate Nursing Course. . . 95

13. Methods Respondents Use to Present Intuition in Undergraduate Nursing courses................ 104

14. Time spent Teaching Intuition on the Quarter System............. 105 
15. Time Spent Teaching Intuition on the Semester System........... . 105

16. Respondents' Use of Strategies to Develop Their Own Intuition... . . 107

17. Effectiveness of Strategies Respondents Use to Develop Their Own Intuition. . . 110

18. Respondents' Use of Strategies to Develop Student Intuition... . . . 113

19. Effectiveness of Strategies Respondents Use to Develop Student Intuition.

20. Faculty Use of Strategies with Self vs. Use of Strategies with Students . . . 118

21. Correlations of Effectiveness of Strategies to Develop Faculty and Student Intuition.......... . 120

22. Intuition Preparation . . . . . . . . 122

23. Intuition Preparation vs. Perception of Adequacy of Preparation to Teach Intuition . . . . . . . . . . . . . 124

24. A Comparison of Respondents who Include Intuition in a Nursing Course and Perceived Adequacy of Intuition Preparation............. . 125

25. Factor Analysis of Respondents' Intuition Attitudes . . . . . . . . . . 128

26. Attitudes by Program Type . . . . . . . 130

27. Intuition in Curricula vs. Program Type. . . . . . . . . . . . . 133

28. A Comparison of Baccalaureate vs. Associate Faculty Use of Strategies With Self............. . 135

29. A Comparison of Baccalaureate vs. Associate Faculty Use of Strategies With Students... . . . . . . . . . . 
30. Baccalaureate Faculty Use of Strategies with Self vs. Use of Strategies with students.

31. Associate Faculty Use of Strategies with Self vs. Use of Strategies with students. . . . . . . . . . . . . . . . 144

32. Perception of Preparation to Teach Intuition vs. Program Type. . . . . . 146

33. Intuition Preparation vs. Program Type. . 147

34. Intuition Attitudes and Workshop Attendance. . . . . . . . . . . 150

35. Intuition Attitudes and Personal Study. . 151

36. Intuition Attitudes and Learned About Intuition in Degree Program. . . . . . 153

37. Intuition Attitudes and Interest in Learning More.. . . . . . . . . . . 154

38. Intuition Attitudes and Years in Nursing Education . . . . . . . . . . . . 156

39. Intuition Attitudes and Degree in Nursing . . . . . . . . . . . . . 158

40. Intuition Attitudes and Narrative Responses............... . 160 
CHAPTER I

\section{INTRODUCTION}

\section{Introduction}

Undergraduate nursing programs have, as their primary goal, the responsibility to prepare students for nursing practice. This challenge is becoming increasingly complex due to social, economic, and political factors affecting practice. Further, the process may be hindered by the near sole reliance on the scientific method, both in nursing practice and nursing education. The practice of nursing often requires the ability to make nursing judgments in situations of uncertainty and ambiguity without the benefit of objective data. The ability to rapidly "read" a situation and respond appropriately is critical to safe nursing care (Benner, 1984; Benner \& Tanner, 1987; Gerrity, 1987; Morse, Miles, Clark, \& Doberneck, 1994; Rew, 1986; Tanner, Benner, Chesla, \& Gordon, 1993). When students are taught to rely only on the rational, scientific way of knowing, they may be unprepared to meet the demands of nursing practice.

Nursing practice and nursing education at the undergraduate, graduate and continuing education levels 
have been rooted in the scientific problem solving method (Benner, 1984; Bevis \& Watson, 1989; Gerrity, 1987; Rew \& Barrow, 1987). The specific model, known as the nursing process, describes a linear problem-solving system of beginning with assessment, followed by problem identification, planning, intervention, and evaluation. This linear model has been questioned by Benner (1984), Benner and Tanner (1987), Rew and Barrow (1987), and other nurse researchers. These researchers argue that the scientific process is not applied in a linear manner in practice and that relying solely on this process causes nurses to discredit the holistic, synergistic, intuitive problem solving method. These arguments validate the experience of many practicing nurses. The research suggests that the use of intuition in nursing practice may lead to more rapid decisions in crisis situations and better patient outcomes. As a result, intuition and the intuitive way of knowing is beginning to be recognized as an important component of safe nursing practice.

Rew (1991) writes,

While the basic education of nurses focuses on a linear model of nursing practice, evidence is mounting that nursing experts rely on more than a simple analytic reasoning algorithm in making decisions about patient care. (p. 114)

Interest in the phenomenon of intuition is not limited to nursing. In recent years it has gained respect 
in medicine (Hamm, 1988), education (Bastick, 1982;

Noddings \& Shore, 1984), business (Agor, 1986b;

Rockenstein, 1988; Rowan, 1986), and psychology (Emery, 1994; Goldberg, 1983). These professions address the value of intuition in decision making and the need to acknowledge intuition as a legitimate way of knowing.

As nursing examines its goal to prepare students for practice, some nurse educators are concerned that emphasis on the scientific way of knowing has led to neglect of the intuitive way of knowing in undergraduate nursing education. Intuition is currently being recognized as an important component of clinical decision making. As a result, some nurse researchers and educators are urging that the intuitive way of knowing be included in undergraduate curricula.

In the United States, nursing education is guided by the National League for Nursing (NLN), the accrediting agency for nursing programs. The mission of the NLN (1995) is to improve nursing education and health outcomes. To achieve this mission, the NLN (1996a) and the National League for Nursing Accrediting Commission (NLNAC 1997a, 1997b) has set guidelines for curriculum and other program components for each type of nursing program. The guidelines for curriculum require a focus on the discipline of nursing and the interaction with the 
humanities and sciences. The criterion for baccalaureate programs reads:

The nursing curriculum is developed by the nursing faculty and provides for a variety of learning experiences consistent with... attainment of outcomes. (1996a, p. 14)

The NLN guidelines and criterion implicitly create a space to teach about the intuitive way of knowing, but there is no explicit statement regarding the need for and value of including intuition.

In addition to curriculum, baccalaureate programs must address five required outcomes in program evaluation: (a) critical thinking, (b) communication, (c) therapeutic nursing interventions, (d) graduation rates, and (e) patterns of employment (NLN, 1996a). Associate and diploma programs address the first 4 outcomes (NLNAC, 1997a, 1997b). Although critical thinking is one of the required outcomes, each program has the freedom to provide its own definition of critical thinking, which may or may not encompass intuition. However, the definition must be congruent with the following description from the NLN:

This outcome reflects students' skills in reasoning, analysis, research, or decision making relevant to the discipline of nursing. (NLN, 1996a, p. 26)

While this description does not necessarily exclude intuitive thinking, the guidelines do not explicitly address intuition either. 
The literature reveals several reasons for the underrepresentation of intuition in nursing, especially in nursing education: (a) diverse definitions of intuition (Benner, 1984; Benner \& Tanner, 1987; Gerrity, 1987; McCormack, 1992; Moch, 1990; Pyles \& Stern, 1983; Rew, 1986; Rew \& Barrow, 1987; Young, 1987), (b) difficulties of measurement (Benner, 1984; Gerrity, 1987; Miller, 1993; Polge, 1995), (c) a culture that values the rational scientific method (Benner, 1984; Benner \& Tanner, 1987; Benner \& Wrubel, 1989; Bevis \& Watson, 1989; Gerrity, 1987; Rew \& Barrow, 1987), (d) intuition as a threat to the profession of nursing (Gerrity, 1987; Rew, 1991), and (e) questions of how to teach or enhance intuition (Benner, 1984; Benner \& Tanner, 1987; Correnti, 1992; Leners, 1992, 1993; Rew, 1986; Schraeder \& Fischer, 1987). Several critical questions emerge from the discussion of intuition and the intuitive way of knowing that is occurring among nursing faculty: (a) If the intuitive way of knowing is not being addressed in undergraduate nursing courses, are undergraduate nursing educators achieving their primary goal of preparing students for the practice of nursing? (b) Can nursing faculty teach holistic nursing care that includes connecting with and understanding the client perspective without providing instruction in the intuitive way of knowing? (c) If the 
intuitive way of knowing is not being addressed in the undergraduate curriculum, can nursing education meet its goal to develop and advance educational models that are most appropriate for emerging health care needs and services? and (d) If intuition is being addressed in the nursing curricula, do the faculty have the necessary professional education to teach about this way of knowing? A review of the nursing literature revealed that there is little available evidence to address these questions.

\section{Purpose Statement}

Intuition is being recognized as a critical aspect of nursing practice. Some nurse educators urge the inclusion of the intuitive way of knowing, in addition to the scientific, rational way of knowing, in nursing education programs. Several concerns regarding including intuition in the undergraduate curriculum have been described and debated in the literature. No evidence is available regarding current faculty practices of including intuition in undergraduate nursing courses.

The purpose of this study was to do a descriptive survey of National League for Nursing (NLN) faculty members to provide information on undergraduate nursing faculty in the area of intuition by assessing the following: (a) faculty attitudes about using intuition, 
(b) faculty attitudes about including intuition in the nursing curriculum, (c) the current level of inclusion of intuition in undergraduate nursing courses, (d) faculty practices and strategies related to the development and teaching of intuition, and (e) faculty preparation for teaching about intuition.

\section{Research Questions}

The study was designed to answer the following research questions:

1. What are National League for Nursing (NLN) faculty attitudes about using intuition in nursing?

2. What are NLN faculty attitudes about including intuition in the undergraduate nursing curriculum?

3. What percent of faculty teach an undergraduate nursing course that directly addresses the intuitive way of knowing and is the course required or elective?

4. What practices that emerge from the intuition literature as making a difference in the development of incuition do NLN faculty use and how effective do they think the practices are?

5. What teaching strategies that emerge from the intuition literature do NLN faculty use in teaching about intuition in the undergraduate nursing curriculum and how effective do they think the strategies are? 
6. What preparation do NLN faculty have to teach about intuition and do faculty perceive themselves as adequately prepared to teach about intuition in the undergraduate nursing curriculum?

7. Do significant differences exist between diploma, associate degree and baccalaureate degree faculty regarding responses to each of the preceding questions?

8. Do significant differences exist in each demographic variable (age, gender, number of years practicing nursing, number of years in nursing education, highest academic degree completed in nursing, highest academic degree completed outside nursing, geographic location of school of nursing, type of nursing program, primary area of teaching responsibility, preparation to teach about intuition) and attitudes about using intuition?

9. Do significant differences exist in each demographic variable lage, gender, number of years practicing nursing, number of years in nursing education, highest academic degree in nursing, highest academic degree outside nursing, geographic location of school of nursing, type of nursing program, primary area of teaching responsibility, preparation to teach about intuition) and attitudes about including intuition in the undergraduate nursing curriculum? 
Significance of the study

Professional dialogue is occurring related to the use of intuition in the practice of nursing. Intuition is being recognized as an important, yet undervalued component of clinical decision making in nursing. Research on intuition in nursing has focused primarily on nursing practice (Agan, 1987; Benner, 1984; Benner \& Tanner, 1987; Gerrity, 1987; Leners, 1992, 1993; Miller, 1995; Pyles \& Stern, 1983; Rew, 1988a, 1988b, 1990, 1991; Schraeder \& Fischer, 1987; Young, 1987). To date, no study has explored intuition in nursing education. Yet, a number of nurse educators and researchers urge faculty to include intuition in nursing education programs (Benner, 1984; Benner \& Tanner, 1987; Bevis \& Watson, 1989; Correnti, 1992; Gerrity, 1987; Leners, 1992, 1993; Miller \& Rew, 1989; Paul \& Heaslip, 1995; Polge, 1995; Rew, 1986, 1989; Rew \& Barrow, 1987; Young, 1987). One of the questions implied in the literature is whether or not the nursing education profession can achieve its primary goal to prepare undergraduate students for the practice of nursing without addressing the intuitive way of knowing in the nursing curricula.

This study provides basic knowledge related to attitudes, practices and preparation of NL.N undergraduate faculty regarding teaching about intuition. The study 
was designed to provide evidence to support or refute the nursing literature regarding intuition and its inclusion in undergraduate nursing courses.

\section{Assumptions}

Two basic assumptions were made by the researcher. The first assumption was that the respondents who participated in the study provided honest answers to the survey questions. Assuring anonymity minimized this concern, although it is still possible that respondents answered in ways that make them look good to themselves. The second assumption was that the nursing faculty who responded to the survey adequately represent all nursing faculty who are members of the NLN.

\section{Limitations}

The survey sample included only nursing faculty who were members of the NLN at the time the survey list was produced. The survey did not represent other nursing faculty who were teaching in undergraduate nursing programs. The research findings are generalizable to NLN faculty teaching undergraduate nursing students, not to all nursing faculty.

The survey was developed by the researcher, since no standardized instrument was available. Use of a survey is 
limited by self selection and self reporting. The respondents are likely to be faculty who feel very strongly for or against the inclusion of intuition in undergraduate nursing curricula. Faculty who are in the middle or who have little interest in the topic are less likely to respond. Another limitation of this research is that descriptive surveys provide superficial data. This study was designed to provide data on current attitudes and practices related to intuition in undergraduate nursing programs which is currently not available in the literature. Further research is needed to provide a more complete understanding of the status of intuition in nursing education. This research study helps move the profession to that direction.

\section{Definition of Terms}

For the purposes of this study, the following definition was used:

Intuition: an immediate way of knowing without being able to articulate how one knows. It is knowledge received without the conscious use of reasoning. It is also described as a "gut feeling," "sixth sense," "ability to anticipate," or "recognize the possibilities in any situation." 
CHAPTER II

\section{LITERATURE REVIEW}

\section{Introduction}

The literature on intuition is both challenging and confusing. The purpose of this literature review is to gain an understanding of the complexities of intuition within an organizational framework and to examine more closely the role of intuition in undergraduate nursing education. Selected perspectives on intuition serve as a foundation for the research study.

This chapter includes an exploration of intuition drawn from the psychology, business, education, medicine and nursing literature. Definitions of intuition as perception, cognitive inference, and a way of knowing are presented, addressing level of processing, outcomes and accuracy of intuition. A brief discussion of levels of intuitive awareness and the role of imagery and intuitive modalities helps clarify the intuitive process. Types of intuition, intuition and the creative process, and intuition and experience will also be discussed. A taxonomy for the intuitive domain will be outlined and concept analysis of intuition in nursing will be 
described. The research on intuition in nursing will be summarized and the reasons for the under-representation of intuition in the literature, especially in nursing education, will be discussed. These reasons include: (a) diverse definitions of intuition, (b) difficulties of measurement, (c) a cliture which values the rational scientific method, (d) intuition as a threat to the profession of nursing, and (e) concerns regarding how to teach or enhance intuition.

\section{Definitions of Intuition}

The term intuition is derived from the Latin word in which means "in" as it does in English, and tueri which means to look at, view, or look into. Intuition means looking inward, listening to an inner voice. Webster's New World College Dictionary (Neufeldt, 1996) proposed the following definition of the noun intuition:

1: the direct knowing or learning of something without the conscious use of reasoning; immediate understanding 2: something known or learned in this way 3 : the ability to perceive or know things without conscious reasoning. (p. 709)

\section{Intuition as Perception}

Intuition is defined as a form of perception, or awareness, by several authors: Jung (1962); Berne (1977); Gerrity (1987); and to some extent, Clinchy (1975); and 
Noddings and Shore (1984). The work of two psychologists, Jung and Berne, are addressed here.

Jung (1962) describes a theory of intuition within a theory of personality. Intuition is defined as one of four basic psychological functions (thinking, feeling, sensation and intuition) which are present to some degree in all people.

According to Jung (1962), thinking and feeling are discriminating functions, that is, ways of judging and coming to conclusions. Sensing and intuition are perceptual functions. Sensing is defined as perception of the world through the five senses. In contrast, intuition "transmits perceptions in an unconscious way" (p. 568). Jung writes that intuition may appear as sensation, feeling, or intellectual conclusion, but is none of these. Intuition presents information in wholes, without our being able to articulate how we arrived at the answer.

Like sensation, intuition is described as an irrational function, because it does not involve judgment. Jung (1962) explains what he means by the term irrational:

it does not denote something contrary to reason, but something outside the province of reason, whose essence, therefore, is not established by reason. (p. 569)

Intuition perceives possibilities, principles, implications, and wholes at the expense of details which 
are gained by sensation. Intuitive perceptions, like sensations, are accepted as given truths. The primary function of intuition is to transmit information which either cannot be obtained by the other functions or can be obtained only by more roundabout, inefficient processes. Intuition may appear in a subjective or an objective form. Subjective intuition is defined as a perception of unconscious "psychic facts" of subjective origin. Objective intuition is a perception of facts originating from what Jung termed "subliminal perceptions of the object" and the thoughts and feelings accompanying these perceptions (Jung, 1962, p. 568).

Jung (I962) distinguishes between concrete and abstract forms of intuition. Concrete intuition is described as a reactive process to actual circumstances. Abstract intuition is an active process, in that an individual uses theoretical association of intuitive perceptions to provide a direction or a purpose.

Jung (1962) identified characteristics of individuals who are guided more by intuition than sensation. Intuitive types search for and see possibilities, generate unique ideas and solutions to problems, and manage the complexity of ambiguous situations. 
In Intuition and Ego States Berne (1977) provides a practical definition of intuition based on his clinical experience:

Intuition is knowledge based on experience and acquired through sensory contact with the subject, without the "intuiter" being able to formulate to himself or others exactly how he came to his conclusions. (p. 4)

This definition is similar to Jung's description of intuition as perception. Berne credits Aristotle as the philosopher having a perspective on intuition closest to his own. Aristotle used the term "intuitive induction" to describe the hierarchical organizational ability of an organism to: (a) experience sensory perceptions, (b) retain sensory perceptions, and (c) systematize these memories. Berne concludes that intuition functions as part of a series of perceptive processes working above and below conscious level in an integrated manner, depending on the specific situation. He recognized that "what is intuited" is different from what the "intuiter" is able to verbalize about his intuition. He suggests that logical and ethical thinking can interfere with the process of intuition. Berne supports the use of intuition but urges caution against overconfidence about intuitive knowledge.

Berne (1977) provides a summary of conditions which enhance the intuitive mood, the state which encourages intuition: 
The intuitive mood is enhanced by an attitude of alertness and receptiveness without actively directed participation of the perceptive ego. It is attained more easily with practice; it is fatigable, and fatiguing . . Extraneous physical stimuli, both external and internal, appear to be irrelevant. (pp. 25-26)

\section{Intuition as cognitive Inference}

Intuition as cognitive inference is viewed as a rapid processing of information and not a separate way of knowing. Intuition is defined as cognitive inference by Westcott (1968) and Bastick (1982), and to a lesser extent, by Loye (1983), Noddings and Shore (1984), Dreyfus and Dreyfus (1986), and Benner and Tanner (1987). Westcott and Bastick best represent this perspective.

Westcott (1968) views intuition as cognitive inference or unconscious inference. From this perspective, intuition is very rapid analytical processing, or subliminal processing of information, which results in a sense of knowing something without the use of rational processes. Westcott suggests that some elements of intuition are unconscious and others conscious, making it difficult to explicate the process of knowing. He provides a narrow, behavioral definition of intuition for empirical research. Intuition is "reaching a conclusion on the basis of less explicit information than is ordinarily required to reach that conclusion" (p. 98). Westcott was primarily interested in the ability of 
subjects to problem solve intuitively under conditions of information deprivation and to reach accurate conclusions by way of inexplicit steps.

Bastick (1982) views intuition and reason as two very distinct and separate modes of thought. He suggests that intuition is a separate way of processing information rather than a distinct way of knowing. Bastick defines intuition as unconscious inference mediated by emotion. It is emotion or feelings which distinguishes intuition from rational, logical thought. According to Bastick, intuition is the default mode where there is insufficient information or in situations which are too complex for the analytical process. At the same time, Bastick maintains that analytic thought and intuitive thought are interwoven and do not exist independently of one another.

\section{Intuition as a Way of knowing}

Intuition as a way of knowing is a distinct mode of direct knowing which bypasses rational thought processes. It is therefore differentiated from analytical, logical, and rational thinking. Many authors describe intuition as a way of knowing; several are considered in this paper: (Agor, 1984; Emery, 1994; Noddings \& Shore, 1984; Vaughn, 1979). Other authors are not explicit regarding intuition as a way of knowing (Bruner, 1966; Bruner \& Clinchy, 
1971); however, their writings suggest support for this view.

Vaughn (1979) defines intuition as a way of knowing, recognizing the possibilities in any situation. Her definition of intuition includes the idea that it is possible to know in ways that are not solely dependent on the five basic senses (sight, sound, smell, taste and touch). This broad view of intuition encompasses many types of phenomena including extrasensory perception, clairvoyance, telepathy, precognition, remote viewing, and psychokinesis. According to Vaughn, all of the above are manifestations of intuitive ability on one level or another.

Vaughn (1979) contrasts two separate ways of knowing, the personal and the transpersonal. These modes of knowing may also be considered two levels of consciousness or views of reality. A personal mode views reality as a "multiplicity of objects and events, existing separately in time and space;" a transpersonal view of reality perceives the "underlying oneness of the universe" and transcends the boundaries of time and space (p. 52). Rational thought is appropriate to the personal way of knowing; the transpersonal mode is only "apprehended intuitively" (p. 53). Vaughn argues for acceptance of 
both personal and transpersonal consciousness to achieve human potential.

Agor (1984) describes intuition as a rational and logical brain skill that can be used to guide decisionmaking. His definition of intuition is borrowed from Robert Assagioli's concept of the superconscious. The development of intuition is seen as a spiritual journey. Intuition develops as we become open to new experiences and trust the intuitive process, thereby enabling the subconscious and conscious mind to become one.

Agor (1984) believes that we have a genetic predisposition to intuition which passes from generation to generation. This predisposition to intuition can be developed through life experiences which foster intuitive processes. When fully developed, intuition is a rapid, accurate, efficient way of knowing.

Agor (1984) tested 2,000 managers in business, government and academia for intuitive ability using selected questions from the Meyers-Briggs Type Indicator. Top managers scored higher than middle and lower managers in both intuitive ability and use of intuition in decision-making. An integrative decision-making style was the most common style of top managers, with more reliance on intuition when the time comes to act. 
A follow-up study by Agor (1986b) of executives ( $N=$ 70) who scored in the top $10 \%$ on intuitive decision making ability showed that all but one used intuition for their most important decisions. Subjects indicated that intuition was most useful in the following situations:

When a high level of uncertainty exists.

When little previous precedent exists.

When variables are less scientifically predictable.

When "facts" are limited.

When facts don't clearly point the way to go.

When analytical data are of little use

(e.g., new trends are emerging).

When several plausible alternative solutions

exist to choose from, with good arguments

for each.

When time is Iimited and there is pressure

to come up with the right decision. (p. 29)

Noddings and Shore (1984) discuss intuition as a way

of knowing. Their definition of intuition is:

that function that contacts objects directly in

phenomena. This direct contact yields something

we might call "knowledge" in that it guides our

actions and is precipitated by our own quest

for meaning. (p. 57)

They identify two domains of intuition, the perceptual and the cognitive. Intuition includes the ability to look at, or see, what is in the world of perception as well as what is created with the reason. Intuition is described as a fully conscious process.

Noddings and Shore (1984) describe four major features of intuitive modes. The four features are: (a) involvement of the senses, (b) commitment and receptivity, 
(c) a search for empathy or understanding, and (d) a continuing tension between subjective certainty and objective uncertainty.

Involvement of the senses refers to an inward form of looking, listening, and touching. It is accepting and involves returning over and over to the object for direction and information. The individual is moved in ways that he or she cannot explicate, and when engaged intuitively, the individual does not see and hear things outside this domain (Noddings \& Shore, 1984).

Commitment and receptivity requires that the person is inactive or passive, in order that what is in the situation may act on the intuition. It is necessary to let go of control at this phase and be ready to receive intuition. Receptivity involves being alert and openminded simultaneously. Noddings and Shore (1984) suggest that the incubation and illumination stages of the creative process are an example of the receptivity feature of intuitive modes.

A search for empathy and understanding is contrasted with the product-goal orientation of analytic modes. The goal of the intuitive mode is understanding. The individual attempts to see the "whole picture." He is interested in making meaning. The person alternates between an active--"I'Il try this"--and receptive--"What 
is happening here?"--way of working (Noddings \& Shore, 1984, p. 86).

The subjective certainty and objective uncertainty refer to a system of checks and balance. Intuition is often received with intense (subjective) certainty, but the initial intuitions may be wrong. Objective uncertainty is the intellect remaining "properly skeptical" (Noddings \& Shore, 1984, p. 87). This uncertainty brings a sense of discomfort which people may try to avoid. The challenge to educators, according to the authors, is to help students move into this stage of discomfort and validate their intuitions which come to them as absolute truth.

Emery (1994) describes intuition as an inner way of knowing. She provides two definitions of intuition:

(a) Intuition is a clear knowing without being able to explain how one knows.

(b) Intuition is knowledge gained without logical or rational thought. (p. 9)

Intuition is viewed as separate and distinct from logical and rational processes, although both are considered essential and complementary functions. The intuitive mind is nonverbal and extends beyond the capability of the rational mind. The logical mind is usually more highly developed. Emery identifies two critical reasons for developing the intuitive mind to the same degree as the rational mind: (a) the use of intuition provides a 
shortcut method for solving problems; and (b) intuition is a coping skill in this rapidly changing world.

According to Emery (1994) intuition is nonrational, nonlinear, insightful, nondata-based, and an extension of the five senses. She contrasts what intuition is with what intuition is not. It is not: logical, rational, common sensical, an emotional state, nor based on experience. From her perspective, common sense and past experience, which she says are often confused with intuition,

emanate from the logical and rational mind and are integrated with intuition for effective decision making, but they are not the same as being intuitive. (p. 12)

Processing of intuition. Jung (1962) and Berne (1977), who define intuition as perception, describe intuition as an unconscious process. The role of the unconscious is also recognized by authors who define intuition as cognitive inference. However, Westcott (1968) believes there are both unconscious and conscious elements of intuition, and Bastick (1982) emphasizes the mediating of intuition by emotion. Definitions and level of processing intuition are summarized in Table 1 .

When intuition is defined as a way of knowing, there are diverse views regarding the processing of intuition. It is described as subconscious by Emery (1994), fully 
conscious by Noddings and Shore (1984), superconscious by Agor (1984), and as a transpersonal process by Vaughn (1979).

Table 1

Definitions and Processing of Intuition

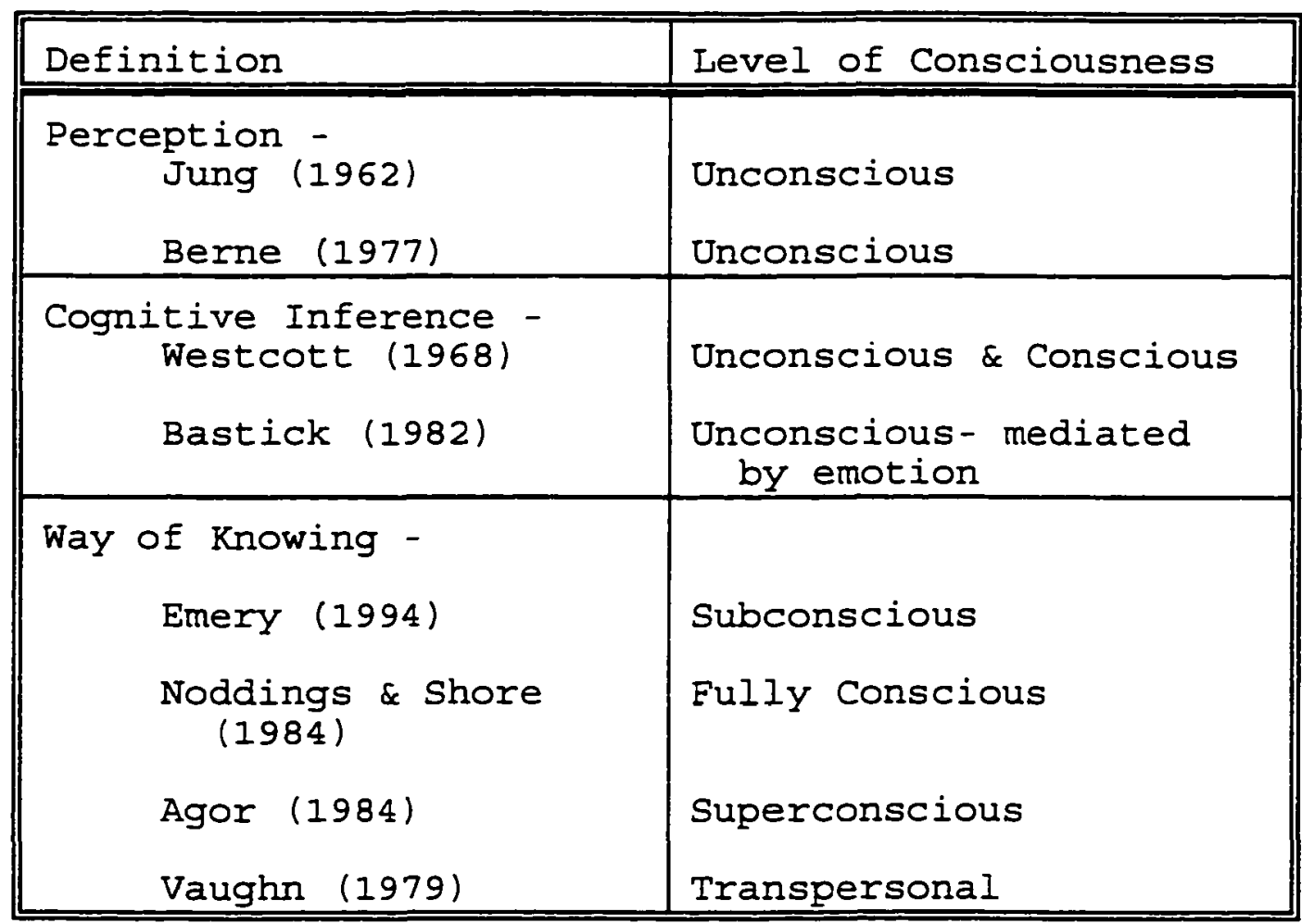

Outcomes of intuition. The outcomes of intuition refer to the results of using the concept (Morse et al., 1994). Two questions relate to outcomes: (a) Is intuition viewed as a complex process or a product? and (b) Is intuition accurate?

Intuition is described as a process and as a product in the literature. It is considered a complex process by the majority of authors (Agor, 1984; Bastick, 1982; Jung, 
1962; Noddings \& Shore, 1984; Vaughn, 1979). Westcott

(1968) considers it both a process and a product but emphasizes intuition as a complex process. Emery (1994) provides two definitions of intuition, one emphasizes process and the other product (Table 2).

Table 2

Outcomes of Intuition

\begin{tabular}{||l|l|l||}
\hline Author & $\begin{array}{l}\text { Does intuition } \\
\text { describe a } \\
\text { process or a } \\
\text { product? }\end{array}$ & $\begin{array}{l}\text { Is intuition } \\
\text { accurate? }\end{array}$ \\
\hline \hline Jung (1962) & Process & Perceived as truth \\
\hline Berne (1977) & $\begin{array}{l}\text { Both, emphasis } \\
\text { on process }\end{array}$ & May be inaccurate \\
\hline Westcott (1968) & $\begin{array}{l}\text { Both, emphasis } \\
\text { on process }\end{array}$ & $\begin{array}{l}\text { Accurate by } \\
\text { definition }\end{array}$ \\
\hline Bastick (1982) & Process & $\begin{array}{l}\text { May be inaccurate } \\
\text { due to perceptual, } \\
\text { processing or } \\
\text { communicating errors }\end{array}$ \\
\hline Vaughn (1979) & Process & $\begin{array}{l}\text { Accurate by } \\
\text { definition }\end{array}$ \\
\hline Agor (1984) & Process & $\begin{array}{l}\text { Accurate, when } \\
\text { fully developed }\end{array}$ \\
\hline Noddings \& Shore & Process & $\begin{array}{l}\text { Tentative knowledge, } \\
\text { to be verified by } \\
\text { the intellect }\end{array}$ \\
\hline Emery (1994) & Both & $\begin{array}{l}\text { Emphasis on accuracy } \\
\text { with practice }\end{array}$ \\
\hline
\end{tabular}

Varying perspectives exist regarding the accuracy of intuition. Jung (1962) writes that intuition is perceived and received as truth. Westcott (1968) and Vaughn (1979) 
think intuition is accurate by definition. According to Vaughn, if it is not accurate, it was not intuition. Agor (1984) views intuition as accurate when fully developed. Emery (1994) emphasizes the accuracy of intuition, noting that it becomes more and more accurate with practice. Bastick (1982) writes that intuition may be inaccurate due to perceptual, processing, or communicating errors. Noddings and Shore (1984) think that intuition, especially initial intuitions, yield tentative knowledge that may be wrong. They recommend validating intuitions with the intellect. Table 2 summarizes the outcomes of intuition, or the results of using intuition as described by the writers previously discussed.

Bruner (1966) adopts Webster's dictionary definition of intuition as "immediate apprehension or cognition" ( $p$. 60). Bruner contrasts intuitive and analytic thinking, noting that intuitive thinking does not proceed in a stepby-step process as is characteristic of analytic thinking. The intuitive thinker does not deduce the answer, rather he "receives" the answer to a problem with little or no awareness of how he obtained the answer and what aspects of the situation he was responding to which gave him the answer. The intuitive answer is typically arrived at more quickly than answers obtained through the well-defined steps of the analytic process. According to Bruner, the 
intuitive answer may be right or wrong and, therefore, should be verified through the analytic process, if possible, while respecting the intuitive hypothesis.

Bruner (1966) expresses concern about the devaluing of intuition by educators in our schools. He attributes this to the fact that intuition may produce the wrong answer and therefore is often ridiculed in an environment where high value is placed on getting and giving the right answer. Bruner suggests that providing low risk opportunities for guessing by students and educators, with critique of these guesses, may encourage intuitive thinking in our schools.

In the Relevance of Education, Bruner and Clinchy (1971) outline some of the aspects of intuition in a chapter titled "Toward a Disciplined Intuition." These aspects are paraphrased below:

1. The learner senses a possible or estimated way to get started solving the problem.

2. Getting started increases the learners selfconfidence and sense that he is up to the challenge and helps him begin to formulate tentative hypotheses.

3. Intuition involves direct perception which the learner experiences as "seeing" the conclusion. The answer may be appropriate or inappropriate. 
4. Intuitive procedures are not very verbally justifiable. However, information communicated by words or symbols can be examined by analysis.

5. Intuition involves a sense of connection. It is a shortcut process "based on an informal and often inexpressible structuring of a task" (p. 85).

6. The learner narrows his range of attention, a process which requires confidence and risk taking. In order to find the solution, the learner ignores some information and follows the direction imposed by the problem.

Bruner and Clinchy (1971) suggest that educators encourage students to use intuitive as well as analytic thinking, rather than continuing to overemphasize analytic models of intellectual activity. At the same time they acknowledge that intuition is most successful when "disciplined by more rigorous techniques of problemsolving and problem formulation" (p. 86). They recommend that intuitions be followed up either intuitively or analytically.

\section{Levels of Intuitive Awareness}

Two authors, Vaughn (1979) and Emery (1994), describe levels of intuitive awareness. Vaughn's work is most well known and used by many authors writing about intuition. 
Emery accepts Vaughn's levels of intuitive awareness and has recently added a level which suggests the context of intuitive awareness.

According to Vaughn, intuitive awareness may be consciously perceived on differing, sometimes overlapping, levels, a contribution she credits to Gerard (cited in Vaughn, 1979). The four levels of intuitive awareness are: (a) physical, (b) emotional, (c) mental, and (d) spiritual.

The physical level of intuitive awareness refers to the body. Intuitive awareness comes through bodily sensations such as the hairs on the back of the neck standing up, a gut feeling, or a stomachache. The emotional level refers to the heart. Intuitive cues come in the form of feelings such as an instant like or dislike of a person. The mental level corresponds to the mind. Intuitive awareness comes in the form of seeing a pattern or order to seemingly unrelated facts. The spiritual level refers to the soul. At this level of intuitive awareness, an individual or organization is aware of how actions are connected with all of humanity.

Emery (1994) added a fifth level, the environmental, to Vaughn's four levels of intuitive awareness. The environmental level refers to place. It includes cues from the environment. An example cited by Emery is having 
a flat tire on your car. She suggests that this may be telling you not to go to a scheduled meeting.

Imagery and Intuitive Modalities

The role of imagery in intuition is addressed by most authors writing about intuition (Agor, 1984; Berne, 1977; Emery, 1994; Goldberg, 1983; Jung, 1962; and Vaughn, 1979). Imagery is described as the "language" of intuition. There is general agreement that the intuitive mind communicates in imagery through the five basic senses and the affective and kinesthetic states. These senses and states are sometimes referred to as modalities for accessing intuition. Most people have a dominant sense to access intuition. It is considered important for individuals to identify their dominant sense as they become aware of intuition and how it works for them. However, asking for intuitive imagery through non-dominant senses, and being receptive to the imagery, broaden the range of imagery an individual receives for intuitive problem soiving (Emery, 1994).

Types of Intuition

Loye (1983) and Goldberg (1983) have identified types of intuition. Loye's types are based on the process and number of cues required to reach a conclusion. Goldberg's 
types are based on functions of intuition. Each type is discussed below and summarized in Table 3 .

Table 3

Types of Intuition

\begin{tabular}{|l|l|}
\hline Author & Type \\
\hline \hline Loye (1983) & 1. cognitive inference \\
& 2. Gestalt intuition \\
& 3. precognitive functioning \\
\hline Goldberg (1983) & 1. discovery \\
& 2. creative \\
& 3. evaluation \\
& 4. operation \\
& 5. prediction \\
& 6. illumination \\
\hline
\end{tabular}

Loye (1983) identifies three types of intuition: cognitive inference, gestalt intuition, and precognitive functioning. Each type of intuition results in reaching a correct conclusion with fewer and fewer environmental cues, with precognitive functioning operating without cues. In addition, each type of intuition is associated with a different kind of time: serial time, spatial time, and timeless time, respectively.

The first type of intuition, cognitive inference, occurs when conclusions are determined spontaneously. This type of intuition is a function of the left brain; analytic reasoning occurs rapidly at a subliminal level, so that the person does not remember engaging in the 
reasoning process. Thought appears to be reflexive, drawing on past experiences. Cognitive inference is associated with serial conception of time, or "clock" time (Loye, 1983).

The second type of intuition, "gestalt intuition," occurs when a person detects missing data, information gaps, or hidden relationships within the whole. Closing of the gaps creates the whole. Thought seems more creative, as a person responds to a new situation which was not part of past experience. The person may consider the data piece-by-piece or all at once as a whole. Both parallel and simultaneous processing occur. According to Loye, gestalt intuition operates when we are open to the energy fields around us. Seeing the gestalt is associated with spatial time, a general sense of time, such as before and after, or past and present (Loye, 1983).

The third type of intuition, precognitive functioning, occurs when information about the future is gained directly, rather than by inference based on knowledge of the past and present. Precognitive functioning is associated with "timeless time," about which Loye (1983) writes:

time and space are collapsed into one, in some sense existing outside of, beyond, and/or before there was time and space as we know it. (p. 52) 
According to Loye, precognitive functioning and timeless time are difficult concepts to apprehend and accept. Goldberg (1983) writes that, while intuition means different things to different people, a simple dictionary definition of intuition as direct knowing, without use of rational thought processes, captures the sense of the word. He identifies and describes six functional types of intuition: (a) discovery, (b) creative, (c) evaluation, (d) operation, (e) prediction, and (f) illumination.

Discovery intuition is known by its detective quality. It reveals singular truths, information which can be verified, and a single answer to specific or more general problems. It appears as a sudden intuitive leap to understanding, ready insight, or flash of knowing. An example cited is Watson's discovery of the double helix structure of the DNA molecule (Goldberg, 1983).

Creative intuition is "appropriately imaginative" as it generates alternatives, options or possibilities. It is similar to a brainstorming session, generating a quantity of ideas which will be more or less appropriate to the problem or situation. The ideal or best solution can be selected from the list of unusual solutions. Creative intuition can also be used to clarify what the problem itself is, and again to generate a number of solutions. At times, discovery and creative intuition 
seem to overlap. Once a hypotheses is verified as true, it is, in the strict sense of the term, discovery intuition (Goldberg, 1983).

Evaluation intuition sends a signal of "yes" or "no" when we are faced with a choice. Intuition does not evaluate in the analytical sense of examining or investigating; however, it will help guide the process. Evaluation intuition has an element of discrimination making "ideas feel more or less true; tentative solutions feel more or less right" (Goldberg, 1983, p.52). Therefore, it may be useful when we make our final choice. Operation intuition provides direction, guiding us one way or another. It often precedes anything specific, subtly drawing us toward this or away from that. At times operative intuition may be more forceful, similar to the "stop/go," "do/don't do" quality of evaluation intuition (Goldberg, 1983, p. 54). The difference, according to Goldberg, is that evaluation intuition works when there is something specific to evaluate.

Operation intuition is sometimes referred to as luck, and is evident in people "who seem to be in the right place at the right time" and to whom wonderful "accidents seem to happen" (Goldberg, 1983, p. 54). This type of event may also be accompanied by the comment that these people "just live right." In other words, they have the 
good sense to listen to and act on their intuition. Goldberg (1983) suggests that operation intuition may account for the phenomenon that Carl Jung called "synchronicity," when two events with no apparent causal connection have meaning or significance to a person.

Prediction intuition makes it possible for us to predict future events and outcomes. Predictions may be a warning device alerting us to possible danger, positive feelings about a future engagement, or hunches that help in the timing or organizing of events. According to Goldberg (1983), the test for prediction intuition "hinges on its precision and on whether it is likely to have been made by most people" (p. 58).

Illumination intuition, or transcendence, is similar to Frances Vaughn's (1979) spiritual level of intuitive awareness. According to Goldberg (1983), illumination has been called by many other names in other times and places such as: "nirvana, cosmic consciousness, self-realization, and union with God" (p. 58). Illumination intuition is described as the highest form of knowing. Understanding illumination intuition facilitates understanding all forms of intuition. Furthermore, cultivating illumination simultaneously cultivates the other five functional types of intuition by opening up other intuitive channels (Goldberg, 1983). 
Intuition and the Creative Process

Intuition is viewed as closely related to creativity by authors from a variety of disciplines (Bastick, 1982; Emery, 1994; Rockenstein, 1988; Rowan, 1986). Siebert (1994) provides a description of the relationship:

"intuition is a matter of listening to the subconscious; creativity is a matter of putting the subconscious to work" (p. 59).

Psychologist Graham Wallas (1926) proposed a four stage model of creativity: (a) preparation, (b) incubation, (c) illumination, and (d) verification. In the preparation stage, all the important data is gathered and the problem is viewed from many different angles. During the incubation stage, the problem is released (not consciously worked on) and given to the unconscious mind. The individual engages in other activities unrelated to the problem. In the illumination stage, the solution appears and may be accompanied by the "aha!" Wallas refers to this as the appearance of the "happy idea" ( $p$. 80). The final stage, verification, consists of testing the idea for validity and giving it outward form. This model has been widely accepted in the literature.

Bastick (1982) proposes a theory of intuitive thought in which he collapses the creative cycle into two stages which he calls intuition and verification (pp. 310-311). 
The intuition stage includes the processes of preparation, incubation, and illumination. According to Bastick, the verification stage may be guided by further intuition or by analysis.

Rowan (1986) describes intuition from a perspective arrived at from interviews with chairs of American companies and a common dictionary definition:

Intuition is knowledge gained without rational thought. And since it comes from some stratum of awareness just below the conscious level, it is slippery and elusive to say the least. (p. 11)

Rowan (1986) writes about intuition in parallel with the four stage creative process. His most useful contribution is a discussion of activities to enhance intuition during each stage. During the preparation stage, reflecting forward and backward, wide-angled visualization, concentration, and practice are recommended. In the incubation stage, receptivity and empathy enhance intuition. During the illumination stage, listening to yourself, trusting hunches, mind play, and looking for analogies aid the intuitive process. In addition, timing is described as a crucial and intrinsic component of intuition. Verification, the final stage, is the time to check that wishful thinking is not being accepted as intuition. It is essential to test out the intuition if possible while remaining receptive to new intuitive awareness which may occur. 
Chinen, Spielvogel, and Farrell (1985) describe a three step model of the process of intuition: (a) attunement, (b) articulation, and (c) interpretation. The first step, attunement, which is similar to incubation, follows data gathering about the situation or problem. Attunement requires relaxation and openness as well as emotional involvement for intuitions to be received. The next step, articulation, is synonymous with illumination. The intuitive image or solution can now be communicated to others. The last step, interpretation, requires figuring out what the intuition means and whether or not to act on it. The authors claim that interpretation is similar to the verification stage of the creative process; however, it does not seem to address accuracy of the intuition.

Emery (1994) describes an eight step intuitive problem-solving (IPS) formula which has some likeness to the steps in the creative process. The steps of IPS are :

1. Define the problem. Write the problem clearly and in the form of a question. This is similar to the preparation stage of the creative cycle.

2. Center yourself with an affirmation, focusing exercise, or instrumental music.

3. Make yourself receptive by sitting quietly, with eyes closed using breathing or relaxation exercises. 
4. Elicit imagery either by passively receiving images or by actively requesting imagery through your senses.

5. Interpret the imagery using clustering, mind mapping, word association, or amplification. This is similar to illumination in the creative process.

6. Rest; let the problem go allowing the solution to come in its own time. This is the incubation stage of the creative cycle.

7. Interpret further as you receive insight regarding the solution. Illumination is at work again.

8. Activate the solution received from the intuitive mind.

Emery (1994) proposes a short form of IPS formula for use in crisis situations. This formula involves moving quickly through the first five steps of the formula. There is no discussion of verification of the solution by analysis or further intuitions, with either version of IPS.

\section{Intuition and Experience}

There are conflicting views regarding whether or not past experience is essential to intuition. Dreyfus and Dreyfus (1986) clearly outline the essential role of past experience and the use of intuition. They define intuition as know-how, or effortless understanding 
following similarity or pattern recognition based on past experiences. They describe five stages of skill acquisition: (a) novice, (b) advanced beginner, (c) competent, (d) proficient, and (e) expert. According to this model, decisions are made analytically at the first four stages. Only the experienced individual, the expert, uses intuition in decision making. A summary of the role of experience and intuition is provided in Table 4.

Table 4

Intuition and Experience

\begin{tabular}{||l|l|}
\hline Author & $\begin{array}{l}\text { Is past experience a } \\
\text { precondition of intuition? }\end{array}$ \\
\hline \hline Bastick (1982) & Yes \\
\hline Benner (1984) & Yes \\
\hline Benner \& Tanner (1987) & Yes \\
\hline Dreyfus \& Dreyfus (1986) & Yes \\
\hline Goldberg (1983) & $\begin{array}{l}\text { Yes, suggested, plus } \\
\text { personal development }\end{array}$ \\
\hline Berne (1977) & No, not always \\
\hline Rowan (1986) & No, not always \\
\hline Noddings \& Shore (1984) & $\begin{array}{l}\text { No, intuition may provide a } \\
\text { foundation for experience }\end{array}$ \\
\hline Emery (1994) & No! \\
\hline
\end{tabular}

Benner (1984) applied the Dreyfus model of skill acquisition to her research of clinical decision making in nursing practice. At the first four levels nurses made decisions analytically. Expert nurses, with several years 
of nursing experience, used an intuitive approach to decision making. Later research by Benner and Tanner (1987) confirmed the role of experience and the use of intuitive decision making by expert nurses.

Bastick ( 1982 ) writes that intuition is influenced by past experiences. We respond to situations and objects emotionally as well as rationally. Past experiences create conditioned responses to emotional states, resulting in what Bastick refers to as emotional sets. These emotional sets, or attitudes, mediate our perceptions of any situation. They are intuitively used to evaluate a present experience which feels familiar. If any element is different, the emotional state changes, resulting in a new reading of the "big picture".

Goldberg (1983) does not address the role of past experience directly. However, he does identify characteristics of intuitive people which suggest that experience or at least some degree of personal development is essential. He asserts that people must be open and create a receptive environment for intuition to work in their lives. People with low self-esteem tend to mistrust anything coming from within. Goldberg writes:

It is no coincidence that intuitive people tend to be confident and independent; such traits are needed in order to be open to an unpredictable, surprising, often unconventional source of knowledge that comes from within ourselves. (p. 156) 
Berne (1977) does not think that past experience is always necessary for intuition. He writes: "Intuitions are not all dependent upon extensive past experience in a given field" (p. 26). Rowan (1986) expresses a similar view in his discussion of the implications of a universal information bank:

when we obey the internal dictates of our own nature and rely on intuition we are really acting under the influence of some external web going back to the beginning of time. and If that is true, intuition is not influenced solely by past experiences or repressed desires stored in our subconscious. (p. 100)

Emery (1994) completely rejects the belief that intuition is based on past experience. She writes:

Many people confuse common sense and past experience with intuition. These processes emanate from the logical and rational mind and are integrated with intuition for effective decision making, but they are not the same as being intuitive. Although several researchers call intuition a logical skill and blend both these processes, my view is that intuition is very distinct and separate from logic. (p. 12)

Noddings and Shore (1984) recognize that people who are very knowledgeable in a field have more intuitions than people outside the field or individuals with less knowledge in a given field. Further, the intuitions tend to be more reliable. At the same time, the authors provide evidence that intuition can help people become familiar with a given field. They write: 
Clearly, if intuition follows, it also leads, and, indeed, we have claimed that it provides the very foundation for experience. (p. 65)

When we actively engage in our search for meaning, intuition can lead us in the right direction. Through intuition we gain experience which helps us get more familiar with the field (Noddings \& Shore, 1984).

\section{A Taxonomy for the Intuitive Domain}

Rockenstein (1988) views intuition as one of the major domains of human thought. She operationally defines the intuitive domain as:

an open channel to universal sources of knowledge and wisdom that transcends the boundaries of time, space, the senses, and the logical/rational mind. (p. 78)

She describes a system for developing intuition as it relates to creative thinking and problem solving. The four levels of the taxonomy for the intuitive domain are: (a) awareness, (b) comprehension, (c) development, and (d) individuation. The four stage model of creativity proposed by Wallas (1926) serves as the structure for the comprehension level of the taxonomy. The levels of the taxonomy are paraphrased below:

1. Awareness. At this level the individual learns to consider intuition as a separate mode of thought by (a) learning about related terms such as imagery, insight, and intuitive leap; (b) reflecting on past intuitive 
experiences; (c) hearing about the intuitive experiences of others; and (d) imagining the possibility of being more intuitive in the future.

2. Comprehension. At the second level, intuition is integrated with other forms of thinking and understood as part of the creative process described by wallas.

During the preparation stage of the creative cycle, data gathering and problem formation occur. Intuition may help define the problem or suggest data sources. The second, or incubation stage, operates subconsciously, selecting solutions in the form of imagery from the right brain. The illumination stage, has been referred to as the intuitive leap (Westcott, 1961). At this third stage the image of the solution can be communicated to others. At the fourth stage, verification, the individual checks out the validity of the solution either by intuition or analysis of the anticipated consequences of the solution.

3. Development. The fine tuning of intuition, requires time spent in the non-verbal mind. According to Rockenstein (1988) at this level, the mind constructs new or expanded networks for intuition. Guided imagery and meditation are suggested as good methods to quiet the mind and develop intuition.

4. Individuation. This is the final, ongoing level of the taxonomy. The term individuation is borrowed from 
Jung, and as used in this context, refers to the continued development of an individual's intuitive ability. Rockenstein believes that each person will find his own way in this process.

\section{Concept Analysis of Intuition}

The literature on intuition in nursing as well as other disciplines is confusing and challenging. Two authors, Rew (1986) and McCormack (1992), present an analysis of intuition as a concept in an effort to understand intuition as it applies to nursing. They use Walker and Avant's model to identify attributes, antecedents and consequences of intuition.

Rew's (1986) three attributes of intuition include:

a) knowledge of a fact or truth as a whole;

b) immediate possession of knowledge; and

c) knowledge independent of the linear reasoning process. (p. 23)

Rew and Barrow (1987) confirmed the original three attributes and Rew (1988b) identified three additional attributes:

d) inner knowing;

e) sensing/feeling/ perceiving; and

f) strength of feeling that affects perception. (p. 28 )

McCormack (1992) found confirmation for Rew's original three attributes and identified an additional attribute-"represents synthesis rather than analysis" (p. 341). 
According to Rew (1986), there are two antecedents or events that precede intuition: (a) global truth or knowledge not readily apparent through conscious reasoning, and (b) an open channel to receive this knowledge. McCormack (1992) adds a third antecedent-acknowledgment of intuitive capacity as well as intuitive modes. She expands the description of the open channel to include the feeling of safety and ability to trust intuition.

The consequences of intuition are what happens as a result of the concept. Rew (1986) and McCormack (1992) identify the same two consequences of intuition: (a) verification of intuitive knowledge through linear analysis, and (b) application of the knowledge.

Rew (1988a) interviewed 56 nurses in critical care and home health settings regarding their intuitive experiences. Data analysis showed evidence of Rew's (1986) attributes of intuition and Loye's (1983) three types of intuition. Rew believes that educators should find ways to assist nurses to value intuition and communicate this knowledge to other health professionals.

\section{Ways of knowing}

Carper (1980) describes four fundamental patterns of knowing in nursing: (a) empirics, the science of nursing; 
(b) esthetics, the art of nursing; (c) personal knowledge; and (d) ethics, or moral knowledge in nursing. Each pattern of knowing is necessary to the understanding and practice of nursing. Personal knowledge is essential to understanding the meaning of health from the client's perspective. Yet, personal knowledge is described as the most difficult pattern to learn and to teach. It requires risking commitment, and involvement with the client.

Moch (1990) identifies intuitive knowing as one of the components of personal knowing. She defines the components of personal knowing as follows:

1. Experiential knowing - becoming aware through participation or being in the world. 2 . Interpersonal knowing - increased awareness through intense interaction or being-with the other.

3. Intuitive knowing - immediately knowing something without use of reason. (p. 156)

She identifies the following attributes of personal knowing :

1. It is viewed only in the context of wholeness.

2. It includes a process of encountering.

3. It involves passion, commitment, and integrity.

4. It entails a shift in connectedness/

transcendence. (p. 159)

Moch views intuitive knowing as similar to Polanyi's tacit knowing which "requires the personal participation of the knower" (p. 158). 
Polanyi (1969) states that tacit knowledge is

fundamental to all knowing. Tacit knowledge is comprised of two systems. The first is a process which involves the perception of particulars, including feelings, permitting us to know more than we can articulate (Polanyi, 1966).

The second is intuition and imagination. Polanyi (1968) writes the following about the function of intuition:

It is intuition that senses the presence of hidden resources for solving a problem which launches the imagination in its pursuit. And it is intuition that forms there our surmises and which eventually selects from the material mobilized by the imagination the relevant pieces of evidence and integrates them into the solution of the problem. (p. 42)

Polanyi (1969) writes that:

Intuition is a skill, rooted in our natural sensibility to hidden patterns and developed to effectiveness by a process of learning (p. 118).

This intuitive way of knowing has received little attention in the nursing education Iiterature.

\section{Nursing Research on Intuition}

Starting in the mid 1980s, nurse researchers began a qualitative exploration of intuition. The research on intuition in nursing has focused primarily on nursing practice (Agan, 1987; Benner, 1984; Benner \& Tanner, 1987; Gerrity, 1987; Leners, 1992, 1993; Miller, 1995; Pyles \& Stern, 1983; Rew, 1988a, 1988b, 1990, 1991; Schraeder \& 
Fischer, 1987; and Young, 1987). To date, no study has explored intuition in nursing education.

Pyles and Stem (1983) studied assessment and decision-making processes of 28 critical care nurses. Analysis of the interviews led to the development of the "Nursing Gestalt" theory to describe the intuition of the expert nurse. The authors suggested that the intuitive process may be taught to the novice nurse through mentoring by the expert nurse.

Benner (1984) analyzed the clinical nursing practices of novice and expert nurses. Intuitive judgment was described as a skill of the expert nurse. In a later study, Benner and Tanner (1987) define intuition as "understanding without a rationale" (p. 23). Examples of Dreyfus's six key aspects of intuitive judgment were found in each of the 21 interviews of expert nurses. These six aspects are: (a) pattern recognition, (b) similarity recognition, (c) commonsense understanding, (d) skilled know-how, (e) sense of salience, and (f) deliberative rationality (Dreyfus \& Dreyfus, 1985). The authors note that, in nursing practice, intuition and analytic reasoning often work together.

Leners (1992), in an ethnographic study of 40 nurses from a variety of hospital and home health areas, 
identified three levels of intuition: (a) novice,

(b) standard, and (c) veteran.

She writes:

In the novice level of experience, ( 1 to 2 years), informants commented on their inability to trust their intuitions, expressing at the same time their hope for comfort and confidence in their intuitions in the future. In the standard level of 3 to 8 years of experience, informants were noted to express their increasing sense of self-confidence in identifying, recognizing, focusing in on, and trusting intuition in practice. Informants in the veteran level, ( 8 or more years in practice), did not have to stop to think about recognizing intuitions or worry about trusting them. (pp. 146-147)

There is a similarity between Lener's findings and Benner's (1984) work describing the novice to expert use of intuition.

In a study of seven holistic nurses, Agan (1987) described intuition from the nurses' descriptions of nursing assessment and their knowledge of intuitive knowing. Intuitive knowing was described as a component of personal knowing (Carper, 1980). According to Agan, if intuitive knowing is acknowledged, it has the potential to expand and change nursing knowledge.

Young (1987) observed and interviewed 41 nurses about intuitive experiences in several different agencies and clinical areas. She defined intuition as:

a process whereby the nurse knows something about a patient that cannot be verbalized, that 
is verbalized with difficulty, or for which the source of knowledge cannot be determined. ( $p$. 52)

She concluded that intuition is an important source of knowledge and part of nursing process and practice.

Rew (1990) interviewed critical care nurses to determine whether they experienced intuition in their nursing practice, if they use intuition in the steps of the nursing process, and what feelings and sensations were associated with intuition. Findings were consistent with the work of Young (1987). All nurses used intuition in some steps of the nursing process and described intuition as an important dimension of clinical decision-making.

In a study of neonatal intensive care nurses, Schraeder and Fischer (1987) define intuition as perception, involving sensing and feeling. They state:

Intuitive perception is the immediate knowing of something without the conscious use of reason. [and]

Intuition is the sudden inexplicable feeling that something is wrong. (p. 47)

Gerrity (1987) also describes intuition as perception. She reports that Myers-Briggs Type Indicator (MBTI) data on file indicate that the majority (56\%) of nurses prefer sensing. Intuition is the least developed process of nurses. Gerrity advocates development of both sensing and intuition because both are needed to make sound nursing assessments. 
Rew (1991) studied 16 psychiatric-mental health nurses to explore the way these nurses define and act on intuition, and to identify supports and barriers related to acting on intuition in practice. The nurses defined intuition as "knowledge based on a strong feeling, sense, or perception, but not necessarily based on objective evidence" (p. 111). Intuitive knowledge also had the characteristics of being immediate, unexpected, and anticipatory.

The five most frequently identified supports for using intuition were: respect and trust from others, feedback from colleagues, self-confidence, successful outcome, and reading or attending a class on intuition. Mind-quieting practices, experience and willingness to take risks were mentioned less frequently (Rew, 1991). The nurses in this study (Rew, 1991) identified multiple barriers to using intuition in their clinical practice. The most frequently identified barrier was negative response from others. Nurses said that they were made fun of and felt "judged" by colleagues as being "unscientific." Self-doubt and fear, rigidity of the medical system, time constraints, and no emphasis on intuition in nursing education were other frequently identified barriers to intuition. Less frequently noted 
barriers were: role boundaries, outcome risky, not valued in western culture, and intuition was incorrect.

Miller (1995) confirms the characteristics of intuitive nurses. These are:

1. willing to act on intuition,

2. a skilled, innovative clinician,

3. having a spiritual connection, a

"self-receptivity" in interactions with clients,

4. interested in the abstract, and

5. a risk taker. (p. 314)

In addition, Miller found that nurses who prefer intuition to sensing and are extroverted on personality typology (MBTI) are more likely to perceive themselves as intuitive. There is a similarity between the supports identified by Rew (1991) and the characteristics of intuitive nurses.

Intuition has been defined in a variety of overlapping ways in the nursing research. Intuition is more than a facet of personality, perception, or cognitive inference. In the studies presented here, intuition may be conceptualized as a way of knowing which is different from rational thinking.

\section{Difficulties of Measurement}

Intuition poses a challenge for measurement and has been approached both qualitatively and quantitatively. The instruments which currently exist are simple, mechanistic lab experiments; measure intuition as a 
personality characteristic; or are self-report scales of the degree to which a person is intuitive (Agor, 1989; Bastick, 1982; Loomis, 1982; Miller, 1993; Myers \& Myers, 1980; and Myers \& Myers, 1985).

The Myers-Briggs Type Indicator (MBTI) has been widely accepted as a measure of intuition and used to test the incidence of intuitive type in a variety of nursing settings (Myers \& Myers, 1980). The MBTI has good reliability and validity but has been criticized for its forced-choice design and bipolar nature. The singerLoomis Inventory of Personality (SLIP) was designed to correct the problems of the MBTI and to measure intuition as an aspect of a person's cognitive style. The SLIP was described as more accurate aue to independent rather than forced choice items (Loomis, 1982). Psychometric evaluation of the SLIP indicates satisfactory support for reliability and marginal validity (Macdonald \& Holland, 1993).

Agor developed the Agor Intuitive Management Survey (AIM) to measure intuitive ability and the degree to which intuitive ability is used (Agor, 1989). The first part of this test consists of 12 items from the MBTI which contrast thinking with intuition for decision making. The second part of the instrument tests whether or not, and how, the individual actually uses intuition to make 
decisions. The AIM has the same bipolar quality as the MBTI; if intuition is high, thinking is low and the reverse. The individual who measures high in intuition does so at the expense of thinking. Validity and reliability are addressed only in relation to part one of the instrument.

Bastick (1982) describes many mechanistic experiments designed to measure intuition. Subjects are asked to make predictions based on incomplete information. Accurate predictions using few clues are accepted as evidence of intuition. However, these experiments are not useful in the teaching about intuition in the practice of nursing. More recently, Miller (1993) developed the Miller Intuitiveness Instrument (MII) to measure self-perception of intuitiveness of practicing nurses. This instrument was tested for validity and reliability and found to have construct and criterion-related validity and evidence of reliability. The MII represents an important contribution to nursing because it provides a way to quantify intuition.

Cultural Value of Scientific Method in Nursing

Nursing practice and nursing education at the undergraduate, graduate and continuing education levels 
has been rooted in the scientific problem solving method.

For more than 40 years, nursing education has relied primarily on the Tyler model which stresses the importance of gathering data and studying behaviors which are scientifically observable. The exclusive use of this model led educators to emphasize sensory perceptions and ignore intuition. Use of the Tyler rationale encouraged the view that intuitive perceptions were oppositional to empirical and factual knowledge and therefore had no place in nursing (Benner, 1984; Bevis \& Watson, 1989; Gerrity, 1987; and Rew \& Barrow, 1987).

Benner and Wrubel (1989) describe the limitations of the over-emphasis on the scientific paradigm:

The dominant view of knowledge in the western tradition emphasizes abstract, general, theoretical knowledge while overlooking and devaluing local, specific, practical knowledge and expert skiliful clinical judgments about particular clinical situations. The way involvement is central to expert knowledge is overlooked, reinforcing the myth that the expert must stand outside the situation, aloof and detached, in order to pronounce expert judgment. (p. xv)

In its struggle to emerge as a profession, nursing perpetuated the problem of near exclusive reliance on the scientific method by developing the nursing process in the 1960s. This five step nursing process was described and presented as a linear process for nursing practice, beginning with assessment, followed by problem 
identification, planning, intervention, and evaluation. This linear model has been questioned by Benner (1984), Benner and Tanner (1987), Rew and Barrow (1987), and other nurse researchers. These researchers argue that the scientific process is not applied in a linear manner in practice and that relying solely on this process causes nurses to discredit the holistic, synergistic, intuitive problem solving method. These arguments validate the experience of many practicing nurses. In addition, the research suggests that the use of intuition in nursing practice may lead to more rapid decisions in crisis situations and better patient outcomes.

In her classic study of excellence in clinical nursing practice, Benner (1984) writes the following about the intuitive aspects of perception in nursing:

perceptual awareness is central to good nursing judgment and . . this begins with vague hunches and global assessments that initially bypass critical analysis; conceptual clarity follows more often than it precedes. Expert nurses often describe their perceptual abilities using phrases such as "gut feeling," a "sense of uneasiness," or a "feeling that things are not quite right." This kind of talk makes educators and clinicians uncomfortable, because assessment must move from these perceptual beginnings to conclusive evidence. Expert nurses know that in all cases definitive evaluation of a patient's condition requires more than vague hunches, but through experience they have learned to allow their perceptions to lead to confirming evidence. (p. xviii) 
Intuition is considered an important aspect of perception. It is equally as valuable as sensing to understand the meaning of an experience. Bevis (Bevis \& Watson, 1989) provides the following illustration:

Perception, to be useful, must be intuitive and imaginative. Perception without intuition makes it difficult to grasp wholes or at least to relate the parts in ways that make it easy to quickly and easily assimilate an organismic sense of meanings in situations. This involves the ability to perceive what is significant and what is trivial in a situation, a judgment that can only be made in the light of experience. (pp. 288-289)

Bevis (Bevis \& Watson, 1989) suggests an adaptation of the Eisner (1985) connoisseurship model in nursing education because it challenges students to examine both what they see and the significance of what they see. In other words, it helps them move beyond categorizing to educating their perceptions. This model requires that the faculty risk educating not only in the scientific method but also in the intuitive way of knowing. Bevis has the following to say about teaching to intuition:

Teaching students to attend to their "guts," their intuition, has long been anathema to nursing. In our search for recognition and status through "science," nursing faculty in academia have discounted intuitive knowing and adjured students not only to avoid relying on it, but to refuse to admit using it at all. One of the worst evaluation statements a teacher could make about an aspiring student in the 1950 s through the 1970 s was that the student relied on intuition rather than scientific rationale for making nursing care decisions. The goal should not be the substitution of one 
for the other but the development of many ways of knowing without limiting the legitimate ways to the empirical. (pp. 289-290)

There is no literature regarding whether current nursing faculty continue to devalue and ignore the role of intuitive knowing in nursing.

Since the 1980s, some nurse educators have departed from the "applied science" perspective of nursing and defined their profession as a human science as described by Watson. According to Watson (Bevis \& Watson, 1989) this view of nursing considers the person as a whole in contrast to the behavioral and psychoanalytic view which sees reality objectively, reducible to parts, and context and value-free. Watson explains, "A human science relies heavily on meaning, understanding, intuition, creativity, and human values as pervasive" (p. 221).

As we move beyond the Tyler model in nursing education Bevis (Bevis \& Watson, 1989) argues that nursing must take the successes of the model with us. She writes:

We must do this for the good they did us, for the infusion of wonders, discoveries, inventions, theories, truths, and half-truths they revealed. We must find a balance, a truce, a truly liberated climate of teaching, of inquiry, so that we fuse the "scientific" with the metaphysical, and infuse a new respect for those things uniquely human: morality, judgment, intuition, reflection, imagination, creativity, values, meaning, and spiritual sensitivity. (p. 64) 
Currently there is no research to validate or refute whether or not nursing educators are accepting the challenge to address the intuitive way of knowing in undergraduate courses.

\section{Teaching Intuition in Nursing}

Rew argues that intuitive skills are needed at all levels of nursing education, including basic nursing education. Students can develop intuition through mindquieting exercises and then validate their intuition through analytic reasoning. Intuition-nurturing periods of brainstorming, group visualization, and quiet thinking time are essential for nurses to learn to respond creatively to changing client situations (Rew, 1986). In a later article Rew (1989) outlines specific therapies to awaken intuition: (a) relaxing music, (b) gentie physical exercise such as yoga, (c) progressive relaxation, (d) an intuition journal, and (e) brainstorming and clustering to deal with daily problems. These techniques have been suggested by other authors (Agor, 1984; Emery, 1994; Goldberg, 1983; Noddings \& Shore, 1984; Rockenstein, 1988; and Rowan, 1986). However, these methods have not been validated in nursing.

Benner (1984) recommends strong educational preparation in the biological and psychological sciences 
as the basis for advanced skill acquisition. She states that not only is knowledge the basis for safe care, but it is also necessary to gain a sense of salience for developing intuition.

Benner and Tanner (1987) maintain that in order to teach intuition, nurse educators must move beyond the prescribed assessment tools useful for the beginner. They state that skilled pattern recognition can be taught by - focusing on the whole and giving feedback about the accuracy of clinical judgment. Pattern recognition can be developed through case studies, feedback, precepting, and validation of expert nurses. This process may be accelerated by watching how expert nurses make judgments with a number of the same kinds of patients. They do not indicate whether the other five aspects of skill acquisition can be accelerated.

Leners (1992, 1993) found that informants in her study consistently identified the need to develop intuition in nursing practice. The main technique suggested to enhance intuitive development was "sharing or role modeling the use of intuition with students" (1992, p. 150). Another technique suggested was to have the student take the perspective of the client while being quiet and reflecting on feelings. This practice requires empathy with the client's experience and self awareness. 
The teaching strategies suggested by these authors need to be validated by nursing research.

\section{Conclusion}

There is a growing recognition of the limitations of the exclusive reliance on the rational scientific way of knowing. Some nurse researchers are urging nurse educators to address other ways of knowing, including the intuitive way of knowing in undergraduate curricula.

The nursing literature suggests several reasons that intuition is difficult to address in practice and nursing education. Further research is needed to validate or refute the literature regarding intuition and including the intuitive way of knowing in undergraduate nursing curricula. The data obtained from this survey research will help answer the questions introduced in chapter one of this proposal: (a) If the intuitive way of knowing is not being addressed in undergraduate nursing courses, is the nursing education profession achieving its goal of preparing students for the practice of nursing? (b) If intuition is being addressed in the nursing curricula, do the faculty have the necessary professional education to teach about this way of knowing?

No research was found which addresses whether nursing faculty think that the intuitive way of knowing should be 
included in the undergraduate nursing curriculum. To date, there is no research regarding whether or not intuition or the intuitive way of knowing is being addressed in the undergraduate nursing curriculum. Research is needed to determine if faculty think intuition should be included in the undergraduate nursing curriculum and what, if anything, is being done to facilitate intuitive development in undergraduate nursing programs. Therefore, a descriptive study was completed to determine the following: (a) faculty attitudes about intuition, (b) faculty attitudes toward including intuition in the undergraduate nursing curriculum, (c) current practices of nursing educators regarding including intuition and the intuitive way of knowing in their nursing courses, (d) practices and teaching strategies for developing intuition, and (e) professional preparation of nursing faculty for teaching intuition. 
CHAPTER III

METHODOLOGY

Introduction

The purpose of this descriptive research study was to survey National League for Nursing (NLN) faculty in colleges and universities regarding attitudes and practices about intuition in undergraduate nursing programs. The data were collected from current NLN faculty members. This chapter includes the proposed research methodology, a discussion of population and sampling, instrumentation, data collection, and data analysis.

Population and Sampling

The population was college and university nursing faculty who are members of the National League for Nursing, the accrediting body of schools of nursing. The mission of the NLN is "to improve education and health outcomes by linking communities and information" (NLN, 1997, p. 58). The educational goals of the NLN are:

1. To provide leadership in re-designing the delivery of nursing education and health care services through community-focused models. 
2. To develop and advance the educational models most appropriate for emerging health care needs and services.

3. To promote and monitor the quality, accessibility, and appropriateness of nursing education programs.

4. To transform the teaching-learning environment for nursing and health care.

5. To promote access to information and resources that will enhance the positive health status of diverse communities and individuals.

6. To expand nursing's research agenda to include innovative nursing educational models, community-focused education, and health outcomes of diverse communities.

7. To increase and diversify membership.

8. To develop NLN as a knowledge-based educating organization.

9. To assure NLN's economic growth and fiscal soundness (NLN, 1995, P. 2).

NL.N has a membership of approximately 20,000 individuals and 1,707 agencies. Approximately 2,040 members identify themselves as faculty. This number consists of faculty from practical nurse programs, associate degree (2-year programs), diploma (3-year programs), and baccalaureate (4-year programs). A sample of 676 faculty members were randomly selected from the 2,040 faculty members on the NLN list. Names of faculty members who participated in the pilot of the instrument were excluded before the sample was selected. The first three names on the list were entered randomly, and every 
third name was selected after that until the desired sample size was obtained.

The researcher studied individual faculty members of the NLN rather than agencies who belong to the NLN for the following four reasons: (a) individual membership in the NLN indicates a special commitment to the goals of the $\mathrm{NLN}$; (b) it is the individual faculty member who makes the decision whether or not to teach about intuition; (c) the individual is better qualified to answer questions about their teaching, not the agency, or an individual appointed by the agency; and (d) the decision about participating is completely voluntary. Voluntary participation is not necessarily operating if the individual is asked to complete the survey by the dean or director of a program.

\section{Instrumentation}

The data collection instrument was a descriptive survey designed specifically for this research study (see Appendix A). Many of the individual items arise from the literature and some from dialogue with nursing faculty and practicing nurses. A pilot study was done with 10 nursing faculty from a baccalaureate program serving as the sample providing feedback about the clarity of individual items. The survey was revised, using the suggestions from the 
pilot group, nursing faculty, a nurse researcher, and members of the dissertation committee.

The survey is divided into six sections. Section one is designed to gather data about personal and professional attitudes toward intuition. Section two of the survey addresses faculty attitudes about including intuition in the undergraduate nursing curriculum. Section three consists of questions about the inclusion of intuition in the current curricula. Section four of the survey asks questions about intuitive development, including faculty and student practices and teaching strategies. Section five consists of questions about faculty preparation to teach about intuition in nursing. Section six of the survey asks for demographic information about the respondent and the school of nursing. Table 5 shows the relationship ampng the research questions and survey questions and the analytical procedures used.

\section{Data Collection}

Data collection began, following approval from Portland State University's Human Subjects Research Review Committee. A cover letter was mailed to respondents with the survey, explaining the purpose of the research, enlisting participation, and addressing respondent anonymity. A pre-addressed stamped envelope was provided 
to the respondent to increase the chance of a response. The survey needed to be sent by the end of september in an effort to capture the attention of respondents as they settled into fall term or semester and before mid-semester or end of term issues took priority. The survey was sent September 29, 1997. A follow-up postcard was mailed to all subjects the first week in October, thanking those who responded and reminding the other subjects to complete and return the survey.

Table 5

Relationship Among Research Questions Survey Questions and Analytic Procedures

\begin{tabular}{|c|c|c|}
\hline Research Question & Survey Question (s) & $\begin{array}{l}\text { Analytical } \\
\text { Procedures }\end{array}$ \\
\hline Question \#I & Items \#1-9 & Erequencies, \% \\
\hline Question \#2 & Items \#10-24 & Erequencies, $\frac{\circ}{6}$ \\
\hline Question \#3 & Items \#25-29 & Erequencies, $\%$ \\
\hline Question \#4 & Item \#30 & Erequencies, $\%$ \\
\hline Question \#5 & Item \#31 & $\begin{array}{l}\text { Erequencies, } \%, \\
\text { correlation, } \\
\text { chi-square }\end{array}$ \\
\hline Question \#6 & Items \#32-35, 15 & $\begin{array}{l}\text { Erequencies, } \%, \\
\text { chi-square }\end{array}$ \\
\hline Question \#7 & Items $\# 1-35,43$ & $\begin{array}{l}\text { factor analysis, } \\
\text { chi-square, } \\
\text { t-tests }\end{array}$ \\
\hline $\begin{array}{l}\text { Question \#8 } \\
\text { and \#9 }\end{array}$ & $\begin{array}{l}\text { Items \#1-8, } \\
10-23,32-35\end{array}$ & $\begin{array}{l}\text { ANOVA, } \\
\text { t-test }\end{array}$ \\
\hline
\end{tabular}


Data Analysis

Returned surveys were analyzed using the SPSS (Statistical Procedures for the Social Sciences) program (SPSS, 1996). A code book was designed to enter data from completed surveys. Once the data were entered, analysis of the research questions began.

Research questions were analyzed using the following: (a) descriptive statistics including frequencies, means, and percentages; (b) chi-square test of significance; (c) factor analysis; (d) t-tests, (e) one-way analysis of variance with a .05 level of significance, and post-hoc Bonferroni analysis where appropriate.

To answer the first research question, what are National League for Nursing (NLN) faculty attitudes about using intuition in nursing, frequencies, percentages, means, and standard deviations were calculated on respondents' answers to survey questions \#1-8. In addition, responses to survey question \#9 were summarized.

To answer the second research question, what are NLN faculty attitudes about including intuition in the undergraduate nursing curriculum, frequencies, percentages, means, and standard deviations were calculated on respondents' answers to survey questions \#10-23. In addition, responses to survey question \#24 were summarized. 
To answer the third research question, what percent of faculty teach an undergraduate nursing course that directly addresses the intuitive way of knowing, and is the course required or elective, frequencies from respondents' answers to survey questions \#25-27 and 29 were calculated. To assess the amount of time spent on intuition, and teaching methods, data was analyzed using information from responses to survey question \# 29. Narrative responses to survey question \#28 regarding reasons for including or not including intuition were summarized.

To answer the fourth research question, what practices that emerge from the intuition literature as making a difference in the development of intuition do NLN faculty use and how effective do they think the practices are, frequency responses to survey question \#30 were calculated.

To answer the fifth research question, what teaching strategies that emerge from the intuition literature do NLN faculty use in teaching about intuition in the undergraduate curriculum and how effective do they think the strategies are, frequency responses to survey question \#31 were calculated. Correlations were run between faculty responses to survey question \#30 and 31, followed by chi-square tests. 
To answer the sixth research question, what preparation do NLN faculty have to teach about intuition, and do faculty perceive themselves as adequately prepared to teach about intuition in the undergraduate nursing curriculum, frequency responses to survey questions \#32-35 were calculated and percents were calculated on responses to survey question \#15. Chi-square tests were run on survey question \#15 by survey questions \#32-35.

To answer the seventh research question, do significant differences exist between diploma, associate degree, and baccalaureate degree faculty regarding responses to each of the preceding questions, factor analysis was run on survey questions \#1-8 and 10-23 resulting in four factors. Reliability analysis was calculated and the resulting scales were used to run $t$ tests with survey questions \#32-35 and 43. Chi-square tests were run on survey questions $\# 25-27,30$ and 31 by survey question \#43.

Research question eight, do significant differences exist in each demographic variable and attitudes about using intuition in nursing, and research question nine, do significant differences exist in each demographic variable and attitudes about including intuition in the undergraduate nursing curriculum were combined for analysis. The combined question was, do significant 
differences exist in each demographic variable and attitudes about using and including intuition in the undergraduate nursing curriculum. Survey questions \#32-35 and demographic survey questions \#36-45 were treated as independent variables. The four intuition attitude scales (responses to survey questions \#1-8 and 10-23) developed to answer research question \#7 were treated as dependent variables. ANOVA and t-tests were run using information from survey questions \#32-45 and the four intuition attitude scales. 
CHAPTER IV

RESULTS

Introduction

This chapter includes the general characteristics of the survey respondents and the results of this descriptive study in the context of the research questions. A discussion of the characteristics of respondents is followed by eight sections that answer the corresponding research questions.

Section one addresses the first research question which describes National League for Nursing (NLN) faculty members' attitudes about using intuition. Section two discusses research question two which includes respondent's attitudes toward including intuition in the undergraduate nursing curriculum. The third research question is addressed in section three and discusses the findings about the percent of faculty teaching about intuition in a nursing course. Section four addresses the fourth research question which identifies strategies faculty used to develop their own intuition and the effectiveness of the strategies. The fifth research question is addressed in section five and describes 
strategies faculty use with students to help them develop intuition and the effectiveness of the strategies. A discussion of the relationship between faculty use of strategies for self and with students is included. Section six describes the findings of research question six concerning faculty preparation and perceived preparation to teach about intuition. Section seven explores differences in responses to the previous research questions and program type identifying four factors which were used to explore differences in intuition attitudes. section eight discusses the results of research question eight which revealed significant differences between demographic variables and attitudes toward using and including intuition in the undergraduate nursing curriculum. An analysis of narrative responses is included in the discussion of research question eight and nine.

General Characteristics of Respondents

\section{Response Rates}

The Intuition Survey was mailed to a random sample of 676 individuals on the NLN faculty list rental. Three surveys were not delivered by the postal service, 11 were eliminated because they were from faculty in practical nurse programs, ten surveys were incomplete, and 16 
individuals were not able to participate because they were in nursing administration (4), not teaching in a school of nursing (5), recently retired (3), had a difference in philosophy regarding intuition (3), or were deceased (1). An additional Eive surveys were received weeks after the set deadline and were not used. The adjusted return rate was $50.6 \%(\underline{N}=330)$.

\section{Respondent Characteristics}

NLN faculty members who responded to the survey (Table 6) were predominately female (98.5\%) and between 45-60 years of age (70\%). The majority of the sample population held a master degree in nursing (73.2\%); approximately $22 \%$ held a doctorate in nursing. The most frequently reported highest degree outside of nursing was a doctorate $(54.3 \%)$.

The respondents were experienced in nursing practice and nursing education. The majority (57\%) had been practicing nursing for more than 25 years. The majority of faculty (65.9\%) had been in nursing education for 15 or more years.

The sample came from throughout the United States, with the largest numbers coming from the southern ( $34.2 \%$ ), North Atlantic $(30.6 \%)$, and Midwestern $(26.4 \%)$ regions. The smallest representation was from the Western ( $8.8 \%$ ) region. Appendix B lists the states for each NLN region. 
Table 6

Characteristics of Respondents

\begin{tabular}{|c|c|c|}
\hline Characteristic & Number & Percentage \\
\hline Y & & \\
\hline $\begin{array}{l}\text { Male } \\
\text { Female }\end{array}$ & $\begin{array}{r}5 \\
322\end{array}$ & $\begin{array}{r}1.5 \% \\
98.5 \%\end{array}$ \\
\hline
\end{tabular}

Age

$\begin{array}{lll}<45 \text { years } & 62 & 19.3 \% \\ 45-49 \text { years } & 62 & 19.3 \% \\ 50-54 \text { years } & 93 & 28.8 \% \\ 55-59 \text { years } & 70 & 21.7 \% \\ 59+\text { years } & 35 & 10.9 \%\end{array}$

NLN Region

North Atlantic 101

Midwestern $\quad 87$

$30.6 \%$

Southern 113

Western

29

$26.4 \%$

$34.2 \%$

$8.8 \%$

Highest Academic Nursing Degree

Bachelor

Master

Doctorate
15

238

72
$4.6 \%$

$73.2 \%$

$22.2 \%$

Highest Academic Degree

out of Nursing

Associate

Bachelor

Master

$2.2 \%$

Doctorate

Years Practicing Nursing

$<21$ years

65

75

78

60

47

$26-30$ years

$31-35$ years

$35+$ years

Years in Nursing Education

$<8$ years

8-14 years

$15-21$ years

22-28 years

$29+$ years

43

68

107

72

36
$20.0 \%$

$23.0 \%$

$24.0 \%$

$18.5 \%$

$14.5 \%$

$13.2 \%$

$20.9 \%$

$32.8 \%$

$22.1 \%$

$11.0 \%$ 
Respondents' Institution

Characteristics

Approximately equal numbers of respondents taught in 2 year associate $(34.8 \%)$ as in 4 year baccalaureate and higher degree (35.1\%) programs (Table 7). The percentage from baccalaureate only programs was $18.3 \%$. Diploma representation was $9.8 \%$; associate to baccalaureate programs accounted for $2.1 \%$ of the sample.

Table 7

Respondents' Institution Characteristics

\begin{tabular}{lrr}
\hline Characteristic & Number & Percentage \\
\hline Type of Nursing Program & 32 & \\
Diploma & 114 & $9.8 \%$ \\
Associate & 60 & $34.8 \%$ \\
Baccalaureate & 115 & $18.3 \%$ \\
Baccalaureate \& Higher & $35.1 \%$ \\
Associate-Baccalaureate & 7 & $2.1 \%$ \\
& & \\
Primary Teaching Area & 115 & $35.5 \%$ \\
Adult Health & 17 & $5.2 \%$ \\
Child Health & 25 & $7.7 \%$ \\
Community Health & 17 & $5.2 \%$ \\
Leadership \& Management & $4.6 \%$ \\
Maternal-Newborn Health & 15 & $7.4 \%$ \\
Psych-Mental Health & 24 & $13.0 \%$ \\
Other & 42 & $21.3 \%$ \\
More than one area & 69 & \\
checked & & \\
Enrollment in Undergraduate & & \\
Nursing Major & & \\
<lo0 students & 102 & $23.8 \%$ \\
100-199 students & 74 & $31.6 \%$ \\
200-299 students & 32 & $22.9 \%$ \\
$300-399$ students & 38 & $11.8 \%$ \\
400 or more students & & \\
\hline
\end{tabular}


One third of the faculty (35.5\%) designated "adult health" as their primary area of teaching responsibility. Sixty-nine (21.3\%) identified more than one area, even though the instructions directed them to check only one. Another $13.0 \%$ marked "other" and wrote in multiple responsibilities such as adult health, leadership, and administration. Fewer than 10\% of faculty checked any other single teaching area.

Enrollment in the nursing major in which the respondents taught showed diversity in size from less than 100 to 400 or more students, with the majority (54.5\%) of respondents teaching in programs with enrollments between 100 and 299.

\section{Intuition Attitudes}

This section includes a discussion of frequency responses, means, and narrative responses related to experiences shaping intuition attitudes.

The first research question asks, "What are National League for Nursing (NLN) faculty attitudes about using intuition in nursing?" Percents were calculated on the first eight survey items to answer this research question (Table 8). The majority of respondents strongly agree or agree with the eight attitude statements regarding using intuition. More than $15 \%$ of the sample disagreed with 
only two items. The items of disagreement related to making better decisions (16.3\% disagreed or strongly disagreed) and to intuition being as important as rational thinking (39.1\% disagreed or strongly disagreed).

Table 8

Respondents' Attitudes Toward Using Intuition in Percentage

\begin{tabular}{|c|c|c|c|c|c|}
\hline Attitude & $\underline{\underline{N}}$ & $\div S A$ & $\div A$ & $\div D$ & $\div S D$ \\
\hline $\begin{array}{l}\text { My intuition is } \\
\text { important to me. }\end{array}$ & 329 & 52.0 & 35.0 & 2.4 & 0.6 \\
\hline $\begin{array}{l}\text { Intuition is more than } \\
\text { "sloppy" thinking. }\end{array}$ & 329 & 59.6 & 38.3 & 1.2 & 0.9 \\
\hline $\begin{array}{l}\text { Intuition is an } \\
\text { important way of } \\
\text { knowing. }\end{array}$ & 330 & 51.5 & 44.2 & 3.6 & 0.6 \\
\hline $\begin{array}{l}\text { I find intuition to be } \\
\text { a comfortable subject. }\end{array}$ & 330 & 50.9 & 42.7 & 6.1 & 0.3 \\
\hline $\begin{array}{l}\text { I use intuition in my } \\
\text { nursing practice. }\end{array}$ & 328 & 47.0 & 49.7 & 2.4 & 0.9 \\
\hline $\begin{array}{l}\text { Intuition makes me a } \\
\text { more effective nurse. }\end{array}$ & 324 & 45.1 & 49.4 & 4.3 & 1.2 \\
\hline $\begin{array}{l}\text { Intuition helps me make } \\
\text { better decisions than } \\
\text { use of rational } \\
\text { processes alone. }\end{array}$ & 324 & 30.6 & 53.1 & 14.8 & 1.5 \\
\hline $\begin{array}{l}\text { Intuition is as } \\
\text { important as rational } \\
\text { thinking. }\end{array}$ & 322 & 14.9 & 46.0 & 32.9 & 6.2 \\
\hline
\end{tabular}

Note: Strongly Agree (SA), Agree (A), Disagree (D), Strongly Disagree (SD)

Means and standard deviations were then calculated on the first eight survey items (Table 9). The scores ranged 
from 1 (strongly disagree) to 4 (strongly agree). A mean score above 2.5 was considered a positive attitude toward using intuition. Mean scores above 2.5 were reported by the respondents in each of the eight intuition attitudes. Two of the intuition attitude statements (My intuition is important to me, and Intuition is more than "sloppy" thinking) had "strong agreement" responses with mean scores above 3.5. Five of the intuition attitude statements had "agreement" responses, with means between 3.0 and 3.5 . The eighth intuition attitude statement (Intuition is as important as rational thinking) reported a mean below 3.0 . The results show that respondents have positive attitudes toward using intuition in nursing.

Considering the emphasis on the scientific method and rational thinking in the nursing literature, the evidence supporting intuition was unexpected. The sample population who returned a completed survey may be biased toward those who find intuition important. Individuals who do not find intuition important may have elected to disregard the survey.

The data reveal that while respondents' viewed intuition as more than "sloppy" thinking, they were in less agreement about whether intuition is as important as rational thinking. Respondents may be unwilling to risk 
making such a claim given the emphasis on rational thinking in nursing education and practice.

Table 9

Respondents' Attitudes Toward Using Intuition

\begin{tabular}{|c|c|c|c|}
\hline Attitude & $\underline{\mathrm{N}}$ & Mean & $\underline{\mathrm{SD}}$ \\
\hline My intuition is important to me & 329 & 3.58 & 0.57 \\
\hline $\begin{array}{l}\text { Intuition is more than "sloppy" } \\
\text { thinking. }\end{array}$ & 329 & 3.57 & 0.57 \\
\hline $\begin{array}{l}\text { Intuition is an important way } \\
\text { of knowing. }\end{array}$ & 330 & 3.47 & 0.60 \\
\hline $\begin{array}{l}\text { I find intuition to be a } \\
\text { comfortable subject. }\end{array}$ & 330 & 3.44 & 0.62 \\
\hline $\begin{array}{l}\text { I use intuition in my nursing } \\
\text { practice. }\end{array}$ & 328 & 3.43 & 0.59 \\
\hline $\begin{array}{l}\text { Intuition makes me a more } \\
\text { effective nurse. }\end{array}$ & 324 & 3.38 & 0.63 \\
\hline $\begin{array}{l}\text { Intuition helps me make better } \\
\text { decisions than use of rational } \\
\text { processes alone. }\end{array}$ & 324 & 3.13 & 0.71 \\
\hline $\begin{array}{l}\text { Intuition is as important as } \\
\text { rational thinking. }\end{array}$ & 322 & 2.70 & 0.80 \\
\hline
\end{tabular}

In summary, the data indicate that faculty placed importance on intuition, viewed intuition as an important way of knowing, were comfortable with intuition, used intuition in nursing practice, believed that intuition 
helped them make better decisions than use of rational processes alone and made them more effective nurses.

Survey item number nine asked respondents to identify experiences that helped shape their attitudes toward using intuition in nursing. The majority $(60.9 \%)$ of the sample population $(\underline{N}=330)$ wrote a response to this item. A selection of responses follow that illustrate the value of intuition in nursing and intuition as a way of knowing.

A 58 year-old nurse who has been in nursing education for 22 years wrote,

Working nights with Kathryn and Julia, two nurses who mentored me as a brand new graduate. I've always been a very intuitive person, but had gotten the idea from my physicist husband, that the "scientific process" was more valid. Kathryn and Julia taught me to use all the tools at my command to assess and care for patients.

A 59 year-old nurse with 27 years in nursing education shared,

I have made it a practice to carefully observe not only verbal but non verbal actions of clients and students and also survey the environment of the room - or belongings quietly register what is seen and heard and remain nonjudgmental and bring forth information as necessary. Using intuition requires me to be very put together myself. At times when I am not at my best I am not able to focus well.

A 57 year-old nurse with thirty years experience in nursing education wrote,

Caring for several patients and having that "gut feeling" that something wasn't right. Although 
concrete assessments helped verify the problem, intuition identified the need for assessment.

A 61 year-old nurse claimed,

Many experiences when [intuition] helped reach the heart of the matter quickly and appropriately.

A 37 year-old nurse and Iicensed massage therapist with 10 years in nursing education lists experiences with intuition as a way of knowing,

Knowing when a child needs to be picked up and cuddled;

Knowing when a child is sick, even though there are no "physical" signs;

Knowing when a parent needs to talk, but hasn't said anything;

Knowing when a student is sick or scared but hasn't said anything;

working on problems when there doesn't seem to be a rational answer, but finding a solution.

Other respondents mentioned their educational experiences as shaping their attitudes toward using intuition. A 57 year-old nurse educator wrote,

During doctoral study course work I did a concept analysis on intuition.

And a 53 year-old nurse shared,

I am a poet. I had a strong liberal education background before I came into nursing.

Also, reading Benner's From Novice to Expert. I am influenced by the thinking of Martha Rogers and Jean Watson.

This nurse also felt that attending a doctoral program with several nurse colleagues who were artists influenced her attitudes. 
Attitudes About Including Intuition

This section includes a discussion of frequency responses, means, and narrative responses related to experiences shaping respondent's attitudes about including intuition.

The second research question asks, "What are NLN faculty attitudes about including intuition in the undergraduate nursing curriculum? Percentages were used to answer this research question. Information was obtained from responses to survey items \#10-23.

The results show that the majority of respondents strongly agree or agree with 10 of the 14 attitude statements regarding including intuition in the undergraduate nursing curriculum (Table 10). More than $40 \%$ of the sample disagreed or strongly disagreed with six of the attitude statements.

Mean and standard deviation scores were calculated on the 14 survey items that addressed attitudes about including intuition in the undergraduate nursing curriculum (Table 11). Scores were coded I for strongly disagree, 2 for disagree, 3 for agree, and 4 for strongly agree. A mean above 2.5 was considered a positive response. 
Table 10

Respondents' Attitudes Toward Including
Intuition in Percentage

\begin{tabular}{|c|c|c|c|c|c|}
\hline Attitude & $\underline{N}$ & $\div S A$ & $\div \mathrm{A}$ & $\div \quad D$ & $\%$ SD \\
\hline $\begin{array}{l}\text { Including intuition is } \\
\text { unlikely to infringe on } \\
\text { student's right to. } \\
\text { religious freedom. }\end{array}$ & 323 & 39.6 & 57.6 & 2.5 & 0.3 \\
\hline $\begin{array}{l}\text { Developing an awareness } \\
\text { of intuition is } \\
\text { important. }\end{array}$ & 323 & 19.8 & 66.6 & 12.7 & 0.9 \\
\hline $\begin{array}{l}\text { Though intuition is a } \\
\text { skill of the expert } \\
\text { nurse, it should be } \\
\text { included. }\end{array}$ & 318 & 21.7 & 63.5 & 11.0 & 3.8 \\
\hline $\begin{array}{l}\text { Students may be better } \\
\text { prepared for nursing } \\
\text { practice by including } \\
\text { intuition. }\end{array}$ & 320 & 15.0 & 67.2 & 16.6 & 1.3 \\
\hline $\begin{array}{l}\text { It would be appropriate } \\
\text { to include intuition. }\end{array}$ & 325 & 19.7 & 56.3 & 20.3 & 3.7 \\
\hline $\begin{array}{l}\text { Students are unlikely } \\
\text { to make serious errors } \\
\text { in patient care when } \\
\text { using intuition. }\end{array}$ & 324 & 12.7 & 61.7 & 23.8 & 1.9 \\
\hline $\begin{array}{l}\text { I have time to include } \\
\text { intuition in teaching. }\end{array}$ & 318 & 11.9 & 62.6 & 21.7 & 3.8 \\
\hline $\begin{array}{l}\text { Including intuition } \\
\text { does not place the } \\
\text { profession at risk of } \\
\text { being viewed as } \\
\text { unscientific, resulting } \\
\text { in lower status. }\end{array}$ & 321 & 9.7 & 59.2 & 27.4 & 3.7 \\
\hline
\end{tabular}

Note: Strongly Agree (SA), Agree (A), Disagree (D), strongly Disagree (SD) 
Table 10

Respondents' Attitudes Toward Including Intuition in Percentage

(continued)

\begin{tabular}{||l|l|l|l|l|l|}
\hline \multicolumn{1}{|c|}{ Attitude } & N & $\%$ SA & $\%$ A & $\%$ D & \% SD \\
\hline $\begin{array}{l}\text { I anticipate support } \\
\text { from my administrators } \\
\text { for including } \\
\text { intuition. }\end{array}$ & 309 & 3.9 & 48.2 & 41.4 & 6.5 \\
\hline $\begin{array}{l}\text { My nursing colleagues } \\
\text { would support including } \\
\text { intuition. }\end{array}$ & 304 & 4.3 & 45.4 & 43.8 & 6.6 \\
\hline $\begin{array}{l}\text { Most of my colleagues } \\
\text { in other disciplines } \\
\text { would support the } \\
\text { inclusion of intuition. }\end{array}$ & 301 & 6.0 & 46.2 & 44.9 & 3.0 \\
\hline $\begin{array}{l}\text { I feel that I have } \\
\text { adequate preparation to } \\
\text { teach about intuition. }\end{array}$ & 324 & 9.6 & 35.8 & 45.1 & 9.6 \\
\hline $\begin{array}{l}\text { It is possible to } \\
\text { "catch a student in the } \\
\text { act" of using intuition } \\
\text { and evaluate it. }\end{array}$ & 323 & 3.4 & 30.7 & 55.7 & 10.2 \\
\hline $\begin{array}{l}\text { It is possible to } \\
\text { define intuition } \\
\text { clearly and include it. }\end{array}$ & 326 & 4.9 & 22.7 & 57.7 & 14.7 \\
\hline
\end{tabular}

Note: Strongly Agree (SA), Agree (A), Disagree (D), Strongly Disagree (SD)

Unlike the results of the previous research question, respondents were in less agreement about their attitudes toward including intuition in the undergraduate nursing curriculum (Table 11). Of the 14 items surveyed, eight reported mean scores above 2.5 . Though intuition is a 
Table 11

Respondents' Attitudes Toward Including

Intuition in the curriculum

Attitude

$\underline{\mathrm{N}}$

Mean

$\underline{S D}$

Including intuition is unlikely

323

3.37

0.55

to infringe on student's right

to religious freedom.

Developing an awareness of

323

3.05

0.60

intuition is important.

Though intuition is a skill of the expert nurse, it should be 318

3.03

0.69 included.

Students may be better prepared

320

2.96

0.60

for nursing practice by including intuition.

It would be appropriate to include intuition.

2.92

0.74

Students are unlikely to make serious errors in patient care when using intuition.

I have time to include intuition 318

2.83

0.68

in my teaching.

Including intuition does not place the profession at risk of 321

2.75

0.68

being viewed as unscientific, resulting in lower status.

I anticipate support from my administrators for including 309

2.50

0.68 intuition.

My nursing colleagues would support including intuition. 
Table 11
Respondents' Attitudes Toward Including Intuition in the curriculum (continued)

Most of my colleagues in other disciplines would support the 301 $2.45 \quad 0.65$ inclusion of intuition.

I feel that I have adequate preparation to teach about intuition.

It is possible to "catch a student in the act" of using intuition and evaluate it.

Note: $1=$ strongly disagree; 4 = strongly agree

skill of the expert nurse, respondents stated that developing an awareness of intuition and including intuition were important and appropriate in the undergraduate nursing curriculum. This positive attitude was noted even though the respondents had concerns regarding assessment and evaluation of intuition. Respondents agreed that students may be better prepared for nursing practice by including intuition and were not concerned that students would make serious errors in patient care when using intuition. In addition, 
respondents agreed that they had time to include intuition in their teaching but expressed concern about their preparation to teach intuition. Respondents were not concerned that including intuition would place the profession at risk of being viewed as unscientific, resulting in lower status. This attitude existed even though respondents expressed some concerns about the support for including intuition. Six statements in this section of the survey report mean scores of 2.5 or lower. Respondents expressed some concerns and uncertainties about including intuition in the undergraduate nursing curriculum. These concerns appear to fall into three categories: (a) support, (b) preparation, and (c) evaluation.

The response to three attitude statements relate to faculty attitudes toward support for including intuition in the undergraduate nursing curriculum. These concerns were: (a) anticipated support from administration, (b) lack of support from nursing colleagues, and (c) lack of support from colleagues in other disciplines.

The results indicate that respondents had concerns about their preparation to teach about intuition. The response to one attitude statement in the survey relates to respondents' attitudes toward preparation when including intuition in the undergraduate nursing 
curriculum. This was: feeling inadequately prepared to teach about intuition. The concern may be addressed by education and training in intuitive development.

The results further indicate that respondents had concerns about evaluation of intuition when including intuition in the undergraduate nursing curriculum. These concerns were expressed in two of the attitude statements. These were: (a) intuition is hard to observe and evaluate, and (b) intuition is difficult to define clearly and include. The concern expressed by these attitudes, viewed in conjunction with previous attitudes of strong support for including intuition in the nursing curriculum, suggest that respondents may be caught in a dilemma between wanting to include intuition and not knowing how to go about it. The concerns may be alleviated by exploring teaching paradigms other than the traditional paradigm for nursing which emphasizes objective, measurable learning. Professional development in the area of intuition may also be useful.

In conclusion, respondents expressed attitudes that support the importance and appropriateness of including intuition in the undergraduate nursing curriculum as well as attitudes that identified areas of concern when including intuition. 
Survey item number 24 asked respondents to identify experiences that helped shape their attitudes toward including intuition in their teaching. Slightly less than one third $(31.2 \%)$ of the sample $(\underline{N}=330)$ wrote a response to this item. A selection of responses follow.

A number of respondents described how success with intuition in nursing practice and education influenced their attitudes toward including intuition in their teaching. A 60 year-old nurse with 10 years in nursing education wrote,

My personal experiences in my clinical practice have made me aware of the effectiveness of combining knowledge, experiences, and "gut feelings" in patient care. Students have verbally expressed this "sixth sense" feeling and have frequently been correct in these thoughts about a particular patient. They need teaching, reinforcement, and guidance applying these feelings.

A 49 year-old nurse with 22 years in nursing education comments,

The experience of using intuition in my day-today practice and being successful with it compelled me to at least make my students aware of the idea and challenge them to try using it. If it doesn't work for them, that's OK, but they need to try it first and then decide.

A 51 year-old nurse educator of 25 years wrote about the value of intuition for students in perioperative nursing, Teaching the development of a "surgical conscience" the ability and willingness to be a patient's advocate when safety is at stake or 
there is the potential for violating patient rights. Students who can recognize internal cues that something may be wrong and who follow up on their hunches develop a stronger surgical conscience.

A 51 year-old nurse with 10 years in nursing education

described the benefits of intuition as a way of knowing,

There is some evidence that nursing students

learn best via application. I have found that use of case studies invite multiple ways of knowing including intuition. My students generally illuminate "facts" but invariably one or more will offer an "odd" perspective which generates much discussion. The latter, I believe, arises from intuition.

A few respondents commented on the use of intuition in their work with students. A 43 year-old nurse educator of 13 years wrote,

As an instructor there are times $I$ am in the right place at the right time...can't really explain why I was drawn there, just glad I was!

A 42 year-old nurse claimed,

I intuit students' needs now after 15 years of teaching.

Some respondents credited students with influencing their attitudes toward including intuition in their teaching.

A 52 year-old nurse with 10 years in nursing education shared,

When I explore with students their pros and cons of using intuition I become more clear about the benefits of teaching students to consider this area. Use of the Myers-Briggs helps students to identify whether relying on intuition is helpful or not helpful to them. 
A 44 year-old nurse with 9 years in nursing education wrote,

Students who have listened to their gut feelings and requested my assistance despite the fact that there's not concrete evidence pointing to a client being in trouble.

Finally, a 50 year-old nurse educator of 6 years commented,

I see a combination of sound scientific rationale and intuition as producing probably the most consistently useful form of critical thinking.

This last response suggests support for the thinking that both intuitive and rational ways of knowing are valuable processes to include in the undergraduate nursing curriculum.

Intuition in current Curricula

This section includes a discussion of responses regarding including intuition in the current curricula, representative narrative responses describing reasons for including and for not including intuition in nursing courses, teaching methods, and time spent on intuition.

The third research question states, "What percent of faculty teach an undergraduate nursing course that directly addresses the intuitive way of knowing, and is the course required or elective?" Frequency data and 
percentages were tabulated to answer this research question (Table 12). The summary data reveal that during the 1997-98 academic year, $30.6 \%(\underline{n}=100)$ of respondents taught an undergraduate nursing course that addressed intuition. The data indicate that $97.9 \%$ of the courses that include intuition are part of the required nursing curriculum; only $2.1 \%$ are elective.

Table 12

Percent of Faculty Including Intuition in an Undergraduate Nursing Course

Faculty

Yes

No

Addressing intuition

$30.6 \div \quad(\underline{n}=100)$

$69.4 \%(\underline{n}=227)$

Required course

$97.9 \%(\underline{n}=95)$

$2.1 \%(\underline{\underline{ }}=2)$

It is interesting to note that, in the sample, the intuitive way of knowing is addressed in the philosophy of the school of nursing of $13.7 \%(\underline{n}=44)$ of respondents. Specific educational objectives related to the development of intuition are included in only $6.2 \%(\underline{n}=20)$ of undergraduate nursing courses taught by respondents. However, $30.6 \%(\underline{\underline{n}}=100)$ of respondents are currently teaching something about intuition in a nursing course. 
This suggests that some faculty feel that it is important to include intuition even if it is not addressed in the philosophy, or do not see a conflict between including intuition and the current philosophy. The data regarding objectives may suggest that objectives specific to intuition are not necessary, are too difficult to write, or that intuition is included in other broader objectives.

\section{Narrative Responses}

Survey item number 28 asked respondents to describe their reasons for including or not including intuition in their undergraduate teaching. More than two thirds $(68.2 \%)$ of the 330 respondents in the sample population responded to this item.

One cluster of responses include intuition because they believe that intuition is a valid way of knowing. A 55 year-old nurse with 17 years in nursing education wrote,

[I] believe that the intuitive way of knowing is a valid way of knowing. By communicating this to students it helps bolster their self-esteem and self-confidence. [I] encourage students to validate their intuition with more experienced nurses.

A 42 year-old nurse educator of 9 years said,

We believe that intuition is included as a component of the ways of knowing as described by Carper. 
A 45 year-old educator wrote,

[Intuition] is an important way of knowing. students already use intuition - it will legitimize its use.

Another cluster of responses included intuition because they view it as a component of critical thinking.

"It is a part of critical thinking," wrote a 43 yearold nurse educator. A 60 year-old respondent with 15 years in nursing education wrote that intuition is

a beginning for critical thinking - Isn't all critical thinking in some way based on intuition?

A 57 year-old nurse educator of 19 years wrote,

I feel strongly that intuition is a motivator for critical thinking in the student.

A 52 year-old respondent with 20 years of nursing education experience wrote,

My colleague and I teach a required course to entry level BSN students called Critical Thinking in Nursing. We acknowledge and nurture students ability to use their natural, innate, extant thinking skills which include intuition.

Another cluster of responses indicated that they include intuition because intuition is an important human dimension. A 58 year-old educator of 22 years wrote,

I include intuition because I want the students to be aware of all the dimensions of nursing in particular and of human ability in general. I'm pretty much a rebel among my colleagues, so this is a personal thing with me. 
A 53 year-old nurse educator of 27 years remarked, Intuition is a part of who we are and what we do - how can we teach and nurse without it?

A 59 year-old with 12 years as a nurse educator wrote,

[Intuition] is an essential concept truiy inherent in perception and integral to the human condition.

Many respondents indicated that they include intuition in their teaching because it is important to good nursing practice. A 56 year-old educator who teaches in a baccalaureate program that addresses intuition in the philosophy wrote,

We believe [intuition] is an integral part of praxis.

A 53 year-old nurse related,

[I] have seen the difference intuition makes in practice,

A 48 year-old nurse educator stated,

I believe [intuition] does exist, that it is important and can be the difference between a good nurse and a better nurse.

A 52 year-old nurse educator of 10 years wrote,

I believe that for some people, intuition facilitates their ability to make good decisions and give good nursing care. For those peopie it is important to give permission to use and develop the skill.

A 54 year-old nurse with 25 years experience in nursing education wrote,

I believe [intuition] is a valuable asset, to practice Iistening to our inner voices is critical to careful judgments in many circumstances. 
A 43 year-old educator commented,

I teach pediatric nursing. Often intuition about children's behavior can be helpful in determining changes in health condition.

The last clustering of responses include intuition in their teaching because students need intuition. A 48 year-old nurse educator asserted,

Students need to trust their "gut" feelings.

No further explanation was provided. A 51 year-old nurse educator of 15 years wrote that she teaches about intuition

so that students can learn to start to trust their intuitive sense.

A similar comment came from a 56 year-old educator,

Students need to believe in their own senses "gut feelings" but this must be coupled with basic knowledge.

A 55 year-old nurse with 30 years in nursing education wrote,

Seed must be planted and nurtured... and students will grow into practitioners who have a sense of confidence in and security about their solidly based sense of intuition.

A 57 year-old educator of 20 years specifically addressed the need for intuition where students are practicing in more autonomous roles,

Teaching students to function in more autonomous roles in community settings - important to pay attention to one's intuitive feelings re. safety, re. what's happening in the family you are visiting, etc. 
Respondents tended to give more than one reason for not including intuition in their teaching. Examples of typical responses follow.

A 59 year-old nurse teaching in a baccalaureate program wrote,

There are many other priorities in the curriculum - no rime. and Intuition is a "loose" science.

A 52 year-old associate degree faculty member stated, Our curriculum is jam packed now. I feel intuition might better be addressed at a higher than basic entry level.

A 55 year-old respondent wrote,

The curriculum looks like it is one big black plastic bag. We keep shoving new content into it but rarely is anything taken out. A major revision is needed. I also am leery about encouraging inexperienced students to use intuition and have them mistake guessing for intuition.

A few respondents indicated that they were not including intuition in their teaching because it was not valued in their program. A 59 year-old educator wrote,

It is not included because [intuition] is not valued as a primary way of knowing, decision making.

Nine respondents, most from associate degree programs, felt that intuition was not appropriate at the undergraduate level. A 52 year-old nurse educator of 15 years wrote, 
I believe that intuition would complicate [the] thinking processes of some undergraduate nursing students; plus it is nonmeasurable and difficult to evaluate.

A 59 year-old educator identified the curriculum focus,

In my opinion, intuition is based on knowledge and experience. I believe we need to concentrate on concrete principles at the undergraduate level.

A 42 year-old educator wrote,

I model intuitive thinking along with critical

thinking when $I$ am answering questions or using

patient examples, but it is not something that

the students are able to do at all until maybe

the end of the program. Some never get it at

all.

Several respondents wrote that they are focusing on how to address critical thinking, the newest required outcome established by the NLN. One educator put it succinctly,

We are trying to teach critical thinking!

A 48 year-old educator of 24 years commented,

Emphasis has been on critical thinking and

diagnostic reasoning in classroom and clinical.

( $I$ personally feel intuition can fit into questions of critical thinking.)

A 51 year-old educator of 28 years wrote,

We have just undergone a curriculum revision and are instituting a new curriculum this fall.

We've been focusing on critical thinking and how to measure it. Consequently intuition has not been given due consideration.

A 72 year-old nurse educator wrote,

I teach in a two year program. We center in on critical thinking and $I$ believe this is 
important. Intuition develops with experience in the field of nursing and I would develop this at a later time with post graduate work.

Nine respondents wrote that they lack the knowledge and skill to teach about intuition. The following responses illustrate this concern. A 54 year-old educator of 16 years wrote,

Not expert enough - not enough information on "how to" teach intuition - still too much emphasis on "doing" vs. "knowing" in this school's current curriculum.

A 53 year-old with 27 years as a nurse educator commented, I would like to include [intuition] in the curriculum but feel inadequate to do so.

Eleven respondents stated that they had not considered including intuition or that it had never been discussed among the faculty. A 37 year-old educator of 5 years remarked,

At this point the thought had not crossed my mind to teach intuition. [Intuition] is something I will consider for the future.

Another respondent wrote that intuition had never come up for discussion in her $20+$ years with the college.

Some respondents questioned how to teach intuition and whether or not it can be taught. A 45 year-old respondent with 5 years in nursing education stated,

Intuition is something that is developed in a person when they are young. My mother taught me to be aware of what is going on. I was born with a sense of knowing. I don't feel this can be taught at the college level. 
A 48 year-old educator of 13 years wrote,

I believe that intuition is discernment of subtle cues in the environment. I believe that recognition is an effective teaching method. It's not readily planned into learning experiences.

A few respondents indicated that they do not relate to the concept of intuition. A 62 year-old respondent with 40 years of nursing practice and 19 in nursing education wrote,

[I] don't understand or relate to intuition enough to "teach" it. However, I can accept that some attribute many decisions to intuition.

Resistance to change was infrequently stated as the reason for not including intuition in teaching. An interesting response came from a 63 year-old educator with 27 years teaching experience,

Faculty is aged; they seem to fight change of any kind.

This educator wrote that she uses intuition all the time in student evaluation.

\section{Teaching Methods}

Faculty were asked to indicate all teaching methods used to present intuition (Table 13). The data show that discussion was the method used most frequently ( $81.4 \%$ ), followed by clinical conference (56.8\%), classroom activities $(47.9 \%)$, readings $(32.3 \%)$, assignments $(18.1 \%)$, and media $(5.4 \%)$. Other methods written in by respondents 
include case study and case presentation $(\underline{n}=4)$, direct practice $(\underline{n}=3)$. Four methods were mentioned once, client assessment, direct questioning of students regarding basis for clinical decisions, private conversations with students, and faculty role modeling of practice.

Table 13

Methods Respondents Use to Present Intuition in Undergraduate Nursing Courses

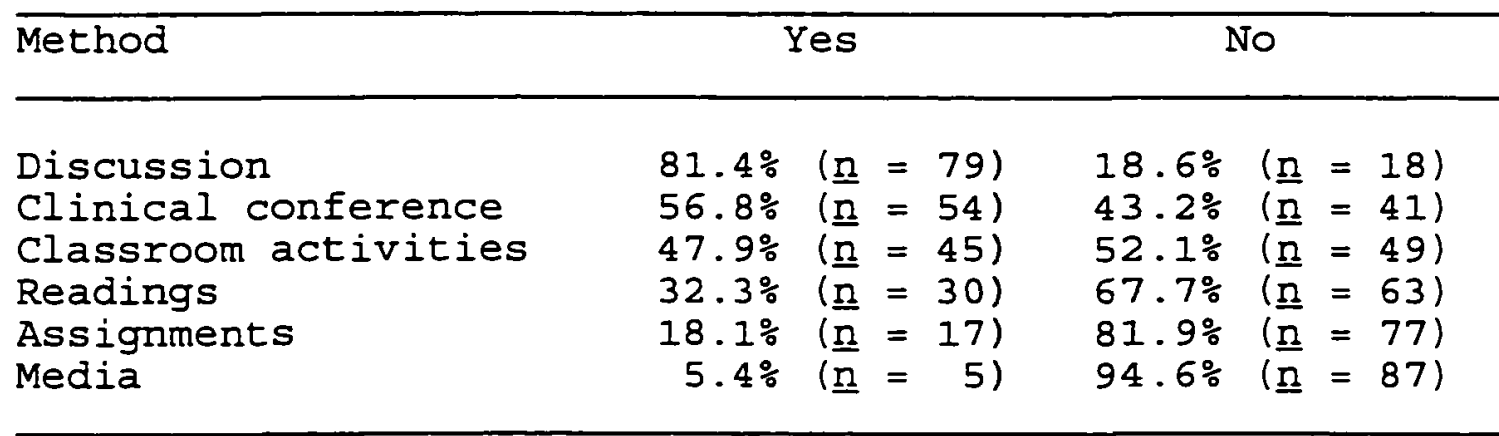

Time Spent Teaching Intuition

Respondents were asked to indicate how much time they spent teaching about intuition in a nursing course (Table 14). The majority of respondents (64\%) teaching in a quarter system spent less than 1 hour on intuition. This finding held regardless of the number of credit hours of the course being taught. Eighteen percent of the courses spent one to two hours teaching about intuition. Nine percent of the courses devoted 3-4 hours and nine percent devoted more than 4 hours to intuition. 
Table 14

Time Spent Teaching Intuition on the Quarter System

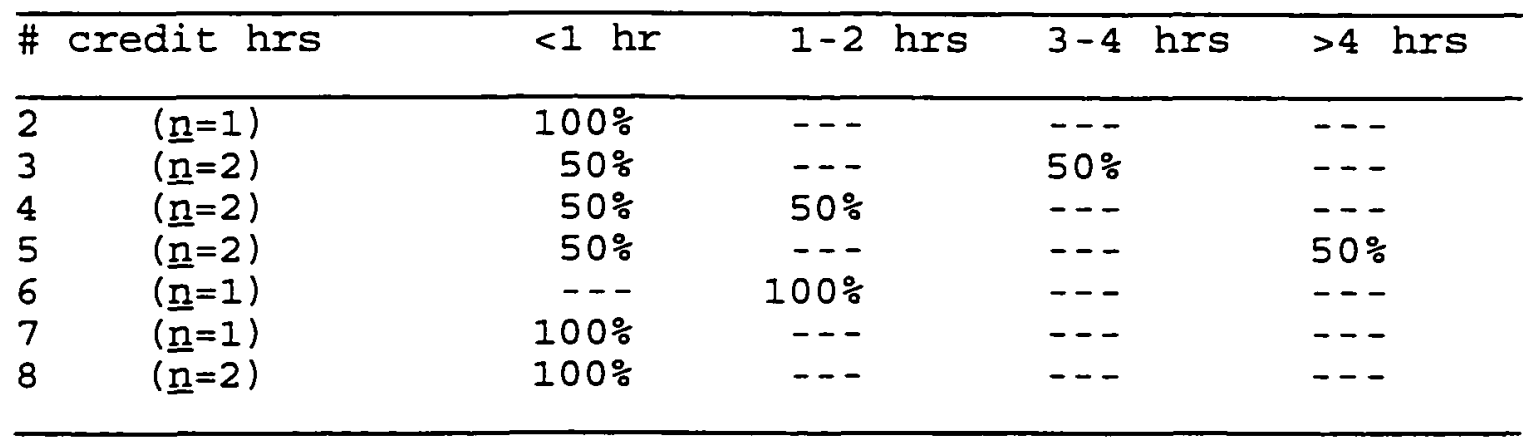

Less than one hour was spent teaching about intuition in $43 \%$ of the nursing courses on a semester system; $39 \%$ spent 1-2 hours on intuition (Table 15). Six percent devoted 3-4 hours to intuition and 12\% devoted more than 4 hours to the topic.

Table 15

Time spent Teaching Intuition on the semester system

\begin{tabular}{|c|c|c|c|c|c|}
\hline \multicolumn{2}{|c|}{ \# credit hrs } & \multirow{2}{*}{$\begin{array}{ll}<\mathrm{hr} \\
---\end{array}$} & \multirow{2}{*}{$\begin{array}{l}1-2 \text { hrs } \\
100 \%\end{array}$} & \multirow{2}{*}{$\begin{array}{ll}3-4 \text { hrs } \\
--- & \end{array}$} & \multirow{2}{*}{$\frac{>4 \text { hrs }}{---}$} \\
\hline 1 & $(\underline{n}=3)$ & & & & \\
\hline 2 & $(\underline{n}=4)$ & $75 \%$ & $25 \%$ & -- & --- \\
\hline 3 & $(\underline{n}=19)$ & $42 \%$ & $48 \%$ & $5 \%$ & $5 \%$ \\
\hline 4 & $(\underline{n}=5)$ & $40 \%$ & $20 \%$ & $20 \%$ & $20 \%$ \\
\hline 5 & $(\underline{\underline{n}}=11)$ & $37 \%$ & $27 \%$ & $9 \%$ & $27 \%$ \\
\hline 6 & $(\underline{n}=9)$ & $33 \%$ & $45 \%$ & --- & $22 \%$ \\
\hline 7 & $(\bar{n}=1)$ & -- & -- & $100 \%$ & -- \\
\hline 8 & $(\underline{n}=3)$ & $67 \%$ & $33 \%$ & --- & --- \\
\hline 9 & $(\underline{\Omega}=6)$ & $50 \%$ & $50 \%$ & --- & --- \\
\hline 10 & $(\underline{n}=1)$ & $100 \%$ & --- & --- & --- \\
\hline 12 & $(\bar{n}=2)$ & $50 \%$ & $\ldots$ & -- & $50 \%$ \\
\hline 14 & $(\underline{\underline{n}}=1)$ & $100 \%$ & --- & --- & --- \\
\hline
\end{tabular}


Faculty Development of Intuition

This section includes a discussion of strategies that respondents use to develop their own intuition and the effectiveness of the strategies.

The fourth research question asks, "What practices that emerge from the intuition literature as making a difference in the development of intuition do NLN faculty use and how effective do they think the practices are?" Percentages were tabulated to answer this research question (Table 16). The data show that nearly two-thirds of the strategies were used by the majority of faculty to develop their intuition. Three strategies were used by more than $90 \%$ of the respondents: becoming aware of gut reactions, accepting more than one way of thinking and knowing, and paying attention to your inner voice. Valuing intuitive skills in nursing, developing selfconfidence based on nursing knowledge of a subject, and being involved in varied clinical experiences were used by 80-90\% of respondents. Five strategies were used by $70-$ $80 \%$ of respondents: taking the client's perspective, becoming aware of using intuition, becoming quiet and reflecting on feelings, engaging in creative activities, and reflecting on past intuitive experiences. Five strategies were used by 55-70\% of faculty: examining the structure of knowledge and how it links to other 
knowledge, practicing self-care, validating intuition with more experienced nurses, using nursing case studies, and using brainstorming or clustering to elicit intuitive responses. Four strategies were used by $40-50 \%$ of faculty: using narrative story telling, observing nurses who model intuition, seeking positive reinforcement for using intuition, and becoming familiar with definitions and terms related to intuition.

Table 16

Respondents' Use of Strategies to Develop Their Own Intuition

\begin{tabular}{||l|c|l|c||}
\hline \hline Strategy & $\underline{\mathrm{N}}$ & $\frac{\%}{6}$ Yes & $\%$ No \\
\hline Becoming aware of gut reactions & 329 & 96.4 & 3.6 \\
\hline $\begin{array}{l}\text { Accepting more than one way of } \\
\text { thinking and knowing }\end{array}$ & 328 & 94.8 & 5.2 \\
\hline $\begin{array}{l}\text { Paying attention to your inner } \\
\text { voice }\end{array}$ & 325 & 94.8 & 5.2 \\
\hline $\begin{array}{l}\text { Valuing intuitive skills in } \\
\text { nursing }\end{array}$ & 328 & 89.3 & 10.7 \\
\hline $\begin{array}{l}\text { Developing self-confidence based } \\
\text { on nursing knowledge of a subject }\end{array}$ & 329 & 86.6 & 13.4 \\
\hline $\begin{array}{l}\text { Being involved in varied clinical } \\
\text { experiences }\end{array}$ & 327 & 80.1 & 19.9 \\
\hline $\begin{array}{l}\text { Taking the client's perspective } \\
\text { Becoming aware of using intuition }\end{array}$ & 325 & 79.4 & 20.6 \\
\hline $\begin{array}{l}\text { Becoming quiet and reflecting on } \\
\text { feelings }\end{array}$ & 325 & 76.6 & 23.4 \\
\hline Engaging in creative activities & 327 & 74.0 & 26.0 \\
\hline $\begin{array}{l}\text { Reflecting on past intuitive } \\
\text { experiences }\end{array}$ & 329 & 73.6 & 26.4 \\
\hline
\end{tabular}


Table 16
Respondents' Use of Strategies to Develop Their Own Intuition
(continued)

\begin{tabular}{|c|c|c|c|}
\hline Strategy & $\underline{\underline{N}}$ & $\because$ Yes & $\div$ No \\
\hline $\begin{array}{l}\text { Examining structure of knowledge and } \\
\text { link to other knowledge }\end{array}$ & 328 & 68.3 & 31.7 \\
\hline Practicing self-care & 328 & 64.0 & 36.0 \\
\hline $\begin{array}{l}\text { Validating intuition with more } \\
\text { experienced nurses }\end{array}$ & 327 & 61.2 & 38.8 \\
\hline Using nursing case studies & 325 & 60.9 & 39.1 \\
\hline $\begin{array}{l}\text { Using brainstorming or clustering to } \\
\text { elicit intuitive responses }\end{array}$ & 328 & 56.7 & 43.3 \\
\hline $\begin{array}{l}\text { Using narrative story telling of } \\
\text { intuitive nursing care }\end{array}$ & 328 & 49.1 & 50.9 \\
\hline Observing nurses who model intuition & 328 & 47.9 & 52.1 \\
\hline $\begin{array}{l}\text { Seeking positive reinforcement for } \\
\text { using intuition }\end{array}$ & 329 & 42.9 & 57.1 \\
\hline $\begin{array}{l}\text { Becoming familiar with definitions } \\
\text { and terms related to intuition }\end{array}$ & 329 & 40.1 & 59.9 \\
\hline $\begin{array}{l}\text { Practicing guessing and recognizing } \\
\text { plausibility of guesses }\end{array}$ & 327 & 38.8 & 61.2 \\
\hline Using guided imagery & 323 & 38.4 & 61.6 \\
\hline $\begin{array}{l}\text { Using clinical journal to record cue } \\
\text { assessments, hunches, outcome }\end{array}$ & 329 & 30.7 & 69.3 \\
\hline Practicing meditation & 327 & 27.2 & 72.8 \\
\hline $\begin{array}{l}\text { Working with nurse preceptors to } \\
\text { promote dialogue about intuition }\end{array}$ & 327 & $11 \cdot 3$ & 88.7 \\
\hline
\end{tabular}

Five strategies were used by less than forty percent of the faculty: practicing guessing and recognizing the plausibility of guesses, using guided imagery, using a 
clinical journal, practicing meditation, and working with nurse preceptors to promote dialogue about intuition.

It appears that the strategies used by the largest percent of faculty are strategies most familiar, relatively safe, and well documented in the literature as important to the development of intuition. Strategies used by the least faculty tend to be time consuming, and some, such as guessing and working with nurse preceptors, include an element of risk. Another possibility is that faculty do not have the necessary skill to use some of the strategies such as guided imagery and meditation.

In the space to record "other" strategies respondents listed prayer $(\underline{n}=6)$, daily exercise $(\underline{n}=2)$, and relaxation techniques $(\underline{\underline{n}}=2)$. The following strategies were noted once each: mindfulness and positive intention; inner peace; developing spirituality; random daydreaming; cooperative learning exercises; runes and Indian medicine cards; use of humor to shift perspective; and developing imagination through study of art, literature, and autobiographical narratives. Therapies noted once were psychotherapy, craniosacral therapy, therapeutic massage, acupuncture, and music therapy.

All strategies were considered extremely or moderately effective by the majority of faculty who 
responded that they had used the strategy to develop their own intuition (Table 17). Less than $3 \%$ of respondents indicated that some strategies were "not effective." It is interesting to note that two of these strategies were guided imagery and meditation, strategies highly recommended in the literature for intuitive development.

Table 17

Effectiveness of Strategies Respondents Use to Develop Their Own Intuition

\begin{tabular}{|c|c|c|c|c|c|}
\hline Strategy & $\underline{\underline{N}}$ & $\div$ EXT & $\div \mathrm{MOD}$ & $\div$ SOM & $\div$ NOT \\
\hline Self-confidence & 273 & 63.7 & 32.6 & 3.7 & $\ldots$ \\
\hline Inner voice & 295 & 61.7 & 32.9 & 5.4 & $-\cdots-$ \\
\hline Gut reactions & 305 & 56.1 & 36.1 & 7.9 & $\ldots--$ \\
\hline Validate intuition & 195 & 50.8 & 35.9 & 13.3 & $\ldots$ \\
\hline More than one way & 297 & 48.1 & 41.8 & 9.8 & 0.3 \\
\hline Value intuition & 282 & 48.9 & 39.4 & 11.7 & $-\ldots$ \\
\hline Practice self-care & 199 & 44.7 & 46.2 & 8.0 & 1.0 \\
\hline Client perspective & 244 & 45.5 & 43.9 & 10.7 & ---- \\
\hline Reflect on feelings & 241 & 46.5 & 42.3 & 10.8 & 0.4 \\
\hline Brainstorm & 180 & 42.2 & 48.9 & 8.9 & $-\cdots$ \\
\hline Creative activities & 236 & 44.5 & 44.1 & 11.4 & ---- \\
\hline Varied clinical & 249 & 45.0 & 43.4 & 11.2 & 0.4 \\
\hline Past intuitions & 232 & 41.4 & 47.4 & 10.8 & 0.4 \\
\hline Aware of using int. & 250 & 37.2 & 51.2 & 11.2 & 0.4 \\
\hline Meditation & 88 & 44.3 & 38.6 & 14.8 & 2.3 \\
\hline Guided imagery & 118 & 40.7 & 44.9 & 11.9 & 2.5 \\
\hline
\end{tabular}

Note: Extremely Effective (EXT), Moderately Effective (MOD), Somewhat Effective (SOM), Not Effective (NOT) 
Table 17

Effectiveness of Strategies Respondents Use to Develop Their Own Intuition (continued)

\begin{tabular}{||l|c|l|l|l|l||}
\hline Strategy & $\underline{N}$ & $\div$ EXT & $\%$ MOD & $\%$ SOM & $\%$ NOT \\
\hline Knowledge links & 219 & 38.8 & 47.0 & 13.2 & 0.9 \\
\hline Clinical journal & 98 & 41.8 & 39.8 & 18.4 & $\ldots .-$ \\
\hline Stories of int. & 160 & 40.6 & 41.3 & 18.1 & $\ldots--$ \\
\hline Model intuition & 156 & 37.2 & 48.7 & 12.2 & 1.9 \\
\hline Case studies & 190 & 33.7 & 47.9 & 16.3 & 2.1 \\
\hline Pos. reinforcement & 137 & 32.1 & 50.4 & 15.3 & 2.2 \\
\hline Guessing & 123 & 31.7 & 47.2 & 21.1 & $-\ldots-$ \\
\hline Nurse preceptors & 36 & 41.7 & 27.8 & 30.6 & $\ldots-.-$ \\
\hline Terms re. intuition & 131 & 26.0 & 39.7 & 32.1 & 2.3 \\
\hline
\end{tabular}

Note: Extremely Effective (EXT), Moderately Effective (MOD), Somewhat Effective (SOM), Not Effective (NOT)

\section{Development of Student Intuition}

This section includes a discussion of strategies that respondents use to promote the development of student intuition and the effectiveness of the strategies. It also includes a comparison faculty use and effectiveness of strategies with self and with students.

The fifth research question asks, "What teaching strategies that emerge from the intuition literature do NLN faculty use in teaching about intuition in the 
undergraduate nursing curriculum and how effective do they think the strategies are?"

Frequency data show that two thirds of the strategies were used by the majority of the respondents to help students develop intuition (Table 18). Four strategies were used by more than $80 \%$ of the respondents to teach about intuition: promote the acceptance of more than one way of thinking and knowing, foster student creativity, promote self-confidence based on nursing knowledge of a subject, and provide varied clinical experiences. Six strategies were used by $65-80 \%$ of faculty with students: encourage taking the client's perspective, promote awareness of gut reactions, encourage self-care activities, emphasize the value of intuitive skills in nursing, encourage paying attention to inner voice, and utilize nursing case studies. Seven strategies were used by 50-60\% of faculty with students: provide positive reinforcement for using intuition, encourage becoming quiet and reflecting on feelings, model the use of intuition, practice brainstorming or clustering to elicit intuitive responses, teach the structure of knowledge and how it relates to other knowledge, increase awareness of using intuition, and encourage validation of intuition with more experienced nurses. Four strategies were used by $35-45 \%$ of faculty: encourage reflection on past 
Table 18

\section{Respondents' Use of Strategies to Develop Student Intuition}

\begin{tabular}{|c|c|c|c|}
\hline Strategy & $\underline{\underline{N}}$ & $\div$ Yes & $\div$ No \\
\hline $\begin{array}{l}\text { Promote the acceptance of more than } \\
\text { one way of thinking and knowing }\end{array}$ & 330 & 87.9 & 12.1 \\
\hline Foster student creativity & 329 & 84.8 & 15.2 \\
\hline $\begin{array}{l}\text { Promote self-confidence based on } \\
\text { nursing knowledge of a subject }\end{array}$ & 329 & 83.9 & 16.1 \\
\hline Provide varied clinical experiences & 327 & 82.6 & 17.4 \\
\hline $\begin{array}{l}\text { Encourage taking the client's } \\
\text { perspective }\end{array}$ & 327 & 77.1 & 22.9 \\
\hline Promote awareness of gut reactions & 329 & 73.9 & 26.1 \\
\hline Encourage self-care activities & 326 & 70.2 & 29.8 \\
\hline $\begin{array}{l}\text { Emphasize the value of intuitive } \\
\text { skills in nursing }\end{array}$ & 329 & 67.8 & 32.2 \\
\hline $\begin{array}{l}\text { Encourage paying attention to inner } \\
\text { voice }\end{array}$ & 330 & 67.6 & 32.4 \\
\hline Utilize nursing case studies & 329 & 65.7 & 34.3 \\
\hline $\begin{array}{l}\text { Provide positive reinforcement for } \\
\text { using intuition }\end{array}$ & 327 & 59.3 & 40.7 \\
\hline $\begin{array}{l}\text { Encourage becoming quiet and } \\
\text { reflecting on feelings }\end{array}$ & 329 & 58.4 & 41.6 \\
\hline Model the use of intuition & 325 & 53.5 & 46.5 \\
\hline $\begin{array}{l}\text { Practice brainstorming or clustering } \\
\text { to elicit intuitive responses }\end{array}$ & 329 & 52.6 & 47.4 \\
\hline $\begin{array}{l}\text { Teach the structure of knowledge and } \\
\text { how it relates to other knowledge }\end{array}$ & 329 & 51.4 & 48.6 \\
\hline $\begin{array}{l}\text { Increase awareness of using } \\
\text { intuition }\end{array}$ & 323 & 51.1 & 48.9 \\
\hline $\begin{array}{l}\text { Encourage validation of intuition } \\
\text { with more experienced nurses }\end{array}$ & 326 & 50.0 & 50.0 \\
\hline
\end{tabular}


Table 18

Respondents' Use of Strategies to Develop student Intuition

(continued)

\begin{tabular}{||l|l|l|l||}
\hline \multicolumn{1}{|c|}{ Strategy } & $\underline{N}$ & $\%$ Yes & $\%$ No \\
\hline $\begin{array}{l}\text { Encourage reflection on past } \\
\text { intuitive experiences }\end{array}$ & 328 & 45.4 & 54.6 \\
\hline $\begin{array}{l}\text { Use of clinical journal to record } \\
\text { cue assessments, hunches, outcome }\end{array}$ & 329 & 43.2 & 56.8 \\
\hline $\begin{array}{l}\text { Encourage guessing and ability to } \\
\text { recognize plausibility of guesses }\end{array}$ & 328 & 38.4 & 61.6 \\
\hline $\begin{array}{l}\text { Encourage narrative story telling of } \\
\text { intuitive nursing care }\end{array}$ & 326 & 38.3 & 61.7 \\
\hline $\begin{array}{l}\text { Encourage the use of terms and } \\
\text { definitions related to intuition }\end{array}$ & 327 & 26.6 & 73.4 \\
\hline $\begin{array}{l}\text { Use of guided imagery } \\
\text { Provide experiences with nurse } \\
\text { preceptors to dialogue about } \\
\text { intuition }\end{array}$ & 326 & 19.9 & 80.1 \\
\hline offer meditation experiences & 327 & 16.2 & 83.8 \\
\hline
\end{tabular}

intuitive experiences; use of a clinical journal to record cue assessments, hunches, outcome; encourage guessing and the ability to recognize the plausibility of guesses; and encourage narrative story telling of intuitive nursing care. Four strategies were used by less than $30 \%$ of faculty: encourage the use of terms and definitions related to intuition, use of guided imagery, provide experience with nurse preceptors to dialogue about intuition, and offer meditation experiences. 
of the strategies used by more than $90 \%$ of the faculty to develop their own intuition, only one, accepting more than one way of thinking and knowing, was also one of the most frequently used strategies to teach students about intuition. Of the strategies used by less than $40 \%$ of the faculty to develop their own intuition, four (guessing, guided imagery, meditation, and work with nurse preceptors) were also used by less than $40 \%$ of faculty to teach students about intuition. It is not surprising that guessing is used less frequently than other strategies because nursing practice involves issues of client safety. Guided imagery and meditation may be used by fewer faculty with students because of the time element involved. Many nursing faculty feel that there is barely time now to cover the essentials.

The findings are similar to the results of the previous research question. Safe, comfortable strategies appear to be used by more respondents to help students develop intuition. Strategies that take more time or involve possible risk are used more infrequently.

In the space to record "other" strategies used to develop student intuition two respondents listed study of the humanities. Prayer, increased spiritual awareness, relaxation techniques, humor to develop the ability to shift perspective, reflective thinking and study of first 
person accounts of illness experiences were each noted once.

All strategies were rated as extremely or moderately effective by the majority of faculty who indicated that they have used the strategy to teach students about intuition in nursing (Table 19). Only 3\% of faculty rated any strategy as not effective for student development of intuition. These findings are similar to faculty ratings of effectiveness of strategies to develop their own intuition. However, it is interesting that no faculty rated guided imagery and meditation as not effective for student development of intuition though a minority rated these strategies as not effective for themselves.

Table 19

Effectiveness of Strategies Respondents Use to Develop Student Intuition

\begin{tabular}{||l|l|l|l|l|c||}
\hline Strategy & $\underline{\mathrm{N}}$ & $\div$ EXT & $\div$ MOD & $\div$ SOM & $\div$ NOT \\
\hline Self-confidence & 260 & 42.7 & 43.8 & 13.1 & 0.4 \\
\hline Student creativity & 264 & 37.5 & 45.8 & 15.2 & 1.5 \\
\hline Client perspective & 235 & 36.6 & 46.8 & 15.3 & 1.3 \\
\hline Varied clinical & 253 & 36.0 & 47.0 & 15.8 & 1.2 \\
\hline Pos. reinforcement & 181 & 34.8 & 47.5 & 17.1 & 0.6 \\
\hline Stories of int. & 119 & 35.3 & 46.2 & 17.6 & 0.8 \\
\hline Brainstorm & 164 & 30.5 & 54.3 & 15.2 & ---- \\
\hline Case studies & 207 & 31.4 & 51.2 & 15.9 & 1.4 \\
\hline
\end{tabular}

Note: Extremely Effective (EXT), Moderately Effective (MOD), Somewhat Effective (SOM), Not Effective (NOT) 
Table 19

Effectiveness of Strategies Respondents Use to Develop Student Intuition

(continued)

\begin{tabular}{|c|c|c|c|c|c|}
\hline strategy & $\underline{\mathbf{N}}$ & $\div E X T$ & $\div$ MOD & : SOM & : NOT \\
\hline Model intuition & 164 & 30.5 & 50.0 & 18.9 & 0.6 \\
\hline Krowledge links & 164 & 29.9 & 51.2 & 17.7 & 1.2 \\
\hline Aware of using int. & 158 & 32.3 & 45.6 & 21.5 & 0.6 \\
\hline Nurse preceptors & 62 & 33.9 & 41.9 & 24.2 & ---- \\
\hline More than one way & 273 & 30.4 & 48.7 & 20.1 & 0.7 \\
\hline Past intuitions & 143 & 28.7 & 51.0 & 20.3 & ---- \\
\hline Clinical journal & 135 & 34.1 & 43.7 & 19.3 & 3.0 \\
\hline Validate intuition & 152 & 29.6 & 48.0 & 22.4 & --- \\
\hline Reflect on feelings & 179 & 26.8 & 53.1 & 19.0 & 1.1 \\
\hline Guided imagery & 75 & 25.3 & 52.0 & 22.7 & --- \\
\hline Gut reactions & 227 & 26.4 & 49.8 & 23.3 & 0.4 \\
\hline Inner voice & 211 & 24.2 & 54.0 & 20.4 & 1.4 \\
\hline Self-care & 213 & 21.6 & 58.2 & 18.8 & 1.4 \\
\hline Use of terms & 86 & 26.7 & 46.5 & 25.6 & 1.2 \\
\hline Value intuition & 215 & 27.4 & 43.3 & 27.9 & 1.4 \\
\hline Meditation & 51 & 27.5 & 37.3 & 35.3 & $---\cdots$ \\
\hline Guessing & 117 & 20.5 & 44.4 & 33.3 & 1.7 \\
\hline
\end{tabular}

Note: Extremely Effective (EXT), Moderately Effective

(MOD), Somewhat Effective (SOM), Not Effective (NOT)

Chi-square tests were used to determine if there was a relationship between faculty use of strategies to develop their own intuition and faculty use of strategies to help students develop intuition (Table 20). Results 
show that there was a significant relationship for all 25 strategies $(\underline{p} \leq .001)$. This finding indicates that if respondents used the strategy to develop their own intuition they were significantly more likely to use the strategy to help students develop intuition. If faculty did not use the strategy to develop their own intuition they were not likely to use it with students.

Table 20

Faculty Use of Strategies with Self vs. Use of Strategies with students*

\begin{tabular}{|c|c|c|c|c|c|}
\hline Strategy & $\underline{N_{\text {wi }}}$ & $\begin{array}{l}\text { Use } \\
\text { self }\end{array}$ & $\frac{\text { Use } W}{\text { Yes }}$ & $\frac{2 \text { Students }}{\text { No }}$ & $\chi^{2}$ \\
\hline Creativity & $\begin{array}{r}241 \\
85\end{array}$ & $\frac{\text { Yes }}{\text { No }}$ & $\begin{array}{l}95.0 \% \\
58.8 \%\end{array}$ & $\begin{array}{r}5.0 \% \\
41.2 \%\end{array}$ & 66.727 \\
\hline Self-care & $\begin{array}{l}207 \\
117\end{array}$ & $\frac{\overline{\text { Yes }}}{\underline{\text { No }}}$ & $\begin{array}{l}91.8 \% \\
32.5 \%\end{array}$ & $\begin{array}{r}8.2 \% \\
67.5 \%\end{array}$ & 126.105 \\
\hline $\begin{array}{l}\text { Self- } \\
\text { confidence }\end{array}$ & $\begin{array}{r}285 \\
43\end{array}$ & $\frac{\overline{\text { Yes }}}{\text { No }}$ & $\begin{array}{l}91.6 \% \\
32.6 \%\end{array}$ & $\begin{array}{r}8.4 \% \\
67.4 \%\end{array}$ & 96.070 \\
\hline $\begin{array}{l}\text { Varied } \\
\text { clinical }\end{array}$ & $\begin{array}{r}259 \\
65\end{array}$ & $\frac{\overline{\text { Yes }}}{\underline{\text { No }}}$ & $\begin{array}{l}91.5 \% \\
47.7 \%\end{array}$ & $\begin{array}{r}8.5 \% \\
52.3 \%\end{array}$ & 69.767 \\
\hline One way & $\begin{array}{r}311 \\
17\end{array}$ & $\frac{\text { Yes }}{\underline{\text { No }}}$ & $\begin{array}{l}91.3 \% \\
29.4 \%\end{array}$ & $\begin{array}{r}8.7 \% \\
70.6 \%\end{array}$ & 58.965 \\
\hline $\begin{array}{l}\text { Client's } \\
\text { perspective }\end{array}$ & $\begin{array}{r}256 \\
66\end{array}$ & $\frac{\overline{Y e s}}{\underline{\text { No }}}$ & $\begin{array}{l}88.3 \% \\
34.8 \%\end{array}$ & $\begin{array}{l}11.7 \% \\
65.2 \%\end{array}$ & 85.454 \\
\hline Case studies & $\begin{array}{l}197 \\
127\end{array}$ & $\frac{\overline{\text { Yes }}}{\underline{\text { No }}}$ & $\begin{array}{l}88.3 \% \\
30.7 \%\end{array}$ & $\begin{array}{l}11.7 \% \\
69.3 \%\end{array}$ & 113.816 \\
\hline Journal & $\begin{array}{r}99 \\
229\end{array}$ & $\frac{\overline{\text { Yes }}}{\underline{\text { No }}}$ & $\begin{array}{l}80.8 \% \\
27.1 \%\end{array}$ & $\begin{array}{l}19.2 \% \\
72.9 \%\end{array}$ & 81.290 \\
\hline Model & $\begin{array}{l}155 \\
168\end{array}$ & $\frac{\overline{Y e s}}{\text { No }}$ & $\begin{array}{l}80.6 \% \\
29.2 \%\end{array}$ & $\begin{array}{l}19.4 \% \\
70.8 \%\end{array}$ & 85.973 \\
\hline Reinforce & $\begin{array}{l}140 \\
186\end{array}$ & $\frac{\overline{\text { Yes }}}{\text { No }}$ & $\begin{array}{l}78.6 \% \\
45.2 \%\end{array}$ & $\begin{array}{l}21.4 \% \\
54.8 \%\end{array}$ & 37.003 \\
\hline Brainstorm & $\begin{array}{l}186 \\
141\end{array}$ & $\frac{\overline{\text { Yes }}}{\underline{\underline{\text { No }}}}$ & $\begin{array}{l}78.0 \% \\
19.9 \%\end{array}$ & $\begin{array}{l}22.0 \% \\
80.1 \%\end{array}$ & 108.655 \\
\hline Gut reaction & $\begin{array}{r}316 \\
12\end{array}$ & $\frac{\text { Yes }}{\underline{\text { No }}}$ & $\begin{array}{l}75.6 \% \\
25.0 \%\end{array}$ & $\begin{array}{l}24.4 \% \\
75.0 \%\end{array}$ & 15.321 \\
\hline Value & $\begin{array}{r}292 \\
35\end{array}$ & $\frac{\text { Yes }}{\underline{\text { No }}}$ & $\begin{array}{l}74.0 \% \\
14.3 \%\end{array}$ & $\begin{array}{l}26.0 \% \\
85.7 \%\end{array}$ & 50.823 \\
\hline
\end{tabular}


Table 20

Faculty Use of Strategies vs. Use of Strategies with Students*

(continued)

\begin{tabular}{|c|c|c|c|c|c|}
\hline strategy & $\underline{\mathrm{N}}$ & $\begin{array}{l}\text { Use } \\
\text { with self }\end{array}$ & $\frac{\text { Use Wit }}{\text { Yes }}$ & $\frac{\text { Students }}{\text { No }}$ & $\chi^{2}$ \\
\hline Validate & $\begin{array}{l}197 \\
127\end{array}$ & $\frac{\text { Yes }}{\text { No }}$ & $\begin{array}{l}71.6 \% \\
16.5 \%\end{array}$ & $\begin{array}{l}28.4 \% \\
83.5 \%\end{array}$ & 93.565 \\
\hline Voice & $\begin{array}{r}308 \\
17\end{array}$ & $\frac{\overline{\text { Yes }}}{\text { No }}$ & $\begin{array}{r}71.4 \% \\
5.9 \%\end{array}$ & $\begin{array}{l}28.6 \% \\
94.1 \%\end{array}$ & 31.809 \\
\hline Preceptor & $\begin{array}{r}35 \\
288\end{array}$ & $\frac{\overline{\text { Yes }}}{\text { No }}$ & $\begin{array}{l}71.4 \% \\
13.9 \%\end{array}$ & $\begin{array}{l}28.6 \% \\
86.1 \%\end{array}$ & 64.278 \\
\hline Reflection & $\begin{array}{r}249 \\
75\end{array}$ & $\frac{\text { Yes }}{\text { No }}$ & $\begin{array}{l}70.3 \% \\
22.7 \%\end{array}$ & $\begin{array}{l}29.7 \% \\
77.3 \%\end{array}$ & 54.126 \\
\hline Guessing & $\begin{array}{l}127 \\
198\end{array}$ & $\frac{\overline{\text { Yes }}}{\underline{\text { No }}}$ & $\begin{array}{l}68.5 \% \\
19.7 \%\end{array}$ & $\begin{array}{l}31.5 \% \\
80.3 \%\end{array}$ & 77.641 \\
\hline $\begin{array}{l}\text { Knowledge } \\
\text { links }\end{array}$ & $\begin{array}{l}223 \\
104\end{array}$ & $\frac{\text { Yes }}{\text { No }}$ & $\begin{array}{l}68.2 \% \\
16.3 \%\end{array}$ & $\begin{array}{l}31.8 \% \\
83.7 \%\end{array}$ & 76.253 \\
\hline story telling & $\begin{array}{l}157 \\
167\end{array}$ & $\frac{\overline{\text { Yes }}}{\underline{\text { NO }}}$ & $\begin{array}{l}68.2 \% \\
10.8 \%\end{array}$ & $\begin{array}{l}31.8 \% \\
89.2 \%\end{array}$ & 112.418 \\
\hline Awareness & $\begin{array}{r}254 \\
68\end{array}$ & $\frac{\overline{Y e s}}{\underline{\text { No }}}$ & $\begin{array}{l}61.4 \% \\
11.8 \%\end{array}$ & $\begin{array}{l}38.6 \% \\
88.2 \%\end{array}$ & 59.915 \\
\hline Terms & $\begin{array}{l}130 \\
197\end{array}$ & $\frac{\text { Yes }}{\text { No }}$ & $\begin{array}{r}57.7 \% \\
6.6 \%\end{array}$ & $\begin{array}{l}42.3 \% \\
93.4 \%\end{array}$ & 103.945 \\
\hline $\begin{array}{l}\text { Past } \\
\text { intuition }\end{array}$ & $\begin{array}{r}241 \\
86\end{array}$ & $\frac{\text { Yes }}{\underline{\text { No }}}$ & $\begin{array}{l}57.3 \% \\
12.8 \%\end{array}$ & $\begin{array}{l}42.7 \% \\
87.2 \%\end{array}$ & 50.537 \\
\hline Imagery & $\begin{array}{l}120 \\
193\end{array}$ & $\frac{\overline{\text { Yes }}}{\text { No }}$ & $\begin{array}{r}55.0 \% \\
5.7 \%\end{array}$ & $\begin{array}{l}45.0 \% \\
94.3 \%\end{array}$ & 96.958 \\
\hline Meditation & $\begin{array}{r}87 \\
237\end{array}$ & $\begin{array}{l}\overline{\text { Yes }} \\
\underline{\underline{\text { No }}}\end{array}$ & $\begin{array}{r}48.3 \% \\
4.6 \%\end{array}$ & $\begin{array}{l}51.7 \% \\
95.4 \%\end{array}$ & 88.558 \\
\hline
\end{tabular}

*Note: $\underline{\mathrm{df}}=1$, all strategies significant $\underline{\mathrm{p}} \leq .001$ Fisher's exact test $\underline{D} \leq .001$ for one way and gut reaction

In order to determine if there was a correlation between faculty ratings of effectiveness of strategies to develop their own intuition and effectiveness of strategies used with students, Pearson correlations were run. The correlations ranged from .609 to .127. There 
was a moderate positive, significant correlation for story telling $(\underline{r}=.609)$, taking the client's perspective $(\underline{r}=$ $.583)$, awareness of using intuition $(\underline{\underline{x}}=.539)$, more than one way of knowing $(\underline{\underline{r}}=.536)$, brainstorm $(\underline{\underline{r}}=.534)$, and case studies $(\underline{\underline{r}}=.523)$. There was a low $(\underline{\underline{r}}=.350$ to .490) positive, significant correlation for seventeen and little correlation for two strategies (Table 21).

Table 21

Correlations of Effectiveness of strategies to Develop Faculty and Student Intuition

\begin{tabular}{lll}
\hline Strategy & Pearson's $\underline{\underline{r}}$ & p \\
\hline Narrative story telling & .609 & .01 \\
Take client's perspective & .583 & .01 \\
Awareness of using intuition & .539 & .01 \\
More than one way of knowing & .536 & .01 \\
Brainstorm/cluster & .534 & .01 \\
Nursing case studies & .523 & .01 \\
Creativity & .490 & .01 \\
Self-care journal & .473 & .01 \\
Clinical jour & .01 \\
Use of terms & .468 & .01 \\
Value of intuitive skills & .447 & .01 \\
Encourage validation & .440 & .01 \\
Model use of intuition & .436 & .01 \\
Work with nurse preceptors & .424 & .05 \\
Awareness of gut reactions & .415 & .01 \\
Guided imagery & .414 & .01 \\
Encourage guessing & .403 & .01 \\
Varied clinical experiences & .388 & .01 \\
Knowledge structure/links & .374 & .01 \\
Quiet reflection on feelings & .369 & .01 \\
Attend to inner voice & .359 & .01 \\
Reflect on past intuition & .359 & .01 \\
Self-confidence & .350 & .01 \\
Positive reinforcement & .142 & $\mathrm{~N} . \mathrm{S}$. \\
Meditation & .127 & $\mathrm{~N} . \mathrm{S}$ \\
\hline
\end{tabular}


Results indicate that correlations were significant for 23 of 25 strategies. Twenty-two of the significant correlations had a $\mathrm{p} \leq .01$; one, working with nurse preceptors, had a $\underline{p} \leq .05$. Two strategies, positive reinforcement for using intuition and meditation, were not significant.

\section{Faculty Preparation to Teach Intuition}

This section includes a discussion of faculty preparation to teach about intuition, their perception of adequacy of preparation, and a discussion of perception of preparation of faculty who are currently teaching about intuition.

The sixth research question states, "What preparation do NLN faculty have to teach about intuition and do faculty perceive themselves as adequately prepared to teach about intuition in the undergraduate nursing curriculum?"

Frequency counts and percentages were tabulated to answer this research question (Table 22). Results show that fewer than one quarter of respondents had preparation to teach about intuition. Learning about intuition in their degree program was the most frequent type of preparation (24.8\%), followed by personal studies (11.3\%), and workshops or conferences (10.7\%). 
Table 22

Intuition Preparation

\begin{tabular}{|c|c|c|c|c|}
\hline \multirow[b]{2}{*}{ Preparation } & \multicolumn{2}{|c|}{ Percentage } & \multicolumn{2}{|c|}{ Number } \\
\hline & Yes & No & Yes & No \\
\hline $\begin{array}{l}\text { Workshops/Conferences } \\
\text { Personal Studies } \\
\text { Degree Program }\end{array}$ & $\begin{array}{l}10.7 \\
11.3 \\
24.8\end{array}$ & $\begin{array}{l}89.3 \\
88.7 \\
75.2\end{array}$ & $\begin{array}{l}35 \\
37 \\
81\end{array}$ & $\begin{array}{l}291 \\
289 \\
245\end{array}$ \\
\hline
\end{tabular}

Survey item number 35 states "I am interested in learning more about the intuitive way of knowing and the relevance to nursing practice." Of those responding to this item, $82 \%(\underline{n}=265)$ indicated that they were interested in learning more about intuition. This suggests that many respondents who have not had preparation to teach about intuition want to learn about it, and some respondents who already have preparation about intuition are interested in increasing their learning about intuition.

Survey item number 15 states "I feel that I have adequate professional preparation to teach about intuition." Respondents indicated their agreement or disagreement with the item. Results show that slightly more respondents disagreed or strongly disagreed $(\underline{n}=177$ ) with this statement than those who agreed or strongly agreed $(\underline{\underline{ }}=147)$. 
Chi-square tests were run on professional preparation about intuition and faculty perception of adequacy of preparation to teach about intuition (Table 23). Significant results were found for perception of preparation to teach intuition by workshop or conference attendance, personal studies, and learning about intuition in a degree program. Significantly more faculty than expected who had attended workshops felt adequately prepared and significantly fewer faculty than expected who had not attended workshops felt adequately prepared $\left(\chi^{2}=\right.$ $7.464, \underline{\mathrm{p}} \leq .006)$. Results show that, of the 36 respondents who had attended workshops or conferences, $66.7 \%$ perceived themselves to be adequately prepared to teach about intuition, compared to $42.6 \%$ of the 284 respondents who had not attended workshops or conferences. There was a significant relationship between conducting personal studies and perception of preparation to teach intuition $\left(\chi^{2}=27.247, \underline{p} \leq .001\right)$. Of the 36 respondents who had conducted personal studies on intuition, $86.1 \%$ perceived themselves to be adequately prepared to teach intuition, compared to $40.1 \%$ of the 284 respondents who had not done personal study. There was a significant relationship between learning about intuition in a degree program and perception of preparation to teach about intuition $\left(\chi^{2}=27.480, \underline{\mathrm{p}} \leq .001\right)$. Of the 81 respondents 
who learned about intuition in a degree program, $70.4 \%$

felt adequately prepared to teach about intuition, compared to $36.8 \%$ of the 239 respondents who did not learn about intuition in a degree program.

Table 23

Intuition Preparation vs. Perception of Adequacy of Preparation to Teach Intuition

\begin{tabular}{|c|c|c|c|c|c|}
\hline & & $\begin{array}{l}\text { dately } \\
\text { Agree }\end{array}$ & $\frac{\text { pared }}{\text { isagree }}$ & $\overline{\chi^{2}}$ & $\underline{p}$ \\
\hline $\begin{array}{l}\text { Workshops/ } \\
\text { conferences }\end{array}$ & $\frac{\text { Yes }}{\underline{\text { No }}}$ & $\begin{array}{l}66.7 \\
42.6\end{array}$ & $\begin{array}{l}33.3 \\
57.4\end{array}$ & 7.464 & .006 \\
\hline $\begin{array}{l}\text { Personal } \\
\text { studies }\end{array}$ & $\frac{\text { Yes }}{\underline{\text { No }}}$ & $\begin{array}{l}86.1 \\
40.1\end{array}$ & $\begin{array}{l}13.9 \\
59.9\end{array}$ & 27.247 & .001 \\
\hline $\begin{array}{l}\text { Degree } \\
\text { program }\end{array}$ & $\frac{\text { Yes }}{\text { No }}$ & $\begin{array}{l}70.4 \\
36.8\end{array}$ & $\begin{array}{l}29.6 \\
63.2\end{array}$ & 27.480 & .001 \\
\hline
\end{tabular}

$\underline{\underline{N}}=320, \underline{\mathrm{df}}=1$

In summary, there was a significant relationship between professional preparation to teach about intuition and faculty perception of adequacy to teach about intuition. More than two thirds of respondents who engaged in professional preparation about intuition perceived themselves to be adequately prepared to teach about intuition.

Chi-square was calculated to determine if those respondents who were teaching about intuition in a nursing course perceived themselves as adequately prepared to do 
so (Table 24). There was a significant relationship between teaching about intuition and perception of adequacy of preparation to teach about intuition $\left(\chi^{2}=\right.$ 28.527, $\underline{\mathrm{p}} \leq .001)$. More than two thirds (68.0\%) of the 97 respondents who included intuition in a nursing course perceived themselves to be adequately prepared to teach about intuition. Almost one third of respondents $(32.0 \%)$ who are teaching about intuition do not perceive themselves to be adequately prepared. It is interesting to note that just over one third $(35.7 \%)$ of the 224 respondents who do not include intuition in a nursing course perceive themselves to be adequately prepared to teach about intuition. This finding supports an earlier finding, that there are reasons other than preparation for faculty decisions about including or not including intuition in their teaching.

\section{Table 24}

A Comparison of Respondents who Include Intuition in a Nursing Course and Perceived Adequacy of Intuition Preparation

\begin{tabular}{llll}
\hline Adequately Prepared & \multicolumn{4}{l}{ Include Intuition in a Course } \\
\cline { 2 - 4 } & \multicolumn{3}{l}{ Nos } \\
\hline Agree & $68.0 \%(\underline{\underline{n}}=66)$ & $35.7 \%(\underline{\underline{n}}=80)$ \\
Disagree & $32.0 \%(\underline{\underline{n}}=31)$ & $64.3 \%(\underline{\underline{n}}=144)$
\end{tabular}

Note: $\chi^{2}=28.527, \underline{\underline{d f}}=1, \underline{\underline{p}} \leq .001$ 
Faculty Responses by Program Type

This section includes a discussion of differences by program type on intuition attitudes, intuition in the current curriculum, faculty use and effectiveness of strategies with self, faculty use and effectiveness of strategies with students, and professional preparation to teach about the intuitive way of knowing.

The seventh research question states, "Do significant differences exist between diploma, associate degree and baccalaureate degree faculty regarding responses to each of the preceding questions?"

Intuition Attitudes and Program Type

The independent samples $t$-test was used to test for differences by program type related to research questions \#1 (attitudes about using intuition) and \#2 (attitudes about including intuition in the undergraduate nursing curriculum). Factor analysis was used to reduce the data on intuition attitudes (survey items $1-8$ and $10-23$ ) to a more comprehensible analysis (Table 25).

The 22 intuition attitude items were factor analyzed with a sample of 330 nursing faculty, using the principal components method of factor extraction. Using a minimum eigenvalue of 1.0 and a minimum of $5.0 \%$ of variance as the 
criteria for the factors, four factors that accounted for $54.39 \%$ of the variance were extracted. The factors were orthogonally rotated using the varimax procedure. The items were sorted by factor and size of loading.

The factor structure that emerged was reasonably interpretable. The first factor, which accounted for $18.84 \%$ of the variance, had eight items with loadings above the cutoff of .35 . This factor appears to address the importance and usefulness of intuition in nursing. This factor is called the Value Factor. Five of the eight items had loadings in excess of .50 on the factor; only two (Students may be better prepared for nursing practice by including intuition, and Developing an awareness of intuition is important in the undergraduate curriculum) had high loadings on another factor (Table 25).

The second factor had six items with loadings above .40 and explained $14.16 \%$ of the variance (Table 25). This factor seems to capture the difficulties defining, evaluating and teaching intuition. This factor was labeled the Challenge Factor. Five of the six items loaded above .50 on the factor; only two (Because intuition is a skill of the expert nurse it should not be included, and Including intuition places the profession at risk of being viewed as unscientific, resulting in lower status) also had high loadings on another factor. 
Table 25

Factor Analysis of Respondents' Intuition Attitudes

\begin{tabular}{|c|c|c|c|c|c|}
\hline \multirow[b]{2}{*}{ Variable } & \multicolumn{4}{|c|}{ Factor Loadings } & \multirow[b]{2}{*}{$\begin{array}{l}\text { Commu- } \\
\text { nality }\end{array}$} \\
\hline & 1 & 2 & 3 & $\overline{4}$ & \\
\hline \multicolumn{6}{|l|}{ Value } \\
\hline More effective nurse &.$\underline{85}$ & -.09 & -.02 & .18 & .78 \\
\hline Use in practice & .83 & -.11 & -.09 & 20 & .74 \\
\hline Important to me &.$\overline{80}$ & -.03 & -.08 & .05 & .65 \\
\hline Way of knowing & .77 & -.14 & -.21 & .03 & .65 \\
\hline Better decisions &.$\underline{59}$ & -.17 & -.20 & -.03 & .41 \\
\hline Students prepared &.$\overline{49}$ & -.48 & -.36 & .17 & .63 \\
\hline Awareness of intuition &.$\overline{43}$ & -.36 & -.41 & .17 & .51 \\
\hline $\begin{array}{l}\text { Not as important as } \\
\text { rational thinking }\end{array}$ &.$- \overline{37}$ & .31 & .31 & -.11 & .35 \\
\hline \multicolumn{6}{|l|}{ Challenge } \\
\hline Difficult to define & -.06 & .77 & .03 & -.04 & .61 \\
\hline Preparation to teach & .18 & -.66 & .09 & .14 & .50 \\
\hline Hard to evaluate & -.05 &.$\overline{62}$ & .11 & -.16 & .42 \\
\hline No time to include & -.14 &.$\overline{54}$ & .32 & -.31 & .51 \\
\hline Expert skill & -.34 &.$\overline{50}$ & .46 & -.15 & .59 \\
\hline $\begin{array}{l}\text { Unscientific, lower } \\
\text { status }\end{array}$ & -.03 &.$\underline{47}$ & .41 & -.32 & .49 \\
\hline \multicolumn{6}{|l|}{ No Fear } \\
\hline Infringe on rights & .03 & -.05 & .73 & -.12 & .54 \\
\hline Inappropriate & -.28 & .23 &.$\overline{53}$ & -.23 & .47 \\
\hline sloppy thinking & -.44 & .08 &.$\overline{53}$ & .03 & .48 \\
\hline Uncomfortable subject & -.23 & .06 &.$\overline{48}$ & -.03 & .31 \\
\hline Student errors & -.20 & .39 & .39 & -.17 & .37 \\
\hline \multicolumn{6}{|l|}{ Support } \\
\hline Administrator support & .16 & -.27 & -.13 &.$\underline{76}$ & .71 \\
\hline $\begin{array}{l}\text { No support from other } \\
\text { disciplines }\end{array}$ & -.01 & .05 & .14 &.$- \overline{76}$ & .60 \\
\hline $\begin{array}{l}\text { Support from nursing } \\
\text { colleagues }\end{array}$ & .19 & -.35 & -.08 & .11 & .66 \\
\hline $\begin{array}{l}\text { Eigenvalue } \\
\% \text { of Variance } \\
\text { Explained }\end{array}$ & $\begin{array}{r}4.15 \\
18.84\end{array}$ & $\begin{array}{r}3.12 \\
14.16\end{array}$ & $\begin{array}{r}2.52 \\
11.44\end{array}$ & $\begin{array}{l}2.19 \\
9.94\end{array}$ & \\
\hline
\end{tabular}

Notes: Principal component extraction with varimax rotation; Attitudes reported from 1 = strongly disagree to 4 = strongly agree 
The third factor had five items with loadings above .35 and accounted for $11.44 \%$ of the variance (Table 25). Three items loaded distinctly on this factor, two (Intuition is nothing more than "sloppy" thinking, and I feel concern that students may make serious errors in patient care when they use their intuition) also loaded on another factor. The underlying theme of this factor appears to involve an element of risk-taking and comfort with the subject of intuition. This factor was named the No Fear Factor.

Three items loaded distinctly on the fourth factor which explained $9.94 \%$ of the variance (Table 25). Each of the items on this factor query attitudes regarding support for intuition; this factor was called the support Factor.

For subsequent analysis, reliability analysis was run on each of the four factors. Negative items were reverse coded for the analysis. The Value Factor had an alpha reliability of $.87(\underline{N}=307)$, the Challenge Factor had a reliability of $.77(\underline{N}=302)$, the No Fear Factor had a reliability of $.63(\underline{N}=317)$, and the support Factor had a reliability of $.74(\underline{N}=288)$. The reliability for each factor was considered high enough to use the four factors as scales for $t$-tests and analysis of variance.

The independent samples t-test was used to test for difference between faculty from baccalaureate and 
associate degree programs and the intuition attitude scales (Table 26). Program type was the independent variable and the four intuition attitude scales were used as dependent variables.

Table 26

Attitudes by Program Type

Attitude

$\mathrm{BD}$

$\mathrm{AD}$

$\underline{t}$

$\underline{d f}$

$\underline{\text { D value }}$

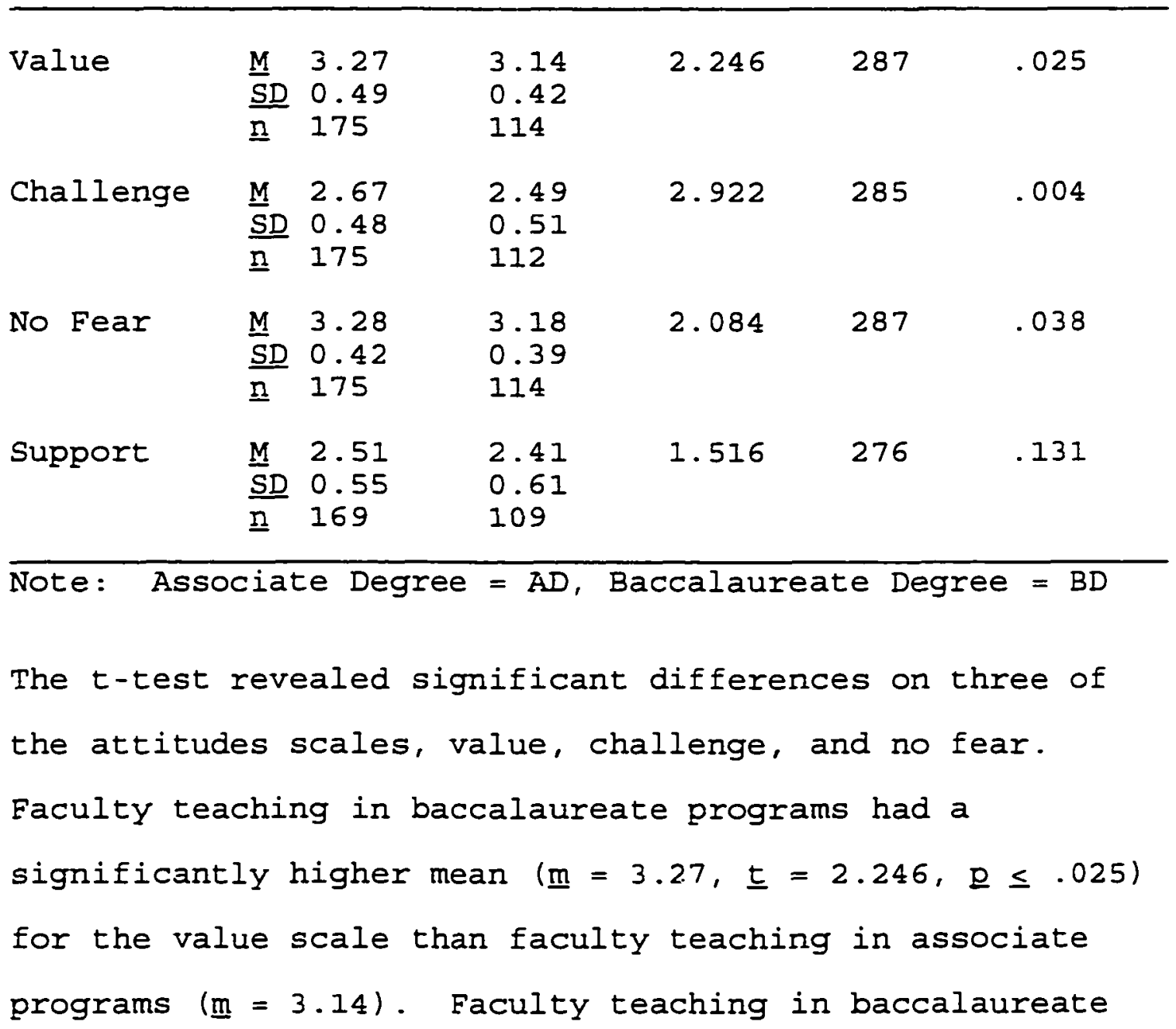


programs had a significantly higher mean for the challenge scale $(\underline{m}=2.67, \underline{t}=2.992, \underline{p} \leq .004)$ than faculty from associate programs $(\underline{m}=2.49)$. Faculty from baccalaureate programs also had a significantly higher mean for the no fear scale $(\underline{m}=3.28, \underline{t}=2.084, \underline{p} \leq .038)$ than associate faculty $(\underline{m}=3.17)$. There was no significant difference by program type and the support attitude scale. These findings suggest that faculty teaching in baccalaureate programs may place a higher value on intuition, consider teaching about intuition a more realistic challenge, and be more comfortable with intuition than faculty teaching in associate programs.

\section{Intuition in current curricula} by Program Type

Chi-square tests was used to test for differences by program type on responses to research question \#3 regarding intuition in the current curricula (survey items \#25-28). Chi-square results (Table 27) show that significantly more faculty from baccalaureate $(\underline{n}=36)$ and significantly fewer faculty from associate $(\underline{n}=5)$ programs include intuition in the philosophy than expected $\left(\chi^{2}=17.437, \underline{\mathrm{p}} \leq .001\right)$. The two diploma faculty including intuition in the philosophy was close to the expected count of 4.4. Less than ten percent of faculty from diploma (6.3\%) and associate programs (4.5\%) and over $20 \%$ 
of baccalaureate faculty responded that the intuitive way of knowing is included in the philosophy of the school of nursing. There was no significant difference by program type for course objectives related to intuition. No diploma respondents taught an undergraduate nursing course that included objectives related to the development of intuition and less than $10 \%$ of associate and baccalaureate faculty had specific objectives related to intuition in a nursing course. There was a significant difference by program type and teaching about intuition in a nursing course. Just $12.5 \%(\underline{\mathrm{n}}=4)$ diploma faculty were teaching about intuition during the 1997-98 academic year compared to $35.3 \%(\underline{n}=61)$ of baccalaureate faculty $\left(\chi^{2}=\right.$ $6.994, \underline{D} \leq .030)$. The 32 associate respondents $(28.3 \%)$ teaching about intuition was close to the 34.5 expected. In summary, chi-square results show that there is a significant difference by program type for the inclusion of intuition in the philosophy of the school of nursing and for teaching about intuition. Significantly more faculty teaching in baccalaureate programs and fewer faculty teaching in associate programs included intuition in the philosophy than expected. Significantly more faculty in baccalaureate programs and fewer faculty in diploma programs were teaching about intuition than 
expected. There were no significant differences by program type for educational objectives related to intuition.

Table 27

Intuition in Curricula vs. Program Type

Intuition Program $\div$ Yes $\%$ No $\underline{N} \chi^{2}$ p

\begin{tabular}{llrrrrr}
\hline \multirow{2}{*}{ Philosophy } & D & 6.3 & 93.8 & 313 & 17.437 & .001 \\
& AD & 4.5 & 95.5 & & & \\
& BD & 21.2 & 78.8 & & & \\
Objectives & D & 0.0 & 100.0 & 313 & 2.635 & .268 \\
& AD & 6.3 & 93.7 & & & \\
& BD & 10.3 & 89.7 & & & \\
Teaching & D & 12.5 & 87.5 & 318 & 6.994 & .030 \\
& AD & 28.3 & 71.7 & & & \\
& BD & 35.3 & 64.7 & & & \\
& & & & & & \\
\end{tabular}

Note: Diploma (D), Associate (AD), Baccalaureate (BD), $\underline{\mathrm{df}}=2$

Faculty Use and Effectiveness of Strateqies for Self by

Program Type

Chi-square tests were calculated for difference by program type on responses to research question \#4 regarding faculty use of strategies to develop their own intuition and effectiveness of the strategies (Table 28). No significant differences were found by program type for 21 of the 25 strategies. Results show that four 
strategies were used differently: (a) knowledge linking, (b) using a clinical journal, (c) developing selfconfidence, and (d) involvement in varied clinical experiences. Two of the strategies, knowledge linking and clinical journal were used by significantly more faculty in baccalaureate programs than expected and fewer in associate programs than expected. Seventy-three percent of baccalaureate faculty used knowledge linking compared to $59.6 \%$ of associate faculty $\left(\chi^{2}=5.605, \underline{Q} \leq .018\right)$. Journaling was used by $36.8 \%$ of baccalaureate faculty compared to $22.8 \%$ of associate faculty $\left(\chi^{2}=6.261, \underline{\underline{ }} \leq\right.$ .012). Two of the strategies, developing self-confidence based on nursing knowledge of a subject and involvement in varied clinical experiences were used by significantly more associate faculty than expected and fewer baccalaureate faculty than expected. Developing selfconfidence was used by $91.2 \%$ of associate faculty compared to $82.8 \%$ of baccalaureate faculty $\left(\chi^{2}=4.131\right.$, $\left.\underline{\mathrm{p}} \leq .042\right)$. Involvement in varied clinical experiences was used by $85.0 \%$ associate faculty compared to $74.7 \%$ baccalaureate faculty $\left(\chi^{2}=4.294, \underline{D} \leq .038\right)$. These findings suggest that there was very little difference in respondents' use of strategies to develop their own intuition by program type (see Table 28). 
Table 28

A Comparison of Baccalaureate vs. Associate Faculty Use of Strategies With Self

\begin{tabular}{|c|c|c|c|c|c|c|c|}
\hline \multirow[t]{2}{*}{ strategy } & \multirow[t]{2}{*}{$\underline{\mathbf{N}}$} & \multicolumn{4}{|c|}{$\%$ Use With Self } & \multirow[t]{2}{*}{$\chi^{2}$} & \multirow[t]{2}{*}{ Q } \\
\hline & & $(\underline{n})$ & $\mathrm{BD}$ & $(\underline{n})$ & $\overline{A D}$ & & \\
\hline $\begin{array}{l}\text { Knowledge } \\
\text { links }\end{array}$ & 288 & $(174)$ & $73.0 \%$ & $(114)$ & $59.6 \%$ & 5.605 & .018 \\
\hline Journal & 288 & $(174)$ & $36.8 \%$ & $(114)$ & $22.8 \%$ & 6.261 & .012 \\
\hline Self confid. & 288 & $(174)$ & $82.8 \%$ & $(114)$ & $91.2 \%$ & 4.131 & .042 \\
\hline $\begin{array}{l}\text { Varied } \\
\text { clinical }\end{array}$ & 286 & $(174)$ & $74.7 \%$ & $(113)$ & $85.0 \%$ & 4.295 & .038 \\
\hline Gut reaction & 288 & $(174)$ & $94.3 \%$ & $(114)$ & $98.2 \%$ & 2.750 & .097 \\
\hline One way & 288 & $(174)$ & $94.3 \%$ & $(114)$ & $95.6 \%$ & 0.258 & .611 \\
\hline Voice & 285 & $(172)$ & $94.2 \%$ & $(113)$ & $95.6 \%$ & 0.264 & .607 \\
\hline Value & 287 & $(174)$ & $88.5 \%$ & $(113)$ & $88.5 \%$ & 0.000 & .998 \\
\hline $\begin{array}{l}\text { Client's } \\
\text { perspective }\end{array}$ & 285 & $(172)$ & $82.6 \%$ & $(113)$ & $76.1 \%$ & 1.774 & .183 \\
\hline Awareness & 287 & $(173)$ & $80.3 \%$ & $(114)$ & $78.1 \%$ & 0.218 & .640 \\
\hline Reflection & 284 & $(172)$ & $79.7 \%$ & $(112)$ & $69.6 \%$ & 3.694 & .055 \\
\hline Creativity & 286 & $(172)$ & $78.5 \%$ & $(114)$ & $69.3 \%$ & 3.074 & .080 \\
\hline Past int. & 287 & $(174)$ & $73.6 \%$ & $(114)$ & $71.1 \%$ & 0.218 & .641 \\
\hline Self-care & 288 & $(174)$ & $67.2 \%$ & $(114)$ & $56.1 \%$ & 3.635 & .057 \\
\hline Case studies & 285 & $(172)$ & $62.8 \%$ & $(113)$ & $58.4 \%$ & 0.551 & .458 \\
\hline Validate & 287 & $(174)$ & $59.8 \%$ & $(113)$ & $62.8 \%$ & 0.270 & .603 \\
\hline Brainstorm & 288 & $(173)$ & $56.6 \%$ & $(114)$ & $57.9 \%$ & 0.044 & .834 \\
\hline
\end{tabular}


Table 28

A Comparison of Baccalaureate vs. Associate Faculty Use of Strategies With Self (continued)

\begin{tabular}{|c|c|c|c|c|c|c|c|}
\hline \multirow[t]{2}{*}{ strategy } & \multirow[t]{2}{*}{$\underline{\mathbf{N}}$} & \multicolumn{4}{|c|}{$\%$ Use With Self } & \multirow[t]{2}{*}{$\chi^{2}$} & \multirow[t]{2}{*}{$\underline{p}$} \\
\hline & & $(\underline{\underline{n}})$ & $\mathrm{BD}$ & (프) & $\overline{\mathrm{AD}}$ & & \\
\hline Model & 288 & $(174)$ & $49.4 \%$ & $(114)$ & $43.9 \%$ & 0.856 & .355 \\
\hline Story teliing & 287 & $(173)$ & $49.1 \%$ & $(114)$ & $45.6 \%$ & 0.341 & .559 \\
\hline Imagery & 279 & $(173)$ & $43.4 \%$ & $(112)$ & $33.0 \%$ & 3.033 & .082 \\
\hline Terms & 288 & $(174)$ & $43.1 \%$ & $(114)$ & $33.3 \%$ & 2.758 & .097 \\
\hline Reinforce & 288 & $(174)$ & $42.0 \%$ & $(114)$ & $41.2 \%$ & 0.015 & .903 \\
\hline Guessing & 287 & $(174)$ & $37.4 \%$ & (113) & $39.8 \%$ & 0.176 & .675 \\
\hline Meditation & 286 & $(172)$ & $30.8 \%$ & $(114)$ & $22.8 \%$ & 2.199 & .138 \\
\hline Preceptor & 286 & $(173)$ & $13.3 \%$ & $(113)$ & $6.2 \%$ & 3.670 & .055 \\
\hline
\end{tabular}

In the chi-square computations for differences by program type on effectiveness of strategies, the categories "extremely" and "moderately" effective were combined (Appendix B, Chart 2). The category "not effective" was eliminated due to the small number of respondents selecting this response. The resulting chisquares consisted of a $2 \times 2$ table for effectiveness of strategies for each strategy and program type. The results show that there were no significant differences 
between the responses of faculty teaching in baccalaureate programs and faculty teaching in associate programs on effectiveness of strategies.

In summary, difference by program type on responses to research question \#4 regarding faculty use of strategies to develop their own intuition and effectiveness of the strategies revealed no significant difference by program type on 21 of the 25 strategies faculty used to develop their own intuition. Two strategies, linking knowledge and use of a clinical journal were used by significantly more baccalaureate faculty and two strategies, self-confidence and varied clinical were used by significantly more associate faculty. No significant differences were found between baccalaureate and associate faculty and effectiveness of strategies faculty used to develop their intuition.

\section{Faculty Use and Effectiveness}

of strategies with students

by Program Type

Chi-square tests were calculated to test for difference by program type on responses to research question \#5 regarding faculty use of strategies to help students develop intuition and effectiveness of the strategies (Table 29). No significant differences were found by program type for 17 of the 25 strategies. 
Table 29

A Comparison of Baccalaureate vs. Associate Faculty Use of Strategies with Students

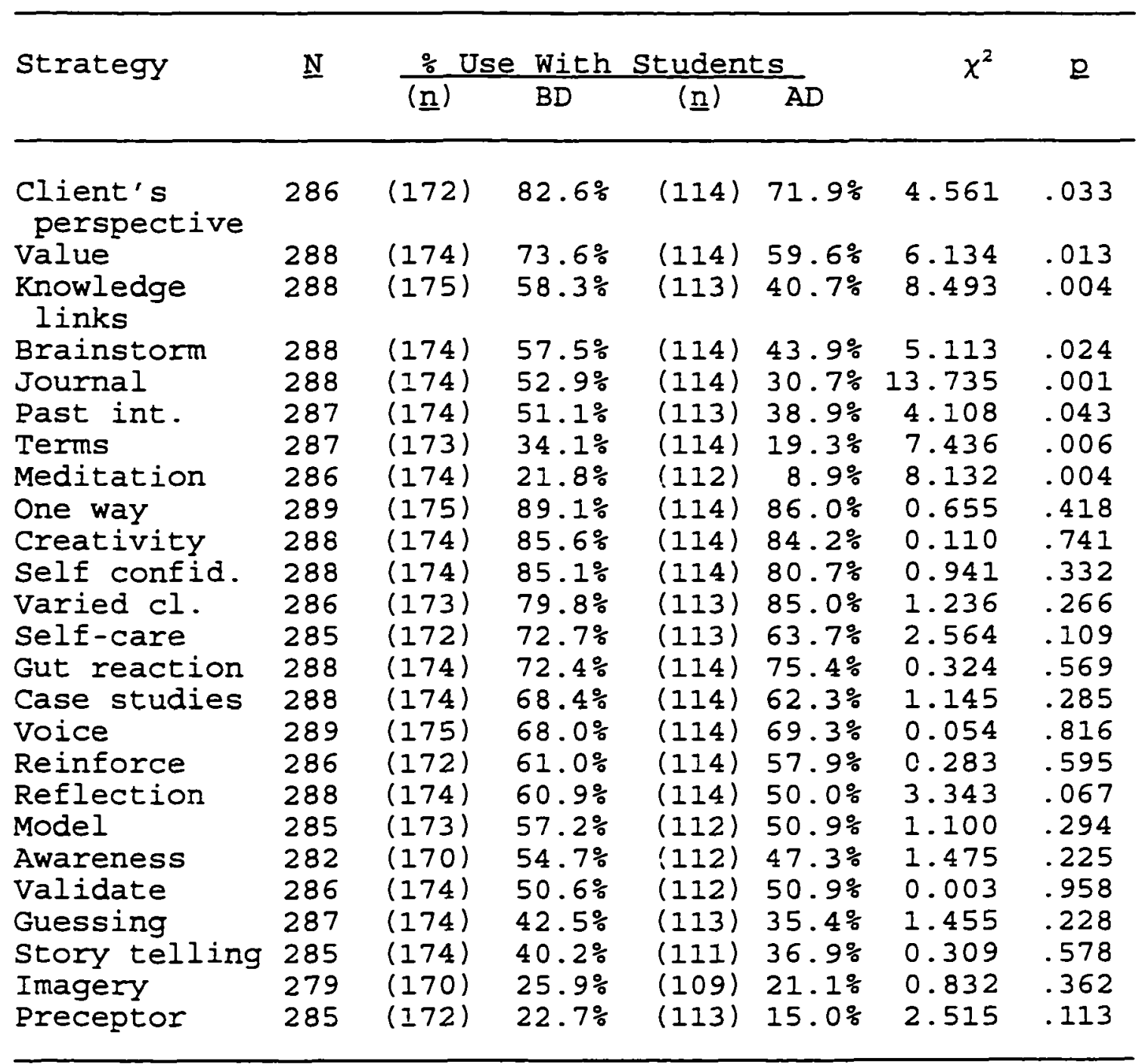

Note: $\underline{d f}=1$

Chi-square results (also Table 29) show that eight strategies were used differently: (a) use of a clinical journal to record cue assessments, hunches, and outcome; (b) offer meditation experiences; (c) teach the structure 
of knowledge and how it is linked to other knowledge;

(d) encourage the use of terms and definitions regarding intuition; (e) emphasize the value of intuitive skilis in nursing; (E) practice brainstorming to elicit intuitive responses; (g) encourage taking the client's perspective; and (h) encourage reflection on past intuitive experiences. Each of the eight strategies were used by significantly more faculty teaching in baccalaureate programs than expected and fewer faculty teaching in associate programs than expected.

Use of a clinical journal was used by $52.9 \%(\underline{\underline{n}}=92)$ of baccalaureate faculty compared to $30.7 \%(\underline{n}=35)$ of associate faculty $\left(\chi^{2}=13.735, \underline{p} \leq .001\right)$. Offer meditation experiences was used by $21.8 \%(\underline{\underline{n}}=38)$ of baccalaureate faculty compared to $8.9 \%(\underline{n}=10)$ associate faculty $\left(\chi^{2}=8.132, \underline{p} \leq .004\right)$. Meditation was the least frequently used strategy to help students develop intuition. Teach knowledge links was used by $58.3 \%$ ( $\underline{\underline{I}}=$ 102) of baccalaureate faculty compared to $40.7 \%(\underline{\Pi}=46)$ of associate faculty $\left(\chi^{2}=8.493, \underline{\underline{p}} \leq .004\right)$. Encourage the use of terms was used by $34.1 \%(\underline{\underline{n}}=59)$ of baccalaureate faculty compared to $19.3 \%(\underline{\underline{n}}=22)$ of associate faculty $\left(\chi^{2}=7.436, \underline{\underline{D}} \leq .006\right)$. Emphasize the value of intuition was used by $73.8 \%(\underline{n}=128)$ of baccalaureate faculty compared to $59.6 \%(\underline{n}=68)$ of 
associate faculty $\left(\chi^{2}=6.134, \underline{D} \leq .013\right)$. Three strategies were significant at $\mathbb{D} \leq .05$. Practice brainstorming was used by $57.5 \%(\underline{n}=100)$ of baccalaureate faculty compared to $43.9 \%(\underline{n}=50)$ of associate faculty $\left(\chi^{2}=5.113, \underline{\mathrm{D}} \leq .024\right)$. Taking the client's perspective was used by $82.6 \%(\underline{n}=142)$ of baccalaureate faculty compared to $71.9 \%(\underline{n}=82)$ of associate faculty $\left(\chi^{2}=\right.$ $4.561, \underline{p} \leq .033)$. Encourage reflection was used by $51.1 \%$ $(\underline{n}=89)$ baccalaureate faculty compared to $38.9 \%(\underline{\underline{n}}=44)$ associate faculty $\left(\chi^{2}=4.108, \underline{\underline{D}} \leq .043\right)$.

Some of the strategies baccalaureate faculty use more than associate faculty are more time intensive than the strategies of no difference. Is it possible that the faculty teaching in two year associate programs do not have the time to use these strategies while faculty in four year baccalaureate programs do not feel the same restriction?

In the computations of chi-squares, for differences by program type on effectiveness of strategies the categories "extremely" and "moderately" effective were combined (see Appendix B, Chart 3). The category "not effective" was eliminated due to the small number of respondents selecting this response. The resulting chisquares consisted of a $2 \times 2$ table for effectiveness of strategies for each strategy and program type. The 
results show that there was no difference on respondent rating of the effectiveness of strategies used with students on 23 of the 25 strategies. Two strategies, quiet reflection and use of a clinical journal were rated more effective by faculty teaching in associate programs. Chi-squares were $5.170(\underline{\mathrm{df}}=1, \underline{\mathrm{n}}=152, \underline{\underline{\mathrm{f}}} \leq .023)$ for quiet reflection and 4.202 ( $\underline{\text { df }}=1, \underline{n}=121, \underline{p} \leq .040$ ) for clinical journal.

In summary, the findings show that there is no difference by program type in faculty use of three fourths of the 25 strategies to help students develop intuition. Some of the strategies used by more faculty from baccalaureate programs are time intensive. There was no difference in respondent ratings of effectiveness on 23 of 25 strategies. Two strategies were rated more effective by faculty from associate programs.

Baccalaureate faculty use of strategies with self and students. Chi-squares were calculated to determine if there was a relationship between baccalaureate faculty use of strategies to develop their own intuition and use of strategies to help students develop intuition (Table 30 ). Results show that there was a significant relationship for all 25 strategies $(\underline{p} \leq .001)$. This finding indicates that, if baccalaureate respondents used the strategy to develop their own intuition, they were significantly more 
likely to use the strategy to help students develop intuition.

Table 30

Baccalaureate Faculty Use of Strategies with Self vs. Use of Strategies with Students*

\begin{tabular}{|c|c|c|c|c|c|}
\hline \multirow[t]{2}{*}{ Strategy } & \multirow[t]{2}{*}{$\underline{\mathbf{N}}$} & \multirow{2}{*}{$\begin{array}{l}\text { Use } \\
\text { with } \\
\text { self }\end{array}$} & \multicolumn{2}{|c|}{ Use With Students } & \multirow[t]{2}{*}{$\chi^{2}$} \\
\hline & & & Yes & No & \\
\hline \multirow[t]{2}{*}{ Creativity } & 134 & Yes & $97.0 \%$ & $3.0 \%$ & 53.930 \\
\hline & 37 & $\underline{\underline{N O}}$ & $51.4 \%$ & $48.6 \%$ & \\
\hline \multirow[t]{2}{*}{ Self-care } & 114 & Yes & $94.7 \%$ & $5.3 \%$ & 126.105 \\
\hline & 57 & No & $28.1 \%$ & $71.9 \%$ & \\
\hline \multirow{2}{*}{ One way } & 164 & Yes & $93.9 \%$ & $6.1 \%$ & 68.211 \\
\hline & 10 & No & $10.0 \%$ & $90.0 \%$ & \\
\hline \multirow{4}{*}{$\begin{array}{l}\text { Self- } \\
\text { confidence } \\
\text { Case studies }\end{array}$} & 144 & $\overline{\text { Yes }}$ & $93.8 \%$ & $6.2 \%$ & 51.843 \\
\hline & 29 & No & $41.4 \%$ & $58.6 \%$ & \\
\hline & 107 & $\overline{\text { Yes }}$ & $91.6 \%$ & $8.4 \%$ & 68.170 \\
\hline & 64 & No & $31.3 \%$ & $68.7 \%$ & \\
\hline \multirow{2}{*}{$\begin{array}{l}\text { Client's } \\
\text { perspective }\end{array}$} & 139 & Yes & $90.6 \%$ & $9.4 \%$ & 33.576 \\
\hline & 30 & No & $46.7 \%$ & $53.3 \%$ & \\
\hline \multirow{2}{*}{$\begin{array}{l}\text { Varied } \\
\text { clinical }\end{array}$} & 128 & $\overline{\text { Yes }}$ & $90.6 \%$ & $9.4 \%$ & 37.177 \\
\hline & 44 & No & $47.7 \%$ & $52.3 \%$ & \\
\hline \multirow{2}{*}{ Reinforce } & 72 & $\overline{\text { Yes }}$ & $88.9 \%$ & $11.1 \%$ & 39.642 \\
\hline & 99 & No & $41.4 \%$ & $58.6 \%$ & \\
\hline \multirow[t]{2}{*}{ Journal } & 63 & $\overline{\text { Yes }}$ & $88.9 \%$ & $11.1 \%$ & 50.744 \\
\hline & 110 & No & $32.7 \%$ & $67.3 \%$ & \\
\hline \multirow[t]{2}{*}{ Brainstorm } & 98 & Yes & $86.7 \%$ & $13.3 \%$ & 76.530 \\
\hline & 74 & No & $20.3 \%$ & $79.7 \%$ & \\
\hline \multirow[t]{2}{*}{ Model } & 84 & Yes & $84.5 \%$ & $15.5 \frac{\circ}{6}$ & 48.870 \\
\hline & 88 & No & $31.8 \%$ & $68.2 \%$ & \\
\hline \multirow{2}{*}{ Value } & 153 & $\overline{Y e s}$ & $80.4 \%$ & $19.6 \%$ & 33.050 \\
\hline & 20 & No & $20.0 \%$ & $80.0 \%$ & \\
\hline \multirow[t]{2}{*}{ Guessing } & 65 & Yes & $80.0 \%$ & $20.0 \%$ & 58.944 \\
\hline & 108 & No & $20.4 \%$ & $79.6 \%$ & \\
\hline \multirow{2}{*}{ Gut reaction } & 163 & Yes & $75.5 \%$ & $24.5 \%$ & 14.456 \\
\hline & 10 & No & $20.0 \%$ & $80.0 \%$ & \\
\hline \multirow[t]{2}{*}{ Validate } & 103 & Yes & $73.8 \%$ & $26.2 \%$ & 56.211 \\
\hline & 70 & & $15.7 \%$ & $84.3 \%$ & \\
\hline \multirow[t]{2}{*}{ Reflection } & 137 & $\overline{\text { Yes }}$ & $72.3 \%$ & $27.7 \%$ & 30.869 \\
\hline & 34 & No & $20.6 \%$ & $79.4 \%$ & \\
\hline \multirow{2}{*}{ Voice } & 162 & Yes & $72.2 \%$ & $27.8 \%$ & 16.930 \\
\hline & 10 & No & $10.0 \%$ & $90.0 \%$ & \\
\hline
\end{tabular}


Table 30

Baccalaureate Faculty Use of Strategies with Self vs. Use of Strategies with Students* (continued)

\begin{tabular}{|c|c|c|c|c|c|}
\hline$\overline{\text { Strategy }}$ & $\underline{N}$ & $\begin{array}{l}\text { Use } \\
\text { with } \\
\text { self }\end{array}$ & $\frac{\text { Use W }}{\text { Yes }}$ & $\frac{\text { students }}{\text { No }}$ & $x^{2}$ \\
\hline $\begin{array}{l}\text { Knowledge } \\
\text { links }\end{array}$ & $\begin{array}{r}127 \\
47\end{array}$ & $\frac{\text { Yes }}{\text { No }}$ & $\begin{array}{l}71.7 \% \\
23.4 \%\end{array}$ & $\begin{array}{l}28.3 \% \\
76.6 \%\end{array}$ & 32.923 \\
\hline Story telling & $\begin{array}{l}84 \\
88\end{array}$ & $\frac{\text { Yes }}{\text { No }}$ & $\begin{array}{l}71.4 \% \\
11.4 \%\end{array}$ & $\begin{array}{l}28.6 \% \\
88.6 \%\end{array}$ & 64.244 \\
\hline Terms & $\begin{array}{l}73 \\
99\end{array}$ & $\frac{\overline{\text { Yes }}}{\text { No }}$ & $\begin{array}{r}68.5 \% \\
9.1 \%\end{array}$ & $\begin{array}{l}31.5 \% \\
90.9 \%\end{array}$ & 65.790 \\
\hline Preceptor & $\begin{array}{r}22 \\
148\end{array}$ & $\begin{array}{l}\text { Yes } \\
\text { No }\end{array}$ & $\begin{array}{l}68.2 \% \\
16.2 \%\end{array}$ & $\begin{array}{l}31.8 \% \\
83.8 \%\end{array}$ & 29.257 \\
\hline $\begin{array}{l}\text { Past } \\
\text { intuition }\end{array}$ & $\begin{array}{r}127 \\
46\end{array}$ & $\frac{\overline{\text { Yes }}}{\underline{\text { No }}}$ & $\begin{array}{l}65.4 \% \\
13.0 \%\end{array}$ & $\begin{array}{l}34.6 \% \\
87.0 \%\end{array}$ & 36.933 \\
\hline Awareness & $\begin{array}{r}136 \\
33\end{array}$ & $\frac{\text { Yes }}{\text { No }}$ & $\begin{array}{l}64.7 \% \\
12.1 \%\end{array}$ & $\begin{array}{l}35.3 \% \\
87.9 \%\end{array}$ & 29.606 \\
\hline Meditation & $\begin{array}{r}53 \\
118\end{array}$ & $\frac{\overline{\text { Yes }}}{\text { No }}$ & $\begin{array}{r}58.5 \% \\
5.9 \%\end{array}$ & $\begin{array}{l}41.5 \% \\
94.1 \%\end{array}$ & 58.452 \\
\hline Imagery & $\begin{array}{l}73 \\
95\end{array}$ & $\frac{\text { Yes }}{\underline{\text { No }}}$ & $\begin{array}{r}52.1 \% \\
6.3 \%\end{array}$ & $\begin{array}{l}47.9 \% \\
93.7 \%\end{array}$ & 44.674 \\
\hline
\end{tabular}

*Note: $\quad$ df $=1$, all strategies significant $\mathrm{D} \leq .001$ Fisher's exact test $\underline{p} \leq .001$ for creativity, one way, self-confidence, gut reaction, voice

Associate use of strategies with self and students. Chi-square tests were run to determine if there was a relationship between associate faculty use of strategies to develop their own intuition and use of strategies to help students develop intuition (Table 31). Results show that there was a significant relationship for 22 of the 25 strategies $(\underline{\mathrm{p}} \leq .001)$. One strategy was significant at $\underline{\mathrm{p}}$ $\leq .002$. Two strategies were not significant. These 
findings indicate that if associate respondents used the strategy to develop their own intuition they were significantly more likely to use the strategy to help students develop intuition. If faculty did not use the strategy to develop their intuition they were not likely to use it with students. There were only two exceptions to this result. This supports an earlier finding regarding use of strategies by faculty. There was a relationship between use of strategies by respondents to develop their own intuition and student intuition which held regardiess of program type.

Table 31

Associate Faculty Use of Strategies with Self vs. Use of Strategies with Students

\begin{tabular}{|c|c|c|c|c|c|c|}
\hline strategy & $\underline{\mathbf{N}}$ & $\begin{array}{l}\text { Use } \\
\text { with } \\
\text { self }\end{array}$ & $\frac{\text { Use } W j}{\text { Yes }}$ & $\frac{\text { th } \text { students }}{\text { No }}$ & $\chi^{2}$ & D \\
\hline$\overline{\text { Creativity }}$ & $\begin{array}{l}79 \\
35\end{array}$ & $\frac{\text { Yes }}{\text { No }}$ & $\begin{array}{l}93.7 \% \\
62.9 \%\end{array}$ & $\begin{array}{r}6.3 \% \\
37.1 \%\end{array}$ & 17.320 & .001 \\
\hline $\begin{array}{l}\text { Varied } \\
\text { clinical }\end{array}$ & $\begin{array}{l}95 \\
17\end{array}$ & $\frac{\text { Yes }}{\text { No }}$ & $\begin{array}{l}91.6 \% \\
47.1 \%\end{array}$ & $\begin{array}{r}8.4 \% \\
52.9 \%\end{array}$ & 22.199 & $.001 *$ \\
\hline Self-care & $\begin{array}{l}64 \\
49\end{array}$ & $\frac{\text { Yes }}{\text { No }}$ & $\begin{array}{l}89.1 \% \\
30.6 \%\end{array}$ & $\begin{array}{l}10.9 \% \\
69.4 \%\end{array}$ & 41.012 & .001 \\
\hline $\begin{array}{l}\text { Self- } \\
\text { confidence }\end{array}$ & $\begin{array}{r}104 \\
10\end{array}$ & $\frac{\text { Yes }}{\text { No }}$ & $\begin{array}{r}88.5 \% \\
.0 \%\end{array}$ & $\begin{array}{r}11.5 \% \\
100.0 \%\end{array}$ & 45.839 & $.001 *$ \\
\hline One way & $\begin{array}{r}109 \\
5\end{array}$ & $\frac{\text { Yes }}{\text { No }}$ & $\begin{array}{l}87.2 \% \\
60.0 \%\end{array}$ & $\begin{array}{l}12.8 \% \\
40.0 \%\end{array}$ & 2.922 & .144 \\
\hline $\begin{array}{l}\text { Client's } \\
\text { perspective }\end{array}$ & $\begin{array}{l}86 \\
27\end{array}$ & $\frac{\overline{Y e s}}{\text { No }}$ & $\begin{array}{l}86.0 \% \\
25.9 \%\end{array}$ & $\begin{array}{l}14.0 \% \\
74.1 \%\end{array}$ & 36.589 & .001 \\
\hline Preceptor & $\begin{array}{r}7 \\
105\end{array}$ & $\frac{\text { Yes }}{\underline{\text { No }}}$ & $\begin{array}{l}85.7 \% \\
10.5 \%\end{array}$ & $\begin{array}{l}14.3 \% \\
89.5 \%\end{array}$ & 28.854 & $.001 *$ \\
\hline Case studies & $\begin{array}{l}66 \\
47\end{array}$ & $\frac{\text { Yes }}{\text { No }}$ & $\begin{array}{l}83.3 \% \\
31.9 \%\end{array}$ & $\begin{array}{l}16.7 \% \\
68.1 \%\end{array}$ & 30.789 & .001 \\
\hline
\end{tabular}


Table 31

Associate Faculty Use of Strategies with Self vs.

Use of Strategies with Students

(continued)

\begin{tabular}{|c|c|c|c|c|c|c|}
\hline strategy & $\underline{\mathrm{N}}$ & $\begin{array}{l}\text { Use } \\
\text { with } \\
\text { self }\end{array}$ & $\frac{\text { Use Wi }}{\text { Yes }}$ & $\frac{\text { th students }}{\text { No }}$ & $\chi^{2}$ & 2 \\
\hline Model & $\begin{array}{l}50 \\
62\end{array}$ & $\frac{\text { Yes }}{\text { No }}$ & $\begin{array}{l}82.0 \% \\
25.8 \%\end{array}$ & $\begin{array}{l}18.0 \% \\
74.2 \%\end{array}$ & 34.972 & .001 \\
\hline Gut reaction & $\begin{array}{r}112 \\
2\end{array}$ & $\frac{\overline{\text { Yes }}}{\text { No }}$ & $\begin{array}{l}75.9 \% \\
50.0 \%\end{array}$ & $\begin{array}{l}24.1 \% \\
50.0 \%\end{array}$ & 0.711 & .433 \\
\hline Validate & $\begin{array}{l}69 \\
42\end{array}$ & $\frac{\text { Yes }}{\text { No }}$ & $\begin{array}{l}72.5 \% \\
16.7 \%\end{array}$ & $\begin{array}{l}27.5 \% \\
83.3 \%\end{array}$ & 32.537 & .001 \\
\hline Voice & $\begin{array}{r}78 \\
5\end{array}$ & $\frac{\overline{\text { Yes }}}{\underline{\text { No }}}$ & $\begin{array}{r}72.2 \% \\
.0 \%\end{array}$ & $\begin{array}{r}27.8 \% \\
100.0 \%\end{array}$ & 11.659 & .002 \\
\hline Reinforce & $\begin{array}{l}47 \\
67\end{array}$ & $\frac{\overline{\text { Yes }}}{\underline{\text { No }}}$ & $\begin{array}{l}70.2 \% \\
49.3 \%\end{array}$ & $\begin{array}{l}29.8 \% \\
50.7 \%\end{array}$ & 4.978 & .001 \\
\hline story telling & $\begin{array}{l}49 \\
62\end{array}$ & $\frac{\overline{\text { Yes }}}{\underline{\text { No }}}$ & $\begin{array}{l}69.4 \% \\
11.3 \%\end{array}$ & $\begin{array}{l}30.6 \% \\
88.7 \%\end{array}$ & 39.659 & .001 \\
\hline Value & $\begin{array}{r}100 \\
13\end{array}$ & $\frac{\overline{\text { Yes }}}{\mathrm{No}}$ & $\begin{array}{r}67.0 \% \\
.0 \%\end{array}$ & $\begin{array}{r}33.0 \% \\
100.0 \%\end{array}$ & 21.396 & .001 \\
\hline Reflection & $\begin{array}{l}78 \\
34\end{array}$ & $\frac{\text { Yes }}{\text { No }}$ & $\begin{array}{l}65.4 \% \\
17.6 \%\end{array}$ & $\begin{array}{l}34.6 \% \\
82.4 \%\end{array}$ & 21.591 & .001 \\
\hline Journal & $\begin{array}{l}26 \\
88\end{array}$ & $\frac{\overline{\text { Yes }}}{\underline{\text { No }}}$ & $\begin{array}{l}65.4 \% \\
20.5 \%\end{array}$ & $\begin{array}{l}34.6 \% \\
79.5 \%\end{array}$ & 19.043 & .001 \\
\hline Brainstorm & $\begin{array}{l}66 \\
48\end{array}$ & $\frac{\overline{\text { Yes }}}{\text { No }}$ & $\begin{array}{l}65.2 \% \\
14.6 \%\end{array}$ & $\begin{array}{l}34.8 \% \\
85.4 \%\end{array}$ & 28.860 & .001 \\
\hline $\begin{array}{l}\text { Knowledge } \\
\text { links }\end{array}$ & $\begin{array}{l}67 \\
46\end{array}$ & $\frac{\overline{\text { Yes }}}{\text { No }}$ & $\begin{array}{r}64.2 \% \\
6.5 \%\end{array}$ & $\begin{array}{l}35.8 \% \\
93.5 \%\end{array}$ & 37.565 & .001 \\
\hline Guessing & $\begin{array}{l}45 \\
67\end{array}$ & $\frac{\overline{\text { Yes }}}{\text { No }}$ & $\begin{array}{l}57.8 \% \\
20.9 \%\end{array}$ & $\begin{array}{l}42.2 \% \\
79.1 \%\end{array}$ & 15.950 & .001 \\
\hline Awareness & $\begin{array}{l}87 \\
25\end{array}$ & $\frac{\overline{\text { Yes }}}{\underline{\text { No }}}$ & $\begin{array}{l}56.3 \% \\
16.0 \%\end{array}$ & $\begin{array}{l}43.7 \% \\
84.0 \%\end{array}$ & 12.666 & .001 \\
\hline Imagery & $\begin{array}{l}35 \\
73\end{array}$ & $\frac{\overline{\text { Yes }}}{\text { No }}$ & $\begin{array}{r}54.3 \% \\
5.5 \%\end{array}$ & $\begin{array}{l}45.7 \% \\
94.5 \%\end{array}$ & 33.622 & .001 \\
\hline $\begin{array}{l}\text { Past } \\
\text { intuition }\end{array}$ & $\begin{array}{l}80 \\
33\end{array}$ & $\frac{\overline{Y e s}}{\text { No }}$ & $\begin{array}{l}50.0 \% \\
12.1 \%\end{array}$ & $\begin{array}{l}50.0 \% \\
87.9 \%\end{array}$ & 14.098 & .001 \\
\hline Terms & $\begin{array}{l}38 \\
76\end{array}$ & $\frac{\overline{\text { Yes }}}{\text { No }}$ & $\begin{array}{r}50.0 \% \\
3.9 \%\end{array}$ & $\begin{array}{l}50.0 \% \\
96.1 \%\end{array}$ & 34.499 & .001 \\
\hline Meditation & $\begin{array}{l}24 \\
88\end{array}$ & $\frac{\overline{\text { Yes }}}{\underline{\text { No }}}$ & $\begin{array}{r}29.2 \% \\
3.4 \%\end{array}$ & $\begin{array}{l}70.8 \% \\
96.6 \%\end{array}$ & 15.386 & $.001 *$ \\
\hline
\end{tabular}

*Fisher's Exact Test

Note: $\underline{\mathrm{df}}=1$ 


\section{Professional Preparation}

Chi-square tests were computed to test for difference by program type on responses to research question \#6 concerning professional preparation to teach about intuition (survey items \#15, \#32-35). Results show that there were significant differences by program type for perception of preparation to teach about intuition (Table 32). More faculty in baccalaureate programs (50.9\%) and fewer faculty in diploma programs (25.0\%) than expected felt adequately prepared to teach about intuition in the undergraduate nursing curriculum $\left(\chi^{2}=7.608, \underline{D} \leq .022\right)$. The percent of associate faculty $(43.5 \%)$ who reported feeling adequately prepared to teach about intuition was close to what was expected.

Table 32

Perception of Preparation to Teach Intuition vs. Program Type

Program $\frac{\text { Preparation }}{\text { Agree Disagree }} \underline{N} \chi^{2} \quad \underline{\mathrm{N}}$

\begin{tabular}{llllll}
\hline Diploma & $25.0 \%$ & $75.0 \%$ & 315 & 7.608 & .022 \\
Associate & $43.5 \%$ & $56.5 \%$ & & & \\
Baccalaureate & $50.9 \%$ & $49.1 \%$ & & &
\end{tabular}

Note: The categories agree and strongly agree, disagree and strongly disagree were combined for chi-square; $\underline{\text { df }}=2$ 
Results show that there were significant differences by program type for conducting personal studies on intuition (Table 33). More faculty teaching in baccalaureate programs $(16.8 \%)$ and fewer faculty teaching in associate programs (6.1\%) had conducted personal studies than expected $\left(\chi^{2}=10.053, \underline{\underline{D}} \leq .007\right)$. Chi-square revealed no significant difference by program type for preparation acquired by attendance at workshops or conferences or by learning about intuition in a degree program. Though not significant, it is of interest that more baccalaureate and fewer associate and diploma faculty than expected reported learning about intuition through workshops or conferences.

Table 33

Intuition Preparation vs. Program Type

\begin{tabular}{llrllll}
\hline Preparation & Program & $\%$ Yes & $\%$ No & $\underline{N}$ & $\chi^{2}$ & D \\
& & & & & & \\
\hline Workshop/ & D & 6.3 & 93.8 & 319 & 5.306 & .070 \\
conference & AD & 7.0 & 93.0 & & & \\
& BD & 15.0 & 85.0 & & & \\
Personal & D & 3.1 & 96.9 & 319 & 10.053 & .007 \\
study & AD & 6.1 & 93.9 & & & \\
& BD & 16.8 & 83.2 & & & \\
Degree & D & 25.0 & 75.0 & 319 & 1.146 & .564 \\
program & AD & 21.1 & 78.9 & & & \\
& BD & 26.6 & 73.4 & & &
\end{tabular}

Note: Diploma (D), Associate (AD), Baccalaureate (BD), $\underline{\mathrm{df}}=2$ 
Chi-square revealed no significant differences by program type for interest in learning more about intuition (see Appendix B, Chart 4).

In summary, significant differences by program type were found for perception of preparation to teach about intuition and conducting personal studies on intuition. Significantly more baccalaureate and fewer diploma faculty than expected felt adequately prepared to teach about intuition. Significantly more baccalaureate and fewer associate faculty than expected had conducted personal studies on intuition. There were no significant differences by program type for attendance at workshops, learning about intuition in a degree program or for interest in learning more about intuition.

Intuition Attitudes and Demographic Variables

This section includes a discussion of differences on intuition attitudes and the following demographic variables: professional preparation, years in nursing education, and highest academic degree in nursing.

The eighth research question asked, "Do significant differences exist between each demographic variable (age, sex, number of years practicing nursing, years in nursing education, highest academic degree completed in nursing, highest academic degree completed outside nursing, 
geographic location of school of nursing, primary area of teaching responsibility, preparation to teach about intuition) and attitudes about using intuition?"

The ninth research question asked, "Do significant differences exist between each demographic variable and attitudes about including intuition in the undergraduate nursing curriculum? These two research questions were collapsed into one question, "Do significant differences exist between each demographic variable and attitudes about using intuition in nursing and including intuition in the undergraduate nursing curriculum?" The factors created to answer research question \#7 were used as the dependent variables to compute t-tests and analysis of variance with the demographic variables.

\section{Professional Preparation}

The $t$-test was used to test for difference between the group of respondents who had participated in preparation activities and the group who had not and each of the four attitude scales (Table 34). Significant findings were noted for workshop and personal studies on three of the attitude scales value, challenge, and no fear. The group who has attended workshops had a higher mean on three of the four attitude scales toward using and including intuition in the undergraduate nursing curriculum. Faculty who had attended workshops or 
conferences had a significantly higher mean $(\underline{m}=3.50, \underline{t}=$ $4.005, \underline{p} \leq .001$ ) on the value scale compared to a mean of 3.19 for the faculty who had not attended. Faculty who had attended workshops had a significantly higher mean (m $=3.02, \underline{t}=5.994, \underline{\underline{ }} \leq .001$ ) on the challenge scale than the group who had not attended workshops (m $=2.52)$. The group who had attended workshops had a significantly higher mean $(\underline{m}=3.51, \underline{t}=4.454, \underline{\underline{p}} \leq .001)$ on the no fear scale than the group who had not attended workshops (m = 3.20). There was no significant difference between the group means for the support scale although it was noted that the group who had attended workshops had a higher mean $(\underline{m}=2.63, \underline{p} \leq .076)$ than the group who had not attended $(\underline{m}=2.45)$.

Table 34

Intuition Attitudes and Workshop Attendance

\begin{tabular}{|c|c|c|c|c|c|c|}
\hline Attitude & & Yes & No & $\underline{E}$ & $d \underline{f}$ & $\underline{p}$ \\
\hline Value & $\frac{\frac{M}{S D}}{\underline{S}}$ & $\begin{array}{l}3.50 \\
0.49 \\
36\end{array}$ & $\begin{array}{l}3.19 \\
0.42 \\
290\end{array}$ & 4.005 & 324 & .001 \\
\hline Challenge & $\frac{\frac{\bar{M}}{S D}}{\underline{\underline{M}}}$ & $\begin{array}{l}3.02 \\
0.52 \\
36\end{array}$ & $\begin{array}{l}2.52 \\
0.46 \\
288\end{array}$ & 5.994 & 322 & .001 \\
\hline No Fear & $\frac{\frac{\bar{M}}{S D}}{\underline{\underline{S}}}$ & $\begin{array}{l}3.51 \\
0.35 \\
36\end{array}$ & $\begin{array}{l}3.20 \\
0.40 \\
290\end{array}$ & 4.454 & 324 & .001 \\
\hline Support & $\frac{\frac{\bar{M}}{S D}}{\underline{\underline{S}}}$ & $\begin{array}{l}2.63 \\
0.63 \\
35\end{array}$ & $\begin{array}{l}2.45 \\
0.54 \\
280\end{array}$ & 1.781 & 313 & .076 \\
\hline
\end{tabular}


The t-test revealed significant differences between the group of faculty who had conducted personal study of intuition and the group who had not on three of the four attitude scales toward using and including intuition in the nursing curriculum (Table 35).

Table 35

Intuition Attitudes and Personal study

\begin{tabular}{|c|c|c|c|c|c|c|}
\hline Attitude & & Yes & No & $\underline{t}$ & $\underline{\mathrm{df}}$ & D value \\
\hline Value & $\frac{\frac{M}{S D}}{n}$ & $\begin{array}{l}3.50 \\
0.43 \\
38\end{array}$ & $\begin{array}{l}3.19 \\
0.43 \\
288\end{array}$ & 4.174 & 324 & .001 \\
\hline Challenge & $\frac{\frac{\bar{M}}{S D}}{\underline{n}}$ & $\begin{array}{l}3.00 \\
0.55 \\
37\end{array}$ & $\begin{array}{l}2.52 \\
0.46 \\
287\end{array}$ & 5.814 & 322 & .001 \\
\hline No Fear & $\frac{\frac{\bar{M}}{S D}}{n}$ & $\begin{array}{l}3.43 \\
0.41 \\
38\end{array}$ & $\begin{array}{l}3.21 \\
0.40 \\
288\end{array}$ & 3.284 & 324 & .001 \\
\hline Support & $\frac{\bar{M}}{\underline{\underline{S}}}$ & $\begin{array}{l}2.59 \\
0.54 \\
37\end{array}$ & $\begin{array}{l}2.45 \\
0.56 \\
278\end{array}$ & 1.439 & 313 & .151 \\
\hline
\end{tabular}

The group who had conducted personal studies had a significantly higher mean $(\underline{m}=3.50, \underline{t}=4.174, \underline{p} \leq .001)$ for the value scale compared to a mean of 3.19 for the group who had not conducted personal studies (also Table 35). The group who had conducted personal studies had a significantly higher mean $(\underline{m}=3.00, \underline{t}=5.814, \underline{p} \leq .001)$ for the challenge scale compared to a mean of 2.52 for the group who had not conducted personal studies. Faculty who had conducted personal studies had a significantly higher 
mean $(\underline{m}=3.43, \underline{t}=3.284, \underline{\underline{p}} \leq .001)$ for the no fear scale compared to a mean of 3.21 for the faculty who had not conducted personal studies. There was no significant difference in the group means for the support scale though it was noted that the group who conducted personal studies had a higher mean $(\underline{m}=2.59, \underline{\underline{p}} \leq .151)$ than the group who had not conducted personal studies $(\underline{m}=2.45)$.

The $t$-test revealed significant differences between the group who learned about intuition in a degree program and the group who had not on each of the four attitude scales toward using and including intuition in the undergraduate nursing curriculum (Table 36). The group who had learned about intuition in a degree program had a significantly higher mean $(\underline{m}=3.32, \underline{t}=2.342, \underline{p} \leq .020)$ for the value scale compared to a mean of 3.19 for the group who had not learned about intuition in a degree program. The group who had learned about intuition in a degree program had a significantly higher mean $(\underline{m}=2.77$, $\underline{t}=4.132, \underline{\underline{L}} \leq .001$ ) for the challenge scale compared to a mean of 2.51 for the group who had not learned about intuition in a degree program. Faculty who had learned about intuition in a degree program had a significantly higher mean $(\underline{m}=3.34, \underline{t}=2.851, \underline{p} \leq .005)$ for the no fear scale compared to a mean of 3.20 for the faculty who had not learned about it in a degree program. The group 
who had learned about intuition in a degree program had a significantly higher mean $(\underline{m}=2.67, \underline{t}=3.833, \underline{Q} \leq .001)$ for the support scale compared to a mean of 2.40 for the group who had not learned about intuition in a degree program.

Table 36

Intuition Attitudes and Learned About Intuition in Degree Program

\begin{tabular}{|c|c|c|c|c|c|c|}
\hline Attitude & & Yes & No & $\underline{t}$ & $\underline{d f}$ & p value \\
\hline Value & $\frac{\frac{M}{S D}}{n}$ & $\begin{array}{l}3.32 \\
0.45 \\
82\end{array}$ & $\begin{array}{l}3.19 \\
0.44 \\
244\end{array}$ & 2.342 & 324 & .020 \\
\hline Challenge & $\frac{\frac{\underline{M}}{S D}}{\underline{\underline{N}}}$ & $\begin{array}{l}2.77 \\
0.49 \\
82\end{array}$ & $\begin{array}{l}2.51 \\
0.48 \\
242\end{array}$ & 4.132 & 322 & .001 \\
\hline No Fear & $\frac{\frac{M}{M}}{\frac{S D}{n}}$ & $\begin{array}{l}3.34 \\
0.39 \\
82\end{array}$ & $\begin{array}{l}3.20 \\
0.40 \\
244\end{array}$ & 2.851 & 324 & .005 \\
\hline Support & $\frac{\frac{\underline{M}}{S D}}{\underline{\underline{M}}}$ & $\begin{array}{l}2.67 \\
0.54 \\
80\end{array}$ & $\begin{array}{l}2.40 \\
0.55 \\
235\end{array}$ & 3.833 & 313 & .001 \\
\hline
\end{tabular}

The $t$-test results indicate a significant difference between the group who were interested in learning more about intuition and the group who was not interested on each of the four attitude scales toward using and including intuition in the undergraduate nursing curriculum (Table 37). The group who were interested in 
Table 37

Intuition Attitudes and Interest in Learning More

\begin{tabular}{|c|c|c|c|c|c|c|}
\hline Attitude & & Yes & No & $\underline{t}$ & $\underline{\mathrm{df}}$ & p value \\
\hline Value & $\frac{M}{S D}$ & $\begin{array}{l}3.29 \\
0.41 \\
266\end{array}$ & $\begin{array}{l}2.91 \\
0.46 \\
57\end{array}$ & 6.309 & 321 & .001 \\
\hline Challenge & $\frac{\frac{\underline{M}}{\mathrm{M} D}}{\underline{\underline{S}}}$ & $\begin{array}{l}2.63 \\
0.49 \\
265\end{array}$ & $\begin{array}{l}2.34 \\
0.40 \\
56\end{array}$ & 4.196 & 319 & .001 \\
\hline No Fear & $\frac{\frac{\underline{M}}{S D}}{\underline{\underline{S}}}$ & $\begin{array}{l}3.28 \\
0.39 \\
266\end{array}$ & $\begin{array}{l}3.05 \\
0.38 \\
57\end{array}$ & 4.114 & 321 & .001 \\
\hline Support & $\frac{\frac{\bar{M}}{\underline{S} D}}{\underline{n}}$ & $\begin{array}{l}2.51 \\
0.56 \\
262\end{array}$ & $\begin{array}{l}2.27 \\
0.46 \\
50\end{array}$ & 3.233 & 80.03 & .002 \\
\hline
\end{tabular}

learning more had a significantly higher mean ( $\underline{m}=3.29, \underline{t}$ $=6.309, \underline{\mathrm{D}} \leq .001$ ) for the value scale compared to a mean of 2.91 for the group who were not interested in learning more about intuition. The group interested in learning more about intuition had a significantly higher mean (m = $2.63, \underline{t}=4.196, \underline{\underline{D}} \leq .001$ ) for the challenge scale compared to a mean of 2.34 for the group not interested in learning more about intuition. Faculty interested in learning more about intuition had a significantly higher mean $(\underline{m}=3.28, \underline{t}=4.114, \underline{\underline{p}} \leq .001)$ for the no fear scale compared to a mean of 3.05 for the faculty not interested in learning more about intuition. The group interested in 
learning more about intuition had a significantly higher mean $(\underline{m}=2.51, \underline{t}=3.233, \underline{\underline{a}} \leq .005)$ for the support scale compared to a mean of 2.27 for the group not interested in learning more about intuition.

\section{Years in Nursing Education}

Respondents were grouped on years in nursing education, using seven year increments, 7 or less, 8-14, 15-21, 22-28, 29 or more years in nursing education. Analysis of variance was used to test for differences in the groups on the four attitude scales (Table 38 ). The results show a significant difference on two attitude scales, value $(\underline{F}=3.711 ; \underline{p} \leq .001)$ and years in nursing education, and challenge and years in nursing education $(\underline{F}=3.715 ; \underline{D} \leq .001)$. Post hoc Bonferroni was done to test for the specific difference. Faculty who have been teaching 30 or more years had a significantly lower mean (2.98) on the value scale than faculty teaching seven or less years $(\underline{m}=3.27, \underline{Q} \leq .043)$ and faculty teaching 8-14 years $(\underline{m}=3.32, \underline{\underline{x}} \leq .002)$. The mean difference was significant at the .05 level. These findings suggest that the newer nurse educators place a higher value on intuition than educators approaching retirement. Faculty with 8-14 years in nursing education placed the highest value on intuition. 
Table 38

Intuition Attitudes and Years in Nursing Education

\begin{tabular}{ll}
\hline Attitude & Mean \\
& \\
\hline & \\
Value & \\
Years NED Group \\
\hline 1. $\quad 8 \quad 8$ & 3.27 \\
2. $8-14$ & 3.32 \\
$3 . \quad 15-21$ & 3.21 \\
4. $\quad 22-28$ & 3.23 \\
$5 . \quad 28+$ & 2.98
\end{tabular}

Challenge

Years NED Group

$\begin{array}{ll}\text { 1. }<8 & 2.57\end{array}$

2. $8-14 \quad 2.75$

3. $15-21 \quad 2.53$

4. $22-28 \quad 2.59$

5. $28+2.39$

No Fear
Years NED Group

$\begin{array}{lll}\text { 1. } & <8 & 3.25 \\ 2 . & 8-14 & 3.23 \\ 3 . & 15-21 & 3.19 \\ 4 . & 22-28 & 3.30 \\ 5 . & 28+ & 3.11\end{array}$

$\begin{array}{lllll}321 & 3.711 & .006 & 1 \& 5,2 \& 5\end{array}$

Post Hoc

Bonferroni

Support $\quad 310 \quad 1.367 \quad .245$

Years NED Group

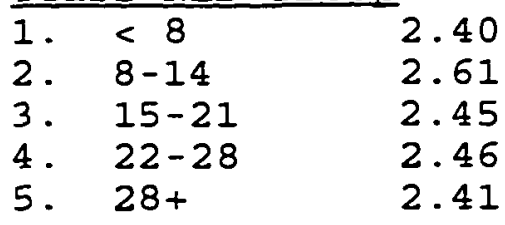

Note: $\mathrm{NED}=$ Nursing education, $4.00=$ Strongly Agree; $1.00=$ strongly Disagree; ${ }^{\star} \underline{\underline{L}} \leq .05$

Faculty who have been teaching 8-14 years had a significantly higher mean (2.75) on the challenge scale 
than faculty teaching 15-21 years $(\underline{m}=2.53, \underline{\mathrm{p}} \leq .037)$ and faculty teaching 30 or more years $(\underline{m}=2.39, \underline{p} \leq .004)$. The mean difference was significant at the $\underline{\underline{ }} \leq .05$ level. These findings suggest that nursing faculty with 8-14 years teaching experience see the challenge of including intuition in the undergraduate nursing curriculum as "doable".

Highest Academic Degree in Nursing

The $t$-test was used to test for difference in intuition attitudes and highest degree completed in nursing (Table 39). Results show a significant difference between the master's and doctoral prepared faculty on three of the four attitude scales. Doctoral prepared faculty had a significantly higher mean $(\underline{m}=3.35, \underline{t}=$ $2.762, \underline{p} \leq .006)$ on the value scale than the group with a master's degree $(\underline{m}=3.18)$. The group with a doctorate had a significantly higher mean $(\underline{m}=2.71, \underline{t}=2.698$, $\underline{\underline{ }} \leq$ $.007)$ on the challenge scale than the group with a master's $(\underline{m}=2.53)$. Doctoral prepared faculty also had a significantly higher mean $(\underline{m}=3.35, \underline{t}=2.839, \underline{p} \leq .005)$ on the no fear scale than the master prepared faculty (m $=$ 3.20). There was no significant difference between the two groups on the support scale although the mean was higher for doctoral prepared faculty. 
Table 39

Intuition Attitudes and Degree in Nursing

\begin{tabular}{|c|c|c|c|c|c|}
\hline Attitude & Doctorate & Master & $\underline{t}$ & $\underline{d f}$ & D value \\
\hline Value & $\begin{array}{ll}\underline{M} & 3.35 \\
\underline{S D} & 0.45 \\
\underline{n} & 72\end{array}$ & $\begin{array}{l}3.18 \\
0.45 \\
238\end{array}$ & 2.762 & 308 & .006 \\
\hline Challenge & $\begin{array}{ll}\frac{\mathrm{M}}{\mathrm{S}} & 2.71 \\
\mathrm{SD} & 0.45 \\
\mathrm{n} & 72\end{array}$ & $\begin{array}{l}2.54 \\
0.51 \\
236\end{array}$ & 2.698 & 306 & .007 \\
\hline No Fear & $\begin{array}{ll}\underline{\bar{M}} & 3.35 \\
\frac{S D}{n} & 0.40 \\
\underline{n} & 72\end{array}$ & $\begin{array}{l}3.20 \\
0.41 \\
238\end{array}$ & 2.839 & 308 & .005 \\
\hline Support & $\begin{array}{ll}\underline{\bar{M}} & 2.52 \\
\underline{S D} & 0.59 \\
\underline{\underline{n}} & 70\end{array}$ & $\begin{array}{l}2.46 \\
0.55 \\
229\end{array}$ & 0.810 & 297 & .418 \\
\hline
\end{tabular}

\section{other Variables}

No significant differences in the four intuition attitude scales were found with the independent variables of age, sex, years practicing nursing, highest academic degree outside of nursing, NLN region, and primary area of teaching responsibility (Appendix B, Charts 5-10).

\section{Summary}

In summary, there were significant differences on intuition attitude scales for professional preparation. The group of respondents who had attended workshops had higher means for the value, challenge and no fear scales than the group who had not. The group of faculty who had 
conducted personal studies had a higher mean on the value, challenge and no fear scales. The group of respondents who learned about intuition in a degree program had significantly higher means on each of the four intuition attitude scales, value, challenge, no fear, and support than respondents who did not learn about intuition in a degree program. Respondents who were interested in learning more about intuition had a significantly higher mean on each of the four attitude scales than respondents who were not interested in learning more about intuition. There were significant differences on two attitude scales, value and challenge, and years in nursing education. Faculty with a doctorate in nursing had significantly higher means on three of the four attitude scales, value, challenge, and no fear than faculty with a master degree. There were no significant differences on the intuition attitude scales and age, sex, years practicing nursing, highest degree outside of nursing, NLN region, and primary teaching responsibility.

\section{Narrative Responses}

\section{Intuition Attitudes and}

\section{Narratives}

An analysis was done to see if there was a difference between the group of respondents who wrote a narrative response to survey question \#9, 24, or 28 and the group 
who did not respond. The $t$-test revealed a significant difference on two of the attitude scales, value and no fear (Table 40). The value mean for the group who wrote a response was $3.25(\underline{t}=2.434$, $\underline{\underline{s}} \leq .015)$ compared to 3.11 for the group who did not write a response. The no fear mean for the group who wrote a response was 3.26 ( $\underline{t}=$ $2.323, \underline{\mathrm{D}} \leq .021)$ compared to 3.14 for the group who did not write a response. These findings suggest that faculty who wrote a narrative response placed a higher value on intuition and consider it to be a reasonable risk in undergraduate nursing education.

Table 40

Intuition Attitudes and Narrative Responses

\begin{tabular}{|c|c|c|c|c|c|c|}
\hline Attitude & & Yes & No & $\underline{t}$ & $\underline{\mathrm{df}}$ & D value \\
\hline$\overline{\text { Value }}$ & $\frac{\underline{M}}{\underline{S D}}$ & $\begin{array}{l}3.25 \\
0.46 \\
249\end{array}$ & $\begin{array}{l}3.11 \\
0.43 \\
81\end{array}$ & 2.434 & 328 & .015 \\
\hline Challenge & $\frac{\frac{M}{S D}}{\underline{\underline{n}}}$ & $\begin{array}{l}2.60 \\
0.51 \\
247\end{array}$ & $\begin{array}{l}2.49 \\
0.41 \\
81\end{array}$ & 1.839 & 326 & .067 \\
\hline No Fear & $\frac{\frac{M}{S D}}{\underline{n}}$ & $\begin{array}{l}3.26 \\
0.41 \\
249\end{array}$ & $\begin{array}{l}3.14 \\
0.37 \\
81\end{array}$ & 2.323 & 328 & .021 \\
\hline Support & $\frac{\frac{M}{S D}}{\underline{\mathrm{n}}}$ & $\begin{array}{l}2.49 \\
0.57 \\
239\end{array}$ & $\begin{array}{l}2.38 \\
0.45 \\
80\end{array}$ & 1.765 & 174.23 & .079 \\
\hline
\end{tabular}


Other Variables

Chi-square tests revealed no significant differences between the group who wrote a narrative response to survey question \#9, 24, or 28 and the variables age, years practicing nursing, years in nursing education, higher degree in nursing, highest degree outside nursing, NLN region, program type, and primary area of teaching responsibility. 
CHAPTER V

DISCUSSION AND RECOMMENDATIONS

Introduction

The findings of this descriptive research study provide some understanding of National League for Nursing (NLN) faculty members' intuition attitudes, attitudes toward including intuition in the undergraduate nursing curriculum, inclusion of intuition in the current curricula, practices related to development and teaching of intuition, and preparation for teaching about intuition. The main themes are presented in the first part of the chapter, followed by a discussion of the implications for the nursing education profession. The chapter concludes with suggestions for future research.

\section{Main Themes}

Six main themes were extracted from the findings: (a) value of intuition, (b) concerns, (c) ways of knowing in nursing, (d) including intuition, (e) professional development, and (E) strategies. 
Value of Intuition

The majority of nursing faculty in this study value intuition and recognize it as integral to effective nursing practice. Results of t-tests revealed that faculty teaching in baccalaureate programs and faculty with a doctorate in nursing placed a higher value on intuition and also considered intuition to be a realistic challenge for undergraduate educators. These respondents felt more support to include intuition than faculty from associate programs and master prepared faculty. These findings are somewhat difficult to interpret. A partial explanation may be that faculty in baccalaureate programs do not feel the same time pressure as faculty in two year programs and therefore may be more open to including it. Doctorate prepared faculty may be more willing to risk innovative teaching practices than faculty with master preparation and faculty who perceive less support.

\section{Concerns}

Respondents expressed attitudes of concern about including intuition while supporting the concept that intuition is important and appropriate to include in the undergraduate nursing curriculum. The concerns involve perceptions of being unprepared to teach about intuition, difficulties with evaluation of intuition, and feeling that they will not have the support of their nursing 
colleagues, colleagues in other disciplines and administrators. The finding regarding support reflects the literature on barriers to intuition (Rew, 1991). The concern about support was true regardless of program type. Concerns about preparation and evaluation were more evident in responses from faculty teaching in associate programs. Narrative statements from respondents illustrate these concerns in comments about lacking the necessary skill to teach intuition, feeling unprepared, describing intuition as unmeasurable and unscientific, and feeling a lack of support from peers and administrators. In addition, narratives listed lack of time as a reason for not including intuition. Faculty in associate programs cited time as a factor as well as the belief that other content was more important than including intuition. The nursing education profession and the accrediting agencies need to decide if 2 year associate programs can prepare students for safe nursing practice without including development of the intuitive way of knowing. The profession must also decide whether baccalaureate programs should be held accountable for including development of personal knowing including the intuitive way of knowing for entry into practice. 
Ways of knowing in Nursing

For decades nursing has relied on the rational scientific way of knowing to the exclusion of other ways of knowing. Carper (1980) has argued that nursing education needs to address four distinct patterns of knowing: (a) empirics, (b) esthetics, (c) personal knowledge which includes intuition, and (d) ethics. Each of the four patterns of knowing are necessary to the understanding and practice of nursing. Personal knowledge is essential to understanding the meaning of health from the client's perspective. Nurses as healers, need to connect with the client, and "get in" however they can, to engage in activities which promote health and wellness. Healers will be better practitioners if they learn to incorporate intuitive knowledge as well as other ways of knowing into their practice.

The findings of this study suggest that nursing faculty are beginning to include intuitive knowing in the undergraduate nursing curriculum. However, this way of knowing continues to receive less than adequate attention in undergraduate nursing education.

\section{Including Intuition}

Intuition is currently included in the undergraduate curriculum by $30 \%$ of respondents on a limited basis. Narrative responses help understand faculty decisions 
regarding including intuition. It appears that the decision to include intuition is relatively complex, involving more than one factor. Preparation, support from colleagues in nursing, academic degree, and program type all influence the decision as do attitudes regarding the value, challenge and perceived risks of including intuition. The data from this study are insufficient to determine the nature of the decision and its complexity.

\section{Professional Development}

The majority of nursing faculty perceived themselves to be inadequately prepared to teach about intuition in nursing. Fewer than one quarter of respondents had participated in professional development preparation to teach intuition. There was a significant relationship between professional preparation to teach about intuition and faculty perception of adequacy to teach about intuition. More than two thirds of respondents who engaged in professional preparation about intuition perceived themselves to be adequately prepared to teach about intuition. In addition, the majority of respondents expressed the desire to learn more about intuition. Narrative responses indicate that some faculty would like to include intuition in their teaching but feel unprepared to do so. These findings suggest that nursing faculty are open to learning more about the intuitive way of knowing 
and that nursing education must plan for faculty development in this area.

\section{Strateqies}

Faculty used many strategies to develop their own and student intuition. However, the strategies universally recommended by writers on intuition development (guided imagery and meditation) are the strategies used by the least faculty. Guided imagery and short meditation exercises could be easily incorporated into students' educational experiences. Use of these strategies may lead to rapid understanding of how intuition works. Students could be encouraged to continue the practice of meditation in their personal lives. Schools of nursing could develop paracurricular courses on meditation and guided imagery for interested students. In addition, nursing programs could create a space for reflection within the class schedule.

\section{Recommendations}

In view of this study's results, I have formulated the following four recommendations to the community of nursing educators.

Recommendation one: Dialogue regarding intuition in nursing education should be promoted by the National League for Nursing. Sponsoring this dialogue by the NLN 
could help to alleviate any existing bias among nurse educators regarding the value of the intuitive way of knowing in nursing. This dialogue could begin in the NLN councils and should move beyond definitions of intuition to questions regarding implementation, preparation and support. For example, the Council of Associate Degree Programs (CADP), Council of Baccalaureate and Higher Degree Programs (CBHDP), and the Council of Diploma Programs (CDP) could address intuition separately and make recommendations for nursing education. In addition, the Council for Research in Nursing Education (CRNE) could examine the issue of the need for more research on intuition in undergraduate nursing education.

Recommendation two: Professional development about intuition, and teaching to the intuitive way of knowing, should be sponsored by the National League for Nursing. The NLN could invite speakers and expert practitioners of intuition to the NLN convention or to conferences and workshops sponsored by the league each year. Schools of nursing could invest professional development dollars in intuition development for faculty.

Recommendation three: The NLN could sponsor a listserv for faculty interested in promoting intuition in undergraduate nursing education. Resources on intuitive development could be compiled and shared among 
participants. Effective practices could also be shared. The listserv should be moderated to ensure appropriate use and communications among participants. The American Association for Higher Education (AAHE) listserv on technology and higher education is an example of a moderated Iistserv that could serve as a model for the NLN .

Recommendation four: Faculty are encouraged to dialogue with nurses in all areas of nursing practice so that changes in nursing education related to intuitive development are congruent with the realities of nursing practice.

\section{Future Research}

The data from this study suggests several areas for future research:

1. Use a research population of accredited undergraduate schools of nursing to obtain information regarding the reliability of the study.

2. Include more qualitative research to obtain in depth understanding of nursing faculty attitudes about including intuition in the undergraduate nursing curriculum.

3. Systematically investigate what and how faculty are teaching about the intuitive way of knowing in nursing 
courses. A followup study of respondents in this study who indicated a willingness to participate in a phone interview about intuition could be a productive next step.

4. Explore intuition education programs in which nursing faculty participate. Specifically, identify the kinds of programs faculty find useful for intuitive development.

5. Conduct research that continues to explore the implementation of intuition in undergraduate nursing education. This could involve a joint study with nurse educators and practicing nurses who work with nursing students.

6. Compare intuition attitudes of NLN faculty, undergraduate nursing students, and practicing nurses.

7. Explore the usefulness of including intuitive thinking as a component of critical thinking.

\section{Conclusion}

Including the intuitive way of knowing in undergraduate nursing education is recommended in the nursing literature (Benner \& Tanner, 1987; Bevis \& Watson 1989; Gerrity, 1987; and Rew, 1986). This descriptive study was designed to provide data on faculty attitudes, practices, and preparation related to intuition in 
undergraduate nursing programs which is currently not available in the literature.

Findings indicate that intuition is valued as an important way of knowing and essential to effective nursing practice. Intuition is considered appropriate to include in the curriculum and may result in better preparation of students for the practice of nursing. Intuition is currently included on a limited bases and the decision to include it appears to be complex involving several variables in addition to faculty preparation. Faculty use numerous strategies to develop their own and student intuition. The majority rate the strategies effective. Faculty express interest in learning more about intuition and the relevance to nursing practice. This study provides a broad overview of intuition in the undergraduate nursing curriculum. Further research is needed to obtain an in depth understanding of intuition and the implementation of intuition in nursing education programs. However, an important first step has been taken. 
Agan, D. R. (1987). Intuitive knowing as a dimension of nursing. Advances in Nursing Science, 10(1), 63-70.

Agor, W. H. (1984). Intuitive management: Integrating left and right brain management skills. Englewood Cliffs, NJ: Prentice-Hall.

Agor, W. H. (1985). Intuition as a brain skill in management, Public Personnel Management Journal, $14(1), 15-24$.

Agor, W. H. (1986a). The logic of intuition: How top executives make important decisions. Organizational Dynamics, 14 (3), 5-18.

Agor, W. H. (1986b). The logic of intuitive decision making: A research-based approach for top management. New York: Quorum.

Agor, W. H. (1989). Intuition in organizations: Leading and managing productively. Newbury Park, CA: Sage Publications, Inc.

Bastick, T. (1982). Intuition: How we think and act. New York: John Wiley \& Sons.

Belenkey, M. F., Clinchy, B. M., Goldberger, N. R., \& Tarule, J.M. (1986). Women's ways of knowing: The development of self, voice and mind. New York: Basic Books.

Benner, P. (1984). From novice to expert: Excellence and power in clinical nursing practice. Menlo Park, CA: Addison-Wesley.

Benner, P., \& Tanner, C. (1987). How expert nurses use intuition. American Journal of Nursing, 87(1), $23-31$.

Benner, P., \& Wrubel, J. (1989). The primacy of caring, stress and coping in health and illness. Menlo Park, CA: Addison-Wesley. 
Berne, E. (1949, April). The nature of intuition. Psychiatric ouarterly, 23, 203-226.

Berne, E. (1962, April). Intuition VI: The psychodynamics of intuition. Psychiatric Quarterly, $\underline{36}, 294-300$.

Berne, E. (1977). Intuition and ego states. New York: Harper \& Row.

Bevis, E. O. \& Watson, J. (1989). Toward a caring curriculum: A new pedagogy for nursing. New York: National League for Nursing.

Bruner, J. (1966). The process of education. Cambridge: Harvard University Press.

Bruner, J., \& Clinchy, B. (1971). Toward a disciplined intuition. In A. Gil (Ed.), The relevance of education (pp. 82-97). New York: W.W. Norton.

Blomquist, K. (1985). Evaluation of students: Intuition is important. Nurse Educator, 10(6), 8-11.

Carper, B. A. (1980). Fundamental patterns of knowing in nursing. Advances in Nursing Science, $1(1), 13-23$.

Carroll, E. (1988). The role of tacit knowledge in problem solving in the clinical setting. Nurse Education Today, $\underline{8}(3), 140-147$.

Chinen, A. B., Spielvogel, A. M., \& Farrell, D. (1985, Fall). The experience of intuition. Psychological Perspectives, 16 (2), 186-197.

Clinchy, B. (1975, March-April). The role of intuition in learning. Today's Education, $\underline{64}(2), 48-51$.

Correnti, D. (1992). Intuition and nursing practice implications for nurse educators: A review of the literature. The Joumal of Continuing Education in Nursing, $23(2), 91-94$.

Dreyfus, H., \& Dreyfus, S. (1986). Mind over machine: The power of human intuition and expertise in the era of the computer. New York: Free Press.

Eisner, E. (1985). The educational imagination (2nd ed.). New York: Macmillan. 
Emery, M. (1994). Intuition workbook: An expert's quide to unlocking the wisdom of your subconscious mind. Englewood Cliffs, NJ: Prentice Hall.

Gerrity, P. L. (1987). Perception in nursing: The value of intuition. Holistic Nursing Practice, $1(3)$, $63-71$.

Goldberg, P. (1983). The intuitive edge. Los Angeles: Tarcher.

Green, S.B., Salkind, N.J., \& Akey, T.M. (1997). Using SPSS for windows: Analyzing and understanding data. Upper Saddle River, NJ: Prentice Hall.

Hamm, R. M. (1988). Clinical intuition and clinical analysis: Expertise and the cognitive continuum. In J. Dotvie \& A. Elstein (Eds.), Professional judoment: a reader in clinical decision making, (pp. 78-105).

Hampton, D. C. (1994). Expertise: The true essence of nursing art. Advances in Nursing Science, 17 (I), 15-24.

Isherwood, R. T. (1995). The curriculum revolution in nursing education. In A. Boykin (Ed.), Power, politics, and public policy: A matter of caring, (pp. 165-169). New York: National League for Nursing Press (Pub. No. 14-2684).

Johnson J. (1991). Nursing science: basic, applied, or practical? Implications for the art of nursing. Advances in Nursing Science, 14 (1), 7-16.

Jung, C. G. (1962). Psychological types. Eleventh impression. Translated by H. J. Baynes. Great Britain, Pantheon Books.

Kenny, C. (1994). Nursing intuition: Can it be researched? British Journal of Nursing, 3 (22), 1191-1195.

Leners, D. W. (1992). Intuition in nursing practice: Deep connections. Journal of Holistic Nursing, I0 (2), 137-153.

Leners, D. W. (1993). Nursing intuition: The deep connection. In D.A. Gaut (Ed.), A global agenda for caring, (pp. 223-240). New York: National League for Nursing Press (Pub. No. 15-2518). 
Loomis, M. (1982). A new perspective for Jung's typology. Journal of Analytical Psychology, 27 (1), 59-69.

Loye, D. (1983). The sphinx and the rainbow (42-53). Boulder, CO: Shambhala Publications, Inc.

Macdonald, D. A., \& Holland, C. J. (1993). Psychometric evaluation of the Singer-Loomis Inventory of Personality. Journal of Analytical Psychology, $\underline{38}(3), 303-320$.

McCormack, B. (1992). Intuition: Concept analysis and application to curriculum development. I. Concept analysis. Journal of Clinical Nursing, 1 (6), 339-344.

McCormack, B. (1993). Intuition: Concept analysis and application to curriculum development. II. Application to curriculum development. Journal of Clinical Nursing, $\underline{2}(1), 11-17$.

McMurray, A. (1989). Time to extend the "process"? The Australian Journal of Nursing, $\underline{6}(4), 40-43$.

Miller, V. G. (1993, October). Measurement of selfperception of intuitiveness. Western Journal of Nursing Research, 15(5), 595-606.

Miller, V. G. (1995, June). Characteristics of intuitive nurses. Western Journal of Nursing Research, 17(3), 305-316.

Miller, V. G., \& Rew, L. (1989). Analysis and intuition: The need for both in nursing education. Journal of Nursing Education, $28(2), 84-86$.

Moch, S. D. (1990, Summer). Personal knowing: Evolving research and practice. Scholarly Inquiry for Nursing Practice, $\underline{4}(2), 155-165$.

Morse, J. M., Miles, M. W., Clark, D. A., \& Doberneck, B. (1994). "Sensing" patient needs: Exploring concepts of nursing insight and receptivity used in nursing assessment. Scholarly Inquiry for Nursing Practice, $\underline{8}(3), 233-254$. 
Myers, P., \& Myers, K. (1980). Gifts differing. Palo Alto, CA: Consulting Psychologists Press.

Myers, P., \& Myers, K. (1985). Manual: A quide to the development and use of the Myers-Briggs Type Indicator. Palo Alto, CA: Consulting Psychologists Press.

National League for Nursing. (1992, October). An agenda for nursing education reform: In support of nursing's agenda for health care reform. New York: National League for Nursing.

National League for Nursing. (1995, March). National league for nursing strategic plan: 1995-2000. New York: Author.

National League for Nursing. (1996a). Criteria and guidelines for the evaluation of baccalaureate and higher degree programs in nursing. New York: National League for Nursing Press.

National League for Nursing. (1996b). Nurse educators 1995: Findings from the RN and LPN faculty census. New York: National League for Nursing Press.

National League for Nursing. (1997, March/April). Nursing \& Health Care: Perspectives on Community, $\underline{18}(2)$, p. 58 .

National League for Nursing Accrediting Commission. (1997a). Interpretive guidelines for standards and criteria 1997 revised: Associate degree programs in nursing. New York: Author.

National League for Nursing Accrediting Commission. (1997b). Interpretive quidelines for standards and criteria 1997 revised: Diploma programs in nursing. New York: Author.

Neufeldt, V. (Ed.). (1996). Webster's new world college dictionary. New York: Macmillan.

Noddings, N., \& Shore, P. (1984). Awakening the inner eye: Intuition in education. New York: Teachers' College Press.

Parse, R. R. (1988). The mainstream of science: Framing the issue. Nursing science Quarterly, 1 (3), 93 . 
Paul, R. W., \& Heaslip, P. (1995). Critical thinking and intuitive nursing practice. Journal of Advanced Nursing, $\underline{22}(1), 40-47$.

Polanyi, M. (1966). The tacit dimension. New York: Anchor Press.

Polanyi, M. (1968). Logic and psychology. American Psychologist, 23(1), 27-43.

Polanyi, M. (1969). The unaccountable element in science. In M. Grene (Ed.), knowing and being (pp. 105-120). Chicago: The University of Chicago Press.

Polge, J. (1995). Critical thinking: The use of intuition in making clinical nursing judgments. Journal of the New York state Nurses Association, $\underline{26}(2), 4-9$.

Pyles, S. H., \& Stern, P. N. (1983). Discovery of nursing Gestalt in critical care nursing: The importance of the gray gorilla syndrome. Image: Journal of Nursing Scholarship, 15, 51-57.

Rew, I. (1986). Intuition: Concept analysis of a group phenomenon. Advances in Nursing Science, $\underline{8}(2)$, $21-28$.

Rew, I. (1987). Nursing intuition: Too powerful - and too valuable to ignore. Nursing $187, \underline{83}(7), 43-45$.

Rew, I. (1988a). Intuition in decision-making. IMAGE: Journal of Nursing Scholarship, 20 (3), 150-154.

Rew, L. (1988b). Nurses' intuition. Applied Nursing Research, 1(1), 27-31.

Rew, L. (1989). Intuition: Nursing knowledge and the spiritual dimension of persons. Holistic Nursing Practice, $3(3), 56-68$.

Rew, I. (1990). Intuition in critical care nursing practice. Dimensions of Critical Care Nursing, $\underline{9}(1), 30-37$.

Rew, L. (1991). Intuition in psychiatric-mental health nursing. Journal of Child and Adolescent Psychiatric and Mental Health Nursing, $4(3), 110-115$. 
Rew, L. (1994). Response to "sensing" patient needs: Exploring concepts of nursing insight and receptivity used in nursing assessment. Scholarly Inquiry for Nursing Practice, $\underline{8}(3), 255-260$.

Rew, L., Agor, W., Emery, M. R., \& Harper, S. C. (1991, Summer). Intuitive skills in crisis management. Nursing Connections, $4(2), 3-12$.

Rew, L., \& Barrow, E. M. (1987). Intuition: A neglected hallmark of nursing knowledge. Advances in Nursing Science, 10 (1), 49-62.

Rew, L., \& Barrow, E. M. (1989). Nurses' intuition: Can it coexist with the nursing process? AORN Journal, $\underline{50}(2), 353-358$.

Rockenstein, Z. (1988). Intuitive processes in executive decision making. The Journal of Creative Behavior, $\underline{22}(2), 77-84$.

Rowan, R. (1986). The intuitive manager. Boston, MA: Little, Brown and Company.

Salk, J. (1983). Anatomy of reality: Merging of intuition and reason. New York: Columbia University Press.

Schraeder, B. D., \& Fischer, D. K. (1987). Using intuitive knowledge in the neonatal intensive care nursery. Holistic Nursing Practice, $1(3), 45-51$.

Siebert, A. (1994). The survivor personality. Portland, OR: Practical Psychology Press.

SPSS. (1996). Statistical program for the social sciences (SPSS 7.5 for Windows). Chicago, II: Author.

Tanner, C. A., Benner, P., Chesla, C., \& Gordon, D. R. (1993). The phenomenology of knowing the patient. Image: Journal of Nursing Scholarship, 25 (4), $273-280$.

Vaughn, F. E. (1979). Awakening intuition. Garden City, NY: Doubleday, Anchor Books.

Wallas, G. (1926). The art of thought. New York: Harcourt Brace. 
Wallas, G. (1976). Stages in the creative process. In A. Roghenburg, \& C. R. Housman (Ed.), The creativity question (pp. 69-73). Durham, NC: Duke University Press.

Westcott, M. (1961). On the measurement of intuitive leaps. Psychological Reports, 9, 267-274.

Westcott, M. (1968). Toward a contemporary psychology of intuition. New York: Holt, Rinehart \& Winston.

Young, C. E. (1987). Intuition and nursing process. Holistic Nursing Practice, $1(3), 52-62$. 
APPENDIX A

INTUITION SURVEY 


\section{INTUITION SURVEY}

For this survey, intuition is defined as an immediate way of knowing without being able to articulate how one knows. It is knowing without the conscious use of reasoning. It is also described as a "gut feeling," "sixth sense," "ability to anticipate," or "recognize the possibilities in any situation."

I. INTUITION ATTITUDES

For each of the following items please check the circle that reflects your attitude towards using intuition.
$S A=$ strongly agree
$A$ = agree
$D=$ disagree
$S D=$ strongly disagree

$S A$ A D SD

1. Intuition is an important way of knowing. $0 \quad 0 \quad 0 \quad 0$

2. My intuition is important to me. $0 \quad 0 \quad 0 \quad 0$

3. I find intuition to be an uncomfortable $0 \quad 0 \quad 0 \quad 0$ subject.

4. I use intuition in my nursing practice. $0 \quad 0 \quad 0 \quad 0$

5. Intuition makes me a more effective 00000 nurse.

6. Intuition is not as important as $\quad 0 \quad 0 \quad 0 \quad 0$ rational thinking.

7. Intuition is nothing more than "sloppy" $0 \quad 0 \quad 0 \quad 0$ thinking.

8. Intuition helps me make better decisions $0 \quad 0 \quad 0 \quad 0$ than use of rational processes alone.

9. If you can identify experiences that helped shape your attitudes toward using intuition in nursing please describe: 


\section{ATTITUDES ABOUT INCLUDING INTUITION}

For each of the following items please check the circle that reflects your attitude towards including intuition in the undergraduate nursing curriculum.

$$
\begin{array}{ll}
\mathrm{SA}=\text { strongly agree } & \mathrm{D}=\text { disagree } \\
\mathrm{A}=\text { agree } & \mathrm{SD}=\text { strongly disagree }
\end{array}
$$

10. It would be inappropriate to include

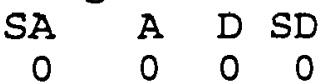
intuition in the undergraduate curriculum.

11. Developing an awareness of intuition is $0 \quad 0 \quad 0 \quad 0$ important in the undergraduate nursing curriculum.

12. Because intuition is a skill of the expert nurse, it should not be included in the undergraduate curriculum.

13. Students may be better prepared for nursing practice by including intuitive content in the curriculum.

14. Intuition is difficult to define clearly, $0 \quad 0 \quad 0 \quad 0$ making it a hard concept to include in the curriculum.

15. I feel that I have adequate professional $0 \quad 0 \quad 0 \quad 0$ preparation to teach about intuition.

16. Because it is hard to "catch a student $0 \quad 0 \quad 0 \quad 0$ in the act" of using intuition, it is hard to evaluate intuitive development.

17. Including intuition in the undergraduate $0 \quad 0 \quad 0 \quad 0$ curriculum may infringe on student's right to religious freedom.

18. I feel concern that students may make $0 \quad 0 \quad 0 \quad 0$ serious errors in patient care when they use their intuition.

19. My nursing colleagues would support the $0 \quad 0 \quad 0 \quad 0$ inclusion of intuition in the nursing curriculum.

20. I anticipate support from my administrators for including intuition in the nursing curriculum.

21. Most of my colleagues in other disciplines would not support the inclusion of intuition in the nursing curriculum.

22. Including intuition in the nursing curriculum places the profession at risk of being viewed as unscientific, resulting in lower status.

23. I do not have time to include intuition $0 \quad 0 \quad 0 \quad 0$ in my undergraduate teaching. 
24. If you can identify experiences that helped shape your attitudes toward including intuition in your teaching please describe:

III. INTUITION IN CURRENT CURRICULA

25. Is the intuitive way of knowing addressed in the philosophy of your school of nursing?

yes no

26. Are there specific educational objectives related to the development of intuition in any undergraduate nursing course that you teach?

yes no

27. During the 1997-98 academic year, are you (or will you be) teaching anything about intuition in any nursing course in your undergraduate curriculum?

yes no

28. Please describe your reason(s) for including or not including intuition in your undergraduate teaching:

29. If your answer to question \#27 is yes, please provide the following information about the undergraduate nursing course in which you address intuition.

a. Course title:

b. How many credits is this course? \# credits quarter

c. Is this a required course?

yes

semester

d. Approximately how much time do you devote to teaching or developing intuition in this course?

$<1$ hr. 1-2 hrs. 3-4 hrs. $>4$ hrs.

e. How is intuition presented in this course (check all that apply)

- assignments discussion

- classroom activities media readings other (specify) 
IV. INTUITIVE DEVELORMENT

Developing your own intuition:

30. Which of the following strategies, if any, have you

used to develop your intuition? (circle yes or no)

For each strategy that you have used, indicate how

effective you think it is. (check the appropriate circle)

$\mathrm{EXT}=$ extremely effective, MOD = moderately effective,

SOM = somewhat effective,

NOT = not effective

STRATEGY

A. Beconing familiar with definitions and terms related to intuition.

B. Accepting more than one way of thinking and knowing.

C. Examining the structure of knowledge and how it links to other knowledge.

D. Valuing intuitive skills in nursing.

E. Paying attention to your inner voice.

F. Becoming aware of gut reactions.

$G$. Observing nurses model intuition.

H. Validating intuition with experienced nurses.

I. Seeking positive reinforcement for using intuition.

J. Engaging in creative activities.

$\mathrm{K}$. Becoming aware of using intuition.

L. Using narrative story telling of intuitive nursing care.

M. Practicing meditation.

N. Using nursing case studies.

0 . Working with nurse preceptors to promote dialogue about intuition.

P. Taking the client's perspective.

Q. Becoming quiet and reflecting on feelings.

R. Practice guessing and recognition of the plausibility of guesses.

S. Being involved in varied clinical experiences.

T. Developing self-confidence based nursing knowledge of a subject.

$U$. Using brainstorming or clustering to elicit intuitive responses.

v. Using a clinical journal to record cue assessments, hunches and outcome.

w. Reflecting on past intuitive experiences.

$X$. Practicing selfcare (mind/body/spirit).

$Y$. Using guided imagery.

Z. Other (specify)
USED? EFFECT?

$\begin{array}{llllll}Y & N & E & M & S & N\end{array}$

$\begin{array}{llllll}\mathrm{Y} & \mathrm{N} & 0 & 0 & 0 & 0\end{array}$

$\begin{array}{llllll}\mathrm{Y} & \mathrm{N} & 0 & 0 & 0 & 0\end{array}$

$\begin{array}{llllll}\mathrm{Y} & \mathrm{N} & 0 & 0 & 0 & 0\end{array}$

$\begin{array}{llllll}Y & N & 0 & 0 & 0 & 0\end{array}$

$\begin{array}{llllll}Y & N & 0 & 0 & 0 & 0\end{array}$

$\begin{array}{llllll}Y & N & 0 & 0 & 0 & 0\end{array}$

$\begin{array}{llllll}Y & N & 0 & 0 & 0 & 0\end{array}$

$\begin{array}{llllll}\mathrm{Y} & \mathrm{N} & 0 & 0 & 0 & 0\end{array}$

$\begin{array}{llllll}Y & N & 0 & 0 & 0 & 0\end{array}$

$\begin{array}{llllll}\mathbf{Y} & \mathbf{N} & 0 & 0 & 0 & 0\end{array}$

$\begin{array}{llllll}Y & N & 0 & 0 & 0 & 0\end{array}$

$\begin{array}{llllll}\mathrm{Y} & \mathrm{N} & 0 & 0 & 0 & 0\end{array}$

$\begin{array}{llllll}Y & N & 0 & 0 & 0 & 0\end{array}$

$\begin{array}{llllll}Y & N & 0 & 0 & 0 & 0\end{array}$

$\begin{array}{llllll}\mathbf{Y} & \mathrm{N} & 0 & 0 & 0 & 0\end{array}$

$\begin{array}{llllll}Y & N & 0 & 0 & 0 & 0\end{array}$

$\begin{array}{llllll}\mathrm{Y} & \mathrm{N} & 0 & 0 & 0 & 0\end{array}$

$\begin{array}{llllll}Y & \mathrm{~N} & 0 & 0 & 0 & 0\end{array}$

$\begin{array}{llllll}\mathbf{Y} & \mathbf{N} & 0 & 0 & 0 & 0\end{array}$

$\begin{array}{llllll}\mathbf{Y} & \mathbf{N} & 0 & 0 & 0 & 0\end{array}$

$\begin{array}{llllll}\mathrm{Y} & \mathrm{N} & 0 & 0 & 0 & 0\end{array}$

$\begin{array}{llllll}\mathrm{Y} & \mathrm{N} & 0 & 0 & 0 & 0\end{array}$

$\begin{array}{llllll}Y & N & 0 & 0 & 0 & 0\end{array}$

$\begin{array}{llllll}Y & N & 0 & 0 & 0 & 0\end{array}$

$\begin{array}{llllll}Y & N & 0 & 0 & 0 & 0\end{array}$

$\begin{array}{llllll}Y & N & 0 & 0 & 0 & 0\end{array}$ 
Developing student intuition:

31. Have you used any of the following strategies to teach students about intuition in nursing? (circle yes or no)

For each strategy that you have used, please indicate how effective you think it is for teaching about intuition. EXT = extremely effective, MOD = moderately effective, SOM = somewhat effective, NOT $=$ not effective

STRATEGY

A. Encourage the use of terms and definitions regarding intuition.

B. Promote the acceptance of more than $Y \quad N \quad 0 \quad 0 \quad 0 \quad 0$ one way of thinking and knowing.

c. Teach the structure of knowledge and $Y \quad N \quad 0 \quad 0 \quad 0 \quad 0$ how it is linked to other knowledge.

D. Emphasize the value of intuitive skills in nursing.

E. Encourage paying attention to inner $Y \quad N \quad 0 \quad 0 \quad 000$ voice.

F. Promote awareness of gut reactions. $\quad \begin{array}{llllll}\mathbf{N} & \mathbf{N} & 0 & 0 & 0 & 0\end{array}$

G. Model the use of intuiticn.

$H$. Encourage validation of intuition with more experienced nurses.

I. Provide positive reinforcement for $\quad Y \quad N \quad \begin{array}{llllll}N & 0 & 0 & 0\end{array}$ using intuition.

$\mathrm{J}$. Foster student creativity.

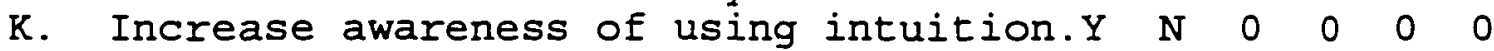

L. Encourage narrative story telling of $Y \quad N \quad \begin{array}{llllll}N & 0 & 0 & 0\end{array}$ intuitive nursing care.

M. Offer meditation experiences.

N. Utilize nursing case studies.

0 . Provide experiences with nurse

$$
\begin{array}{llllll}
Y & N & 0 & 0 & 0 & 0
\end{array}
$$$$
\begin{array}{llllll}
Y & N & 0 & 0 & 0 & 0
\end{array}
$$
preceptors to promote dialogue about intuition.

P. Encourage taking client's perspective.Y $N 0$

Q. Encourage becoming quiet and reflecting on feelings.

$R$. Encourage guessing and the ability to $Y \quad N \quad 0 \quad 0 \quad 0 \quad 0$ recognize the plausibility of guesses.

S. Provide varied clinical experiences. $\quad Y \quad N \quad 0 \quad 00000$

$\mathrm{T}$. Promote self-confidence based on $\quad Y \quad N \quad 0 \quad 0 \quad 0 \quad 0$ nursing knowledge of a subject.

$U$. Practice brainstorming or clustering $Y \quad N \quad \begin{array}{llllllll}N & 0 & 0 & 0\end{array}$ to elicit intuitive responses.

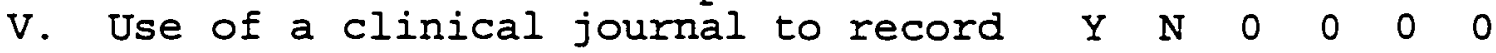
cue assessments, hunches and outcome.

W. Encourage reflection on past intuitive experiences.

$X$. Encourage self-care activities.

$Y$. Use of guided imagery.

Z. Other (specify)
$\begin{array}{llllll}\mathrm{Y} & \mathrm{N} & 0 & 0 & 0\end{array}$

$\begin{array}{llllll}Y & N & 0 & 0 & 0 & 0\end{array}$

$\begin{array}{llllll}\mathbf{Y} & \mathrm{N} & 0 & 0 & 0 & 0\end{array}$

$\begin{array}{llllll}\mathrm{Y} & \mathrm{N} & 0 & 0 & 0 & 0\end{array}$ 
V. INTUITION : PROFESSIONAL PREPARATION

32. I have attended workshops or conferences on intuition.

33. I have conducted personal studies on intuition.

34. I learned about intuition in nursing in my undergraduate or graduate degree program.

yes - no

35. I am interested in learning more about the intuitive way of knowing and the relevance to nursing practice. yes no

\section{DEMOGRAPHIC DATA}

36. Age:

37. Sex: Temale Male

38. Number of years practicing nursing (rounded to the nearest year)

39. Number of years in nursing education (rounded to the nearest year)

40. Highest academic degree completed in nursing:
Bachelor's
Master's
Doctorate

41. Highest academic degree completed outside of nursing: _ Associate Degree Masters Degree - Bachelors Degree - Doctoral Degree

42. Name of the state in which the school of nursing where you currently teach is located:

43. Type of nursing program where you currently teach: Diploma
Associate Degree $\quad \begin{aligned} & \text { Baccalaureate Degree } \\ & \text { Baccalaureate and }\end{aligned}$

44. During the 1997-98 academic year, are you (or will you be) teaching undergraduate students in the nursing major? no

45. Indicate your current primary teaching responsibility: (check only one) adult health child health community health

\section{- other (specify)}
maternal-newborn health
psych-mental health

46. Average age of students in your undergraduate nursing major:

47. Estimated age range of students in your undergraduate nursing major:

48. Total enrollment of students in your undergraduate nursing major:
under 100
$100-199$
200-299
$300-399$
400 and over 
If you are willing to be interviewed by phone regarding your experiences using intuition in nursing or your experiences teaching intuition in the undergraduate nursing curriculum, please write your name and phone number in the space below. Confidentiality will be maintained; individual names will not be reported in the study.

name :

phone number(s) with area code:

please circle your time zone:

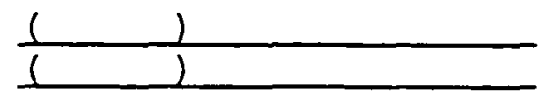

Pacific

Mountain

Central

Eastern 
APPENDIX B

CHARTS 
Chart 1

NLN Regions

\begin{tabular}{llll} 
North Atlantic & Midwestern & Southern & Western \\
\cline { 2 - 3 } & & & \\
Connecticut & Illinois & Alabama & Alaska \\
Delaware & Indiana & Arkansas & Arizona \\
Maine & Iowa & Florida & California \\
Massachusetts & Kansas & Georgia & Colorado \\
New Hampshire & Michigan & Kentucky & Hawaii \\
New Jersey & Minnesota & Louisiana & Idaho \\
New York & Missouri & Maryland & Montana \\
Pennsylvania & Nebraska & Mississippi & Nevada \\
Rhode Island & North Dakota & North Carolina New Mexico \\
Vermont & Ohio & Oklahoma & Oregon \\
Wisconsin & South Dakota & South Carolina Utah \\
District of & & Tennessee & Washington \\
\multicolumn{1}{c}{ Columbia } & & Texas & Wyoming \\
& & Virginia &
\end{tabular}

Source: NLN 1996b, p. ix 
Chart 2

Effectiveness of Strategies Used by Faculty
with Self vs. Program Type

\begin{tabular}{|c|c|c|c|c|c|c|}
\hline$\overline{\text { strategy }}$ & $\underline{N}$ & Pro- & Effect & iveness & $x^{2}$ & p \\
\hline & & & & & & \\
\hline Terms & $\begin{array}{l}39 \\
74\end{array}$ & $\begin{array}{l}\mathrm{AD} \\
\mathrm{BD}\end{array}$ & $\begin{array}{l}41.0 \% \\
29.7 \%\end{array}$ & $\begin{array}{l}59.0 \% \\
70.3 \%\end{array}$ & 1.460 & .227 \\
\hline One way & $\begin{array}{l}103 \\
157\end{array}$ & $\begin{array}{l}\mathrm{AD} \\
\mathrm{BD}\end{array}$ & $\begin{array}{r}14.6 \% \\
7.6 \%\end{array}$ & $\begin{array}{l}85.4 \% \\
92.4 \%\end{array}$ & 3.200 & .074 \\
\hline $\begin{array}{l}\text { Knowledge } \\
\text { I inks }\end{array}$ & $\begin{array}{r}67 \\
123\end{array}$ & $\begin{array}{l}\mathrm{AD} \\
\mathrm{BD}\end{array}$ & $\begin{array}{l}14.9 \% \\
11.4 \%\end{array}$ & $\begin{array}{l}85.1 \% \\
88.6 \%\end{array}$ & 0.493 & .482 \\
\hline Value & $\begin{array}{r}96 \\
148\end{array}$ & $\begin{array}{l}\mathrm{AD} \\
\mathrm{BD}\end{array}$ & $\begin{array}{l}12.5 \% \\
10.1 \%\end{array}$ & $\begin{array}{l}87.5 \% \\
89.9 \%\end{array}$ & 0.331 & .565 \\
\hline Voice & $\begin{array}{l}103 \\
156\end{array}$ & $\begin{array}{l}\mathrm{AD} \\
\mathrm{BD}\end{array}$ & $\begin{array}{l}6.8 \% \\
3.8 \%\end{array}$ & $\begin{array}{l}93.2 \% \\
96.2 \%\end{array}$ & 1.132 & .287 \\
\hline Gut reaction & $\begin{array}{l}106 \\
159\end{array}$ & $\begin{array}{l}\mathrm{AD} \\
\mathrm{BD}\end{array}$ & $\begin{array}{l}6.6 \% \\
9.4 \%\end{array}$ & $\begin{array}{l}93.4 \% \\
90.6 \%\end{array}$ & 0.669 & .413 \\
\hline Model & $\begin{array}{l}50 \\
85\end{array}$ & $\begin{array}{l}\mathrm{AD} \\
\mathrm{BD}\end{array}$ & $\begin{array}{l}14.0 \% \\
11.8 \%\end{array}$ & $\begin{array}{l}86.0 \% \\
88.2 \%\end{array}$ & 0.143 & .705 \\
\hline Validate & $\begin{array}{r}69 \\
102\end{array}$ & $\begin{array}{l}\mathrm{AD} \\
\mathrm{BD}\end{array}$ & $\begin{array}{l}11.6 \% \\
14.7 \%\end{array}$ & $\begin{array}{l}88.4 \% \\
85.3 \%\end{array}$ & 0.342 & .558 \\
\hline Reinforce & $\begin{array}{l}47 \\
69\end{array}$ & $\begin{array}{l}A D \\
B D\end{array}$ & $\begin{array}{r}8.5 \% \\
20.3 \%\end{array}$ & $\begin{array}{l}91.5 \% \\
79.7 \%\end{array}$ & 2.959 & .085 \\
\hline Creativity & $\begin{array}{r}78 \\
130\end{array}$ & $\begin{array}{l}\mathrm{AD} \\
\mathrm{BD}\end{array}$ & $\begin{array}{l}15.4 \% \\
10.0 \%\end{array}$ & $\begin{array}{l}84.6 \% \\
90.0 \%\end{array}$ & 1.337 & .248 \\
\hline Awareness & $\begin{array}{r}86 \\
133\end{array}$ & $\begin{array}{l}\mathrm{AD} \\
\mathrm{BD}\end{array}$ & $\begin{array}{r}12.8 \% \\
9.0 \%\end{array}$ & $\begin{array}{l}87.2 \% \\
91.0 \%\end{array}$ & 0.789 & .374 \\
\hline Story & $\begin{array}{l}52 \\
84\end{array}$ & $\begin{array}{l}\mathrm{AD} \\
\mathrm{BD}\end{array}$ & $\begin{array}{l}13.5 \% \\
19.0 \%\end{array}$ & $\begin{array}{l}86.5 \% \\
81.0 \%\end{array}$ & 0.713 & .398 \\
\hline Meditate & $\begin{array}{l}25 \\
53\end{array}$ & $\begin{array}{l}\mathrm{AD} \\
\mathrm{BD}\end{array}$ & $\begin{array}{l}12.0 \% \\
15.1 \%\end{array}$ & $\begin{array}{l}88.0 \% \\
84.9 \%\end{array}$ & 0.134 & $\star 1.000$ \\
\hline Case studies & $\begin{array}{r}64 \\
103\end{array}$ & $\begin{array}{l}\mathrm{AD} \\
\mathrm{BD}\end{array}$ & $\begin{array}{l}14.1 \% \\
19.4 \%\end{array}$ & $\begin{array}{l}85.9 \% \\
80.6 \%\end{array}$ & 0.789 & .374 \\
\hline Preceptor & $\begin{array}{r}7 \\
22\end{array}$ & $\begin{array}{l}A D \\
B D\end{array}$ & $\begin{array}{r}0.0 \% \\
36.4 \%\end{array}$ & $\begin{array}{r}100.0 \% \\
63.6 \%\end{array}$ & 3.515 & $\star .142$ \\
\hline $\begin{array}{l}\text { Client's } \\
\text { perspective }\end{array}$ & $\begin{array}{r}82 \\
133\end{array}$ & $\begin{array}{l}\mathrm{AD} \\
\mathrm{BD}\end{array}$ & $\begin{array}{l}9.8 \% \\
9.0 \%\end{array}$ & $\begin{array}{l}90.2 \% \\
91.0 \%\end{array}$ & 0.032 & .857 \\
\hline Reflection & $\begin{array}{r}76 \\
131\end{array}$ & $\begin{array}{l}\mathrm{AD} \\
\mathrm{BD}\end{array}$ & $\begin{array}{l}9.2 \% \\
7.6 \%\end{array}$ & $90.8 \%$ & 0.159 & .690 \\
\hline Guessing & $\begin{array}{l}44 \\
63\end{array}$ & $\begin{array}{l}\mathrm{AD} \\
\mathrm{BD}\end{array}$ & $\begin{array}{l}22.7 \% \\
20.6 \%\end{array}$ & $\begin{array}{l}77.3 \% \\
79.4 \%\end{array}$ & 0.067 & .795 \\
\hline $\begin{array}{l}\text { Varied } \\
\text { clinical }\end{array}$ & $\begin{array}{r}92 \\
123\end{array}$ & $\begin{array}{l}\mathrm{AD} \\
\mathrm{BD}\end{array}$ & $\begin{array}{r}10.9 \% \\
8.9 \%\end{array}$ & $\begin{array}{l}89.1 \% \\
91.1 \%\end{array}$ & 0.222 & .638 \\
\hline $\begin{array}{l}\text { Self- } \\
\text { confidence }\end{array}$ & $\begin{array}{l}101 \\
137\end{array}$ & $\begin{array}{l}\mathrm{AD} \\
\mathrm{BD}\end{array}$ & $\begin{array}{l}3.0 \% \\
2.9 \%\end{array}$ & $\begin{array}{l}97.0 \% \\
97.1 \%\end{array}$ & 0.001 & $\star 1.000$ \\
\hline
\end{tabular}


Chart 2

Effectiveness of Strategies Used by Faculty with Self vs. Program Type

(continued)

\begin{tabular}{lrlrrrr}
\hline Strategy & N & Pro- & \multicolumn{2}{c}{ Effectiveness } & $\chi^{2}$ & D \\
& & gram & SOM & MOD/EXT & & \\
\hline Brainstorm & 64 & AD & $4.7 \%$ & $95.3 \%$ & 2.262 & .133 \\
& 95 & BD & $11.6 \%$ & $88.4 \%$ & & \\
Journal & 26 & AD & $15.4 \%$ & $84.6 \%$ & 0.194 & $\star .769$ \\
& 62 & BD & $19.4 \%$ & $80.6 \%$ & & \\
Past & 78 & AD & $12.8 \%$ & $87.2 \%$ & 1.130 & .288 \\
intuition & 122 & BD & $8.2 \%$ & $91.8 \%$ & & \\
Self-care & 63 & AD & $3.2 \%$ & $96.8 \%$ & 3.334 & .068 \\
Imagery & 108 & BD & $11.1 \%$ & $88.9 \%$ & & \\
& 35 & AD & $11.4 \%$ & $88.6 \%$ & 0.289 & $\star .769$ \\
& 72 & BD & $15.3 \%$ & $84.7 \%$ & &
\end{tabular}

*Fisher's Exact Test; $\underline{\text { df }}=1$

Note: Associate (AD), Baccalaureate (BD); Extremely

Effective (EXT), Moderately Effective (MOD), Somewhat

Effective (SOM), Not Effective (NOT). The categories MOD

and EXT were combined for chi-square. The category NOT was eliminated from this analysis 
Chart 3

Effectiveness of Strategies Faculty Used with Students vs. Program Type

\begin{tabular}{|c|c|c|c|c|c|c|}
\hline$\overline{\text { strategy }}$ & $\underline{N}$ & Pro- & Effect & iveness & $\overline{\chi^{2}}$ & p \\
\hline & & gram & SOM & $\mathrm{MOD} / \mathrm{EXT}$ & & \\
\hline Terms & $\begin{array}{l}22 \\
58\end{array}$ & $\begin{array}{l}A D \\
B D\end{array}$ & $\begin{array}{l}22.7 \% \\
27.6 \%\end{array}$ & $\begin{array}{l}77.3 \% \\
72.4 \%\end{array}$ & 0.195 & .659 \\
\hline One way & 91 & $A D$ & $22.0 \%$ & $78.0 \%$ & 0.196 & .658 \\
\hline Knowledge & $\begin{array}{r}148 \\
45\end{array}$ & $\begin{array}{l}B D \\
A D\end{array}$ & $19.6 \%$ & $80.4 \%$ & 41 & 840 \\
\hline links & 99 & $B D$ & $19.2 \%$ & $80.8 \%$ & 0.01 & \\
\hline Value & $\begin{array}{r}65 \\
125\end{array}$ & $\begin{array}{l}A D \\
B D\end{array}$ & $\begin{array}{l}26.2 \% \\
28.8 \%\end{array}$ & $\begin{array}{l}73.8 \% \\
71.2 \%\end{array}$ & 0.149 & .700 \\
\hline Voice & $\begin{array}{r}73 \\
117\end{array}$ & $\begin{array}{l}A D \\
B D\end{array}$ & $\begin{array}{l}23.3 \% \\
18.8 \%\end{array}$ & $\begin{array}{l}76.7 \% \\
81.2 \%\end{array}$ & 0.554 & .457 \\
\hline Gut reaction & $\begin{array}{r}79 \\
120\end{array}$ & $\begin{array}{l}A D \\
B D\end{array}$ & $\begin{array}{l}22.8 \% \\
20.0 \%\end{array}$ & $\begin{array}{l}77.2 \% \\
80.0 \%\end{array}$ & 0.222 & .638 \\
\hline Model & $\begin{array}{l}53 \\
96\end{array}$ & $\begin{array}{l}A D \\
B D\end{array}$ & $\begin{array}{l}17.0 \% \\
16.7 \%\end{array}$ & $\begin{array}{l}83.0 \% \\
83.3 \%\end{array}$ & 0.002 & .961 \\
\hline Validate & $\begin{array}{l}52 \\
84\end{array}$ & $\begin{array}{l}A D \\
B D\end{array}$ & $\begin{array}{l}23.1 \% \\
22.6 \%\end{array}$ & $\begin{array}{l}76.9 \% \\
77.4 \%\end{array}$ & 0.004 & .951 \\
\hline Reinforce & $\begin{array}{r}61 \\
100\end{array}$ & $\begin{array}{l}A D \\
B D\end{array}$ & $\begin{array}{l}13.1 \% \\
20.0 \%\end{array}$ & $\begin{array}{l}86.9 \% \\
80.0 \%\end{array}$ & 1.250 & .264 \\
\hline Creativity & $\begin{array}{r}91 \\
142\end{array}$ & $\begin{array}{l}A D \\
B D\end{array}$ & $\begin{array}{l}19.8 \% \\
14.8 \%\end{array}$ & $\begin{array}{l}80.2 \% \\
85.2 \%\end{array}$ & 0.991 & .319 \\
\hline Awareness & $\begin{array}{l}52 \\
89\end{array}$ & $\begin{array}{l}A D \\
B D\end{array}$ & $\begin{array}{l}26.9 \% \\
15.7 \%\end{array}$ & $\begin{array}{l}73.1 \% \\
84.3 \%\end{array}$ & 2.584 & .108 \\
\hline Story & $\begin{array}{l}39 \\
68\end{array}$ & $\begin{array}{l}A D \\
B D\end{array}$ & $\begin{array}{l}20.5 \% \\
17.6 \%\end{array}$ & $\begin{array}{l}79.5 \% \\
82.4 \%\end{array}$ & 0.134 & .714 \\
\hline Meditate & $\begin{array}{l}10 \\
37\end{array}$ & $\begin{array}{l}A D \\
B D\end{array}$ & $\begin{array}{l}20.0 \% \\
35.1 \%\end{array}$ & $\begin{array}{l}80.0 \% \\
64.9 \%\end{array}$ & 0.830 & $\star .465$ \\
\hline Case studies & $\begin{array}{r}67 \\
116\end{array}$ & $\begin{array}{l}A D \\
B D\end{array}$ & $\begin{array}{l}22.4 \% \\
12.9 \%\end{array}$ & $\begin{array}{l}77.6 \% \\
87.1 \%\end{array}$ & 2.771 & .096 \\
\hline Preceptor & $\begin{array}{l}16 \\
38\end{array}$ & $\begin{array}{l}A D \\
B D\end{array}$ & $\begin{array}{l}12 \cdot 5 \% \\
26.3 \%\end{array}$ & $\begin{array}{l}87.5 \% \\
73.7 \%\end{array}$ & 1.243 & $\star .474$ \\
\hline $\begin{array}{l}\text { Client's } \\
\text { perspective }\end{array}$ & $\begin{array}{r}75 \\
135\end{array}$ & $\begin{array}{l}A D \\
B D\end{array}$ & $\begin{array}{l}14.7 \% \\
16.3 \%\end{array}$ & $\begin{array}{l}85.3 \% \\
83.7 \%\end{array}$ & 0.097 & .756 \\
\hline Reflection & $\begin{array}{r}51 \\
101\end{array}$ & $\begin{array}{l}A D \\
B D\end{array}$ & $\begin{array}{r}7.8 \% \\
22.8 \%\end{array}$ & $\begin{array}{l}92.2 \% \\
77.2 \%\end{array}$ & 5.170 & .023 \\
\hline Guessing & $\begin{array}{l}35 \\
72\end{array}$ & $\begin{array}{l}A D \\
B D\end{array}$ & $\begin{array}{l}40.0 \% \\
33.3 \%\end{array}$ & $\begin{array}{l}60.0 \% \\
66.7 \%\end{array}$ & 0.457 & .499 \\
\hline $\begin{array}{l}\text { Varied } \\
\text { clinical }\end{array}$ & $\begin{array}{r}90 \\
130\end{array}$ & $\begin{array}{l}A D \\
B D\end{array}$ & $\begin{array}{l}17.8 \% \\
16.2 \%\end{array}$ & $\begin{array}{l}82.2 \% \\
83.8 \%\end{array}$ & 0.100 & .752 \\
\hline $\begin{array}{l}\text { Self- } \\
\text { confidence }\end{array}$ & $\begin{array}{r}85 \\
142\end{array}$ & $\begin{array}{l}A D \\
B D\end{array}$ & $\begin{array}{l}12.9 \% \\
15.5 \%\end{array}$ & $\begin{array}{l}87.1 \% \\
84.5 \%\end{array}$ & 0.279 & .598 \\
\hline
\end{tabular}


Chart 3

Effectiveness of Strategies Faculty Used with Students vs. Program Type

(continued)

\begin{tabular}{lrllllll}
\hline Strategy & $\underline{N}$ & $\begin{array}{l}\text { Pro- } \\
\text { gram }\end{array}$ & \multicolumn{2}{l}{ Effectiveness } & $\chi^{2}$ & SOM & MOD/EXT \\
& & & & & & \\
\hline Brainstorm & 47 & AD & $14.9 \%$ & $85.1 \%$ & 0.001 & .980 \\
& 95 & BD & $14.7 \%$ & $85.3 \%$ & & \\
Journal & 32 & AD & $9.4 \%$ & $90.6 \%$ & 4.202 & .040 \\
& 89 & BD & $27.0 \%$ & $73.0 \%$ & & \\
Past & 41 & AD & $19.5 \%$ & $80.5 \%$ & 0.001 & .979 \\
intuition & 88 & BD & $19.3 \%$ & $80.7 \%$ & & \\
Self-care & 67 & AD & $16.4 \%$ & $83.6 \%$ & 0.297 & .586 \\
Imagery & 117 & BD & $19.7 \%$ & $80.3 \%$ & & \\
& 23 & AD & $34.8 \%$ & $65.2 \%$ & 2.135 & .144 \\
& 43 & BD & $18.6 \%$ & $81.4 \%$ & &
\end{tabular}

*Fisher's Exact Test; $\underline{\mathrm{df}}=1$

Note: Associate (AD), Baccalaureate (BD); Extremely Effective (EXT), Moderately Effective (MOD), Somewhat Effective (SOM), Not Effective (NOT). The categories MOD and EXT were combined for chi-square. The category NOT was eliminated from this analysis. 


\section{Chart 4}

Interest in Learning More vs. Program Type

\begin{tabular}{|c|c|c|c|c|c|}
\hline & Program & $\%$ Yes $\div$ No & $\underline{\underline{N}}$ & $x^{2}$ & $\underline{p}$ \\
\hline Learn More & $\begin{array}{l}\mathrm{D} \\
\mathrm{BD}\end{array}$ & $\begin{array}{cc}90.6 & 9.4 \\
82.5 & 79.6^{9.5}\end{array}$ & 20.4 & 2.070 & .355 \\
\hline
\end{tabular}


Chart 5

Respondents' Age and Intuition Attitudes

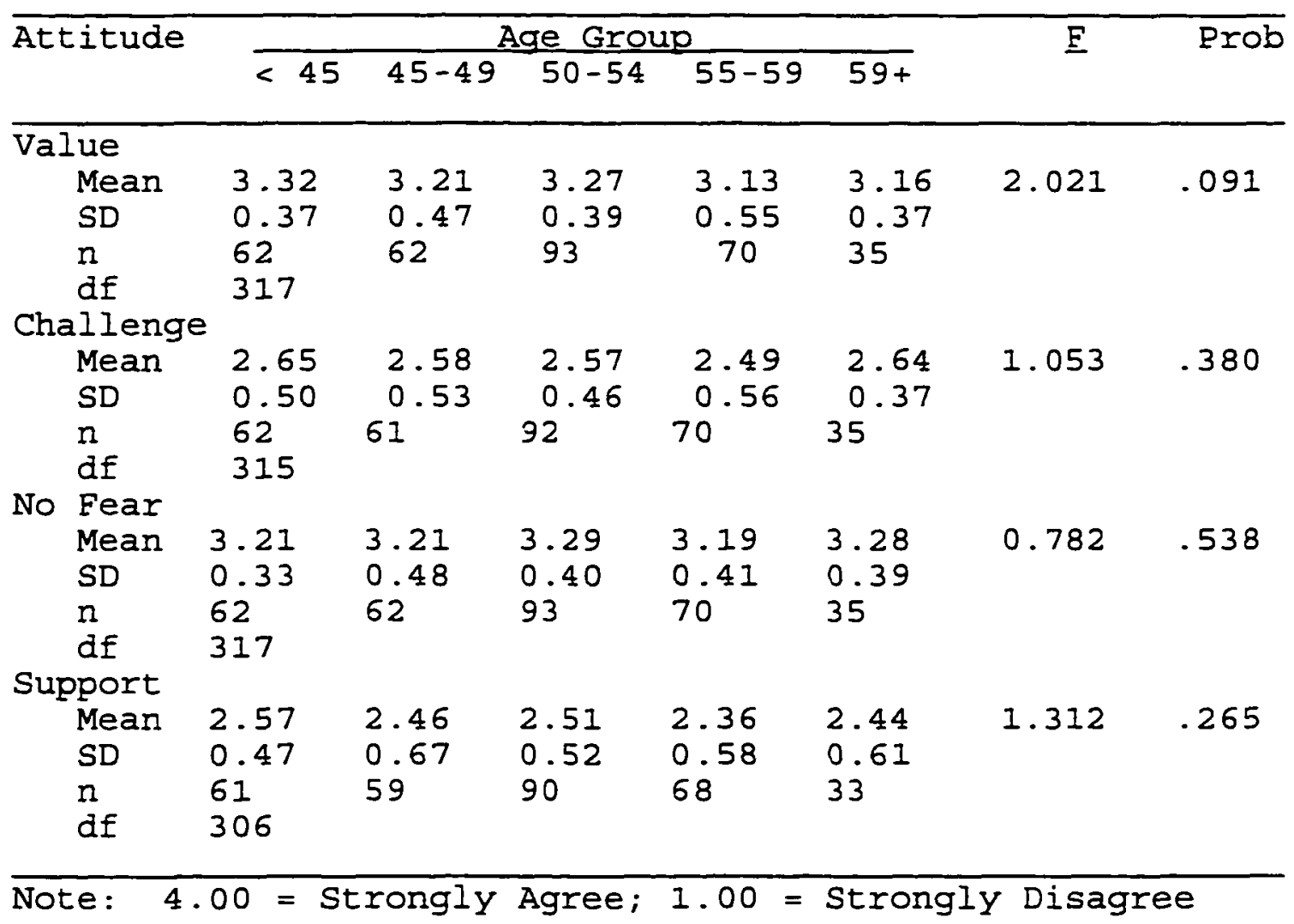


Chart 6

Intuition Attitudes and Sex

\begin{tabular}{lllllll}
\hline $\begin{array}{l}\text { Attitude } \\
\text { value }\end{array}$ & \multicolumn{3}{c}{ Female } & Male & t & P \\
& & & & & \\
\hline Value & M & 3.23 & 3.07 & 0.756 & .450 \\
& SD & 0.44 & 0.41 & & \\
Challenge & M & 322 & 5 & & \\
& M & 2.58 & 2.43 & 0.663 & .508 \\
No Fear & SD & 0.49 & 0.30 & & \\
& n & 320 & 5 & & \\
Support & M & 3.24 & 3.04 & 1.093 & .275 \\
& SD & 0.40 & 0.26 & & \\
& M & 322 & 5 & & \\
& M & 2.47 & 2.33 & 0.562 & .574 \\
& SD & 0.56 & 0.41 & & \\
\hline
\end{tabular}

Note: $4.00=$ Strongly Agree; $1.00=$ Strongly Disagree 
Chart 7

Intuition Attitudes and Years Practicing Nursing

\begin{tabular}{|c|c|c|c|c|c|c|c|}
\hline Attit & Eude & Years & 5 Pract & icing $\mathrm{Nz}$ & irsing & & \\
\hline . & $<21$ & $21-25$ & $26-30$ & $31-35$ & $35+$ & & \\
\hline$\overline{\text { Value }}$ & & & & & & & \\
\hline $\begin{array}{c}\text { Mean } \\
\text { SD } \\
n \\
\text { Challenge }\end{array}$ & $\begin{array}{l}3.31 \\
0.41 \\
65\end{array}$ & $\begin{array}{l}3.23 \\
0.41 \\
75\end{array}$ & $\begin{array}{l}3.20 \\
0.44 \\
78\end{array}$ & $\begin{array}{c}3.22 \\
0.51 \\
60\end{array}$ & $\begin{array}{l}3.09 \\
0.49 \\
47\end{array}$ & 1.681 & .154 \\
\hline $\begin{array}{l}\text { Mean } \\
\text { SD } \\
n\end{array}$ & $\begin{array}{l}2.70 \\
0.58 \\
65\end{array}$ & $\begin{array}{l}2.65 \\
0.36 \\
74\end{array}$ & $\begin{array}{l}2.49 \\
0.51 \\
77\end{array}$ & $\begin{array}{l}2.51 \\
0.53 \\
60\end{array}$ & $\begin{array}{l}2.56 \\
0.41 \\
47\end{array}$ & 2.425 & $.048 *$ \\
\hline No Fear & & & & & & & \\
\hline $\begin{array}{l}\text { Mean } \\
\text { SD } \\
n\end{array}$ & $\begin{array}{l}3.29 \\
0.43 \\
65\end{array}$ & $\begin{array}{l}3.25 \\
0.38 \\
75\end{array}$ & $\begin{array}{l}3.19 \\
0.36 \\
78\end{array}$ & $\begin{array}{l}3.23 \\
0.45 \\
60\end{array}$ & $\begin{array}{l}3.17 \\
0.43 \\
47\end{array}$ & 0.839 & .501 \\
\hline Support & & & & & & & \\
\hline $\begin{array}{l}\text { Mean } \\
\text { SD } \\
n\end{array}$ & $\begin{array}{l}2.58 \\
0.56 \\
64\end{array}$ & $\begin{array}{l}2.51 \\
0.50 \\
71\end{array}$ & $\begin{array}{l}2.44 \\
0.57 \\
74\end{array}$ & $\begin{array}{l}2.38 \\
0.59 \\
58\end{array}$ & $\begin{array}{l}2.44 \\
0.55 \\
47\end{array}$ & 1.252 & .289 \\
\hline
\end{tabular}

Note: *Post hoc Bonferroni not significant

$4.00=$ Strongly Agree; $1.00=$ Strongly Disagree 
Chart 8

Intuition Attitudes and Degree Outside Nursing

\begin{tabular}{llll}
\hline Attitude & $\underline{\mathrm{S}} \quad$ Mean & F-value Prob \\
\hline
\end{tabular}

Value

Degree

$\begin{array}{llllll}\text { Bachelor } & 23 & 3.21 & 0.51 & 0.037 & .963 \\ \text { Master } & 37 & 3.18 & 0.42 & & \\ \text { Doctorate } & 74 & 3.17 & 0.57 & & \end{array}$

Challenge

Degree

\begin{tabular}{llllll}
\hline Bachelor & 23 & 2.64 & 0.44 & 0.067 & .935 \\
Master & 35 & 2.58 & 0.44 & & \\
Doctorate & 74 & 2.61 & 0.62 & &
\end{tabular}

No Fear

Degree

$\begin{array}{llllll}\text { Bachelor } & 23 & 3.29 & 0.48 & 0.555 & .576 \\ \text { Master } & 37 & 3.18 & 0.40 & & \\ \text { Doctorate } & 74 & 3.21 & 0.40 & & \end{array}$

Support

Degree

Bachelor

Master

$22 \quad 2.33$

0.70

$0.146 \quad .865$

Doctorate

$\begin{array}{lll}34 & 2.43 & 0.65\end{array}$

$\begin{array}{lll}71 & 2.40 & 0.66\end{array}$

Note: $4.00=$ Strongly Agree; $1.00=$ Strongly Disagree 
Chart 9

Intuition Attitudes and NLN Region

\begin{tabular}{|c|c|c|c|c|c|}
\hline Attitude & $\underline{N}$ & Mean & $\underline{\mathrm{SD}}$ & F-value & Prob \\
\hline \multicolumn{6}{|l|}{ Value } \\
\hline $\begin{array}{l}\text { Northern } \\
\text { Midwest } \\
\text { Southern } \\
\text { Western }\end{array}$ & $\begin{array}{r}101 \\
87 \\
113 \\
29\end{array}$ & $\begin{array}{l}3.28 \\
3.25 \\
3.13 \\
3.19\end{array}$ & $\begin{array}{l}0.39 \\
0.46 \\
0.51 \\
0.43\end{array}$ & 2.083 & .102 \\
\hline \multicolumn{6}{|l|}{$\begin{array}{c}\text { Challenge } \\
\text { Region }\end{array}$} \\
\hline $\begin{array}{l}\text { Northern } \\
\text { Midwest } \\
\text { Southern } \\
\text { Western }\end{array}$ & $\begin{array}{r}100 \\
87 \\
113 \\
28\end{array}$ & $\begin{array}{l}2.60 \\
2.64 \\
2.48 \\
2.60\end{array}$ & $\begin{array}{l}0.48 \\
0.52 \\
0.46 \\
0.53\end{array}$ & 2.046 & .107 \\
\hline \multicolumn{6}{|l|}{$\begin{array}{l}\text { No Fear } \\
\text { Region }\end{array}$} \\
\hline $\begin{array}{l}\text { Northern } \\
\text { Midwest } \\
\text { Southern } \\
\text { Western }\end{array}$ & $\begin{array}{r}101 \\
87 \\
113 \\
29\end{array}$ & $\begin{array}{l}3.27 \\
3.25 \\
3.18 \\
3.22\end{array}$ & $\begin{array}{l}0.39 \\
0.41 \\
0.42 \\
0.43\end{array}$ & 0.874 & .455 \\
\hline \multicolumn{6}{|l|}{$\begin{array}{l}\text { Support } \\
\text { Region }\end{array}$} \\
\hline $\begin{array}{l}\text { Northern } \\
\text { Midwest } \\
\text { Southern } \\
\text { Western }\end{array}$ & $\begin{array}{r}100 \\
85 \\
106 \\
28\end{array}$ & $\begin{array}{l}2.55 \\
2.47 \\
2.38 \\
2.50\end{array}$ & $\begin{array}{l}0.49 \\
0.58 \\
0.59 \\
0.54\end{array}$ & 1.759 & .155 \\
\hline
\end{tabular}


Chart 10

Intuition Attitudes and Primary Teaching Area

\begin{tabular}{|c|c|c|c|c|c|}
\hline Attitude & $\underline{N}$ & Mean & $\underline{\underline{S D}}$ & E-value & Prob \\
\hline \multicolumn{6}{|l|}{ Value } \\
\hline Adult & 115 & 3.16 & 0.46 & 1.181 & .320 \\
\hline Child & 17 & 3.20 & 0.40 & & \\
\hline Community & 25 & 3.34 & 0.37 & & \\
\hline Lead/manage & 17 & 3.12 & 0.50 & & \\
\hline Mother-baby & 15 & 3.35 & 0.45 & & \\
\hline Psych-mental & 24 & 3.28 & 0.46 & & \\
\hline \multicolumn{6}{|l|}{ Challenge } \\
\hline \multicolumn{6}{|l|}{ Area } \\
\hline$\overline{\text { Adult }}$ & 113 & 2.50 & 0.42 & 2.001 & .080 \\
\hline Child & 17 & 2.50 & 0.44 & & \\
\hline Community & 25 & 2.78 & 0.60 & & \\
\hline Lead/manage & 17 & 2.44 & 0.59 & & \\
\hline Mother-baby & 15 & 2.52 & 0.63 & & \\
\hline Psych-mental & 24 & 2.69 & 0.47 & & \\
\hline \multicolumn{6}{|l|}{$\begin{array}{l}\text { No Fear } \\
\text { Area }\end{array}$} \\
\hline Adult & 115 & 3.20 & 0.40 & 1.060 & .383 \\
\hline Child & 17 & 3.21 & 0.39 & & \\
\hline Community & 25 & 3.22 & 0.44 & & \\
\hline Lead/manage & 17 & 3.06 & 0.51 & & \\
\hline Mother-baby & 15 & 3.29 & 0.39 & & \\
\hline Psych-mental & 24 & 3.34 & 0.46 & & \\
\hline \multicolumn{6}{|l|}{ Support } \\
\hline \multicolumn{6}{|l|}{ Area } \\
\hline$\overline{\text { Adult }}$ & 109 & 2.43 & 0.48 & 0.265 & .932 \\
\hline Child & 17 & 2.37 & 0.55 & & \\
\hline Community & 25 & 2.51 & 0.65 & & \\
\hline Lead/manage & 17 & 2.53 & 0.72 & & \\
\hline Mother-baby & 15 & 2.41 & 0.69 & & \\
\hline Psych-mental & 24 & 2.39 & 0.53 & & \\
\hline
\end{tabular}

